\title{
ANALYSE DER SPÄTRÖMISCHEN GRAB- UND BEIGABENSITTE. LEHRE ZUR ÜBERPRÜFUNG DES GRÄBERFELDMATERIALS VON SOMOGYSZIL
}

\author{
FRIDERIKA HORVÁTH - ANETT MIHÁCZI-PÁLFI
}

\author{
Forschungszentrum für Humanwissenschaften \\ der Ungarischen Akademie der Wissenschaften \\ Archäologisches Institut \\ 4 Tóth Kálmán u., H-1097 Budapest, Ungarn \\ Horvath.Friderika@btk.mta.hu \\ Mihaczi-Palfi.Anett@btk.mta.hu
}

\begin{abstract}
The Somogyszil cemetery had become known in 1964, when a local resident reported the finds. The site was excavated by Balázs Draveczky uncovering 148 late Roman graves up to 1968. The whole cemetery was published in 1979 by Alice Sz. Burger. Our research agenda focuses on the spatial organization of the burial grounds used by the province's rural population as well as on burial customs (funerary rites, grave and burial types), chronology and the mapping of local and non-local tendencies. During the critical re-assessment of the cemetery, we have found that the establishment and use of this late Roman burial ground could be connected to a heterogeneous community.
\end{abstract}

Keywords: late Roman cemetery, funeral practices and rites, late Roman male and female dress, foreign components, South Pannonia, Somogyszil

Das Gräberfeld von Somogyszil erlangte aufgrund einer Mitteilung aus der Bevölkerung Bekanntschaft. Die Freilegung des Fundortes wurde von Balázs Draveczky geleitet, der bis 1968148 spätrömische Gräber mit 152 Bestattungen aufdeckte. ${ }^{1}$

Der Fundort ist unter dem Namen Dögkút-dűlő bekannt. ${ }^{2}$ Das Gräberfeld erstreckte sich von Norden nach Süden, nordöstlich von Somogyszil, zwischen Gadács und Várong, auf der linken Seite des Nebenarms von Magyarádpuszta, am Westhang eines langen Bergrückens, in 160-175 m Höhe über dem Meeresspiegel. ${ }^{3}$ Auf der Spitze und am Osthang des Bergrückens auf der gegenüberliegenden Seite des Wasserlaufes kamen während der Geländebegehungen Tegula- und Steinfragmente, Keramikscherben sowie Münzen zum Vorschein, ${ }^{4}$ anhand derer mit einer zum Gräberfeld gehörenden Siedlung - höchstwahrscheinlich mit einer Villenwirtschaft - zu rechnen ist. Das

${ }^{1}$ Die Publikation über das Gräberfeld erschien im Jahre 1979 aus der Feder von Alice Sz. Burger. Die Autorin verfasste die Beschreibung der Gräber mithilfe von Gräberkarteikarten, nahm Bestand auf und ergänzte ihn mit kurzen Notizen, skizzierte das Fundgut und bestimmte die Münzen. Außerdem fügte sie dem Band 26 Auswertungstabellen bei; BURGER 1979.

${ }^{2}$ Die Benennung ist nicht auf der Karte verzeichnet. Alice Sz. Burger lokalisierte das Gräberfeld ursprünglich südöstlich der heutigen Siedlung, am westlichen Hang eines kleineren Hügels, der am linken Ufer des östlichen Nebenarms des Attala-Inámi-Wasserlaufes liegt (BURGER 1979, Abb. 1). Die wahrhaftige Lage des Gräberfeldes muss aber anhand eines skizzenhaften Lageplans des Jahres 1975 geändert werden; HoRVÁTH et al. 2018, Abb. 1.
${ }^{3}$ Die Revision des Gräberfeldmaterials wurde im Rahmen des NKFI-Projektes „Macht und Kultur im Karpatenbecken des frühen Mittelalters" durchgeführt (National Research, Development and Innovation Office, NK 111853, Forschungsleiter: Béla Miklós Szőke). An der Materialaufnahme war Zsófia Masek beteiligt. Während der Revision haben wir auch die originale Dokumentation und das Fundgut durchgesehen. In unserem Forschungsschwerpunkt stand die Analyse der Bestattungs- und der Beigabensitte. Die Frage nach fremden Komponenten im Gräberfeld wurde in HORVÁTH et al. 2018 behandelt.

${ }^{4}$ Rippl-Rónai Museum in Kaposvár (RRMA), Datenverzeichnis IV/62/6 und 144 (Reisebereicht von 13. 03. 1990). 
freigelegte Gräberfeldteil liegt in südöstlicher Richtung von den Siedlungsspuren und es muss mit einem anderen, kaum 500 Meter davon entfernten Friedhofsteil in südwestlicher Richtung gerechnet werden $(A b b .1 .3) .^{5}$

Alice Sz. Burger verzeichnete die Gräber auf zwei Karten: Nr. I und Nr. II (Beilage). ${ }^{6}$ Karte I stellt den Lageplan der Ausgrabung von 1964-1965 (südliche Fläche), Karte II die Gräber aus den Jahren 1966-1968 (nördliche Fläche) dar. ${ }^{7}$ Zwischen den beiden Flächen verlief ein 17,8 m (?) breiter Feldweg, von dem die nördliche Grenze der Südfläche 5 Meter weiter südlich lag (Abb. 1.4). ${ }^{8}$ Aufgrund der verfügbaren Informationen ist es nicht zu beurteilen, ob es sich um zwei separaten oder um eine zusammenhängende Fläche handelte. Allerdings lag das Grab 78 teils unter dem Feldweg. Die Ausdehnung des Gräberfeldes ist im Nordteil der Fläche II in einer dreieckigen Ausbuchtung durch Gräben und jenseits der Gräben durch zwei Öfen markiert. ${ }^{9}$ Während der Ausgrabungen wurden am Westrand der nördlichen Fläche 4 spätrömische Brandbestattungen in einer Reihe angeordnet registriert (Grab 128, 111, 98 und 106), die die Ausdehnung in westlicher Richtung abzeichnen. Der Ofen „C“ in der südwestlichen Ecke der Fläche I dient ebenfalls der Grenzmarkierung. Südlich davon erwies sich ein $12 \mathrm{~m}$ breiter Abschnitt als fundleer. ${ }^{10}$ Daraus lässt sich folgern, dass die in Dögkút-dülő freigelegten 148 Gräber die wirkliche Grabanzahl fast erreichen.

\section{ORIENTIERUNG DER GRÄBER}

Die überwiegende Mehrzahl der Gräber von Somogyszil ist Ost-West ausgerichtet $(73,85 \%) .{ }^{11}$ Nach der Überprüfung der Ausgrabungsdokumentation stieg die Anzahl dieser Bestattungen (mit einer Abweichung von +/$20^{\circ}$ ) an: Ihr Anteil liegt bei 84,12\%. ${ }^{12}$ Es ist mit zwei weiteren Gräbern zu rechnen, bei denen eine größere Abweichung von der Ost-West-Richtung auftritt (Grab 25, 43) (Abb. 2). ${ }^{13}$

Die Gräber mit West-Ost-Orientierung sind in viel bescheidenerer Menge registriert (insgesamt 6: Grab $67,71,108,143,144$ und 145). Diese befinden sich am nördlichen und südlichen Rand der Bestattungsareale. Grab 143 und 144 liegen unmittelbar nebeneinander im nördlichen Teil der Fläche II. Grab 145 befindet sich ebenfalls in ihrer Nähe. Grab 108 ist etwas weiter südlich gelegen, wird jedoch ebenso zu dieser nördlichen Gruppe gerechnet. Grab 67 und 71 liegen am Südende der Fläche I. Münzen mit einer Schlussmünze von Valentinian I./Valens kamen lediglich aus Grab 71 zum Vorschein. Die Randlage und die Münzdatierung der Gräber lassen auf eine spätere Phase schließen. ${ }^{14}$ Hinsichtlich der Grabtypen ist bei dieser Gruppe eine starke Streuung zu beobachten: Es kommen Erd-, Ziegel-, Nischen- und Absatzgräber ebenfalls vor.

${ }^{5}$ Eine ähnliche Fundsituation konnte am Fundort von Nagykanizsa-Inkey-kápolna beobachtet werden, wo das Gräberfeld I östlich und das Gräberfeld II westlich von der villa rustica lag; EKEHoRvÁTH 2010, Abb. 1.

${ }^{6}$ BuRger 1979, Karte I und II.

${ }^{7}$ Auf den Karten sind die Gräber 69-72 und 73-85 nicht angegeben. Mit den Gräbern 69-72 könnte die Karte I mit Hilfe von Originalzeichnungen in südlicher Richtung ergänzt werden. Das Planum mit den Gräbern 73-85 schließt sich der Südseite der Fläche II an: 1967, ,[...] Nordwestlich vom 1964-1966 freigelegten Gräberfeld, dort, wo zwischen der Straße und dem Tobel das Gestrüpp lag, bzw. an der nord-nordwestlichen Seite des Tobels kamen ebenfalls Gräber, die zu unserem Gräberfeld gehörten, zum Vorschein. An den drei Orten deckten wir die Gräber 69-106 auf [...]." RRMA IV/62/14, Ausgrabungstagebuch von Gyula Takáts. Das Planum I und II mit Grab 86 schließt sich dem Planum der vorherigen Ausgrabungsperiode an. Siehe dazu das Ausgrabungstagebuch von Balázs Draveczky, RRMA IV/62/13 = 708 .

${ }^{8}$ RRMA IV/62/40 (708).

${ }^{9}$ Es kommt öfters vor, dass Töpfer- und Ziegelöfen sowie die Gräberfelder wegen der Feuer- und Infektionsgefahr entlang der Straßen außerhalb der Siedlungen, in ihrer unmittelbaren Nähe gefunden wurden; SÁGI 1954, 109.

${ }^{10}$ RRMA IV/62/14.
${ }^{11}$ Die Autorin gab bei der Beschreibung der Gräber die Zahlenangaben auf den Grabkarteikarten als Gradwerte an. Die Publikation ist hinsichtlich der Daten auf den Gräberkarteikarten in mehreren Fällen unvollständig. Anhand des Vergleichs der Dokumentation mit den Daten der Orientierung lässt sich zurückverfolgen, dass während der Ausgrabung ein Militärkompass des Typs MOM DK 64-00 verwendet und die damit ermittelten Werte auf die Gräberkarteikarten eingetragen wurden. Dieser Kompasstyp ist auf 6400 Strichen unterteilt, der Nullpunkt markiert Süden und nach Osten fortfahrend steigen die Zahlen. Hier möchten wir László Schilling dafür danken, dass er uns auf die verschiedenen Kompasse aufmerksam gemacht hat.

${ }^{12}$ Im langlebigen Gräberfeld von Budaörs dominiert die Ost-West-Ausrichtung zwischen dem 1. und 4. Jahrhundert. Die Zahl der mit dem Kopf nach Westen Bestatteten nimmt erst ab dem 4. Jahrhundert, dann besonders ab der zweiten Hälfte zu; ОтTOмÁNYI 2016, 129.

${ }^{13}$ Oft wird versucht, die leichte Orientierungsabweichung der einzelnen Gräber mit der nach Jahreszeit unterschiedlichen Sonnenposition zu erklären. Die Erfahrung zeigt jedoch, dass die Gräber meist mithilfe von Augenmaß an die Ausrichtung der bereits vorhandenen angepasst wurden; VÁGÓ-BóNA 1976, 145, Anm. 32.

${ }^{14}$ Im Vicus-Gräberfeld von Budaörs steigt ihr Anteil ebenfalls in den Gräberzeilen am Rande; OTTOMÁNYI 2016, 219. 

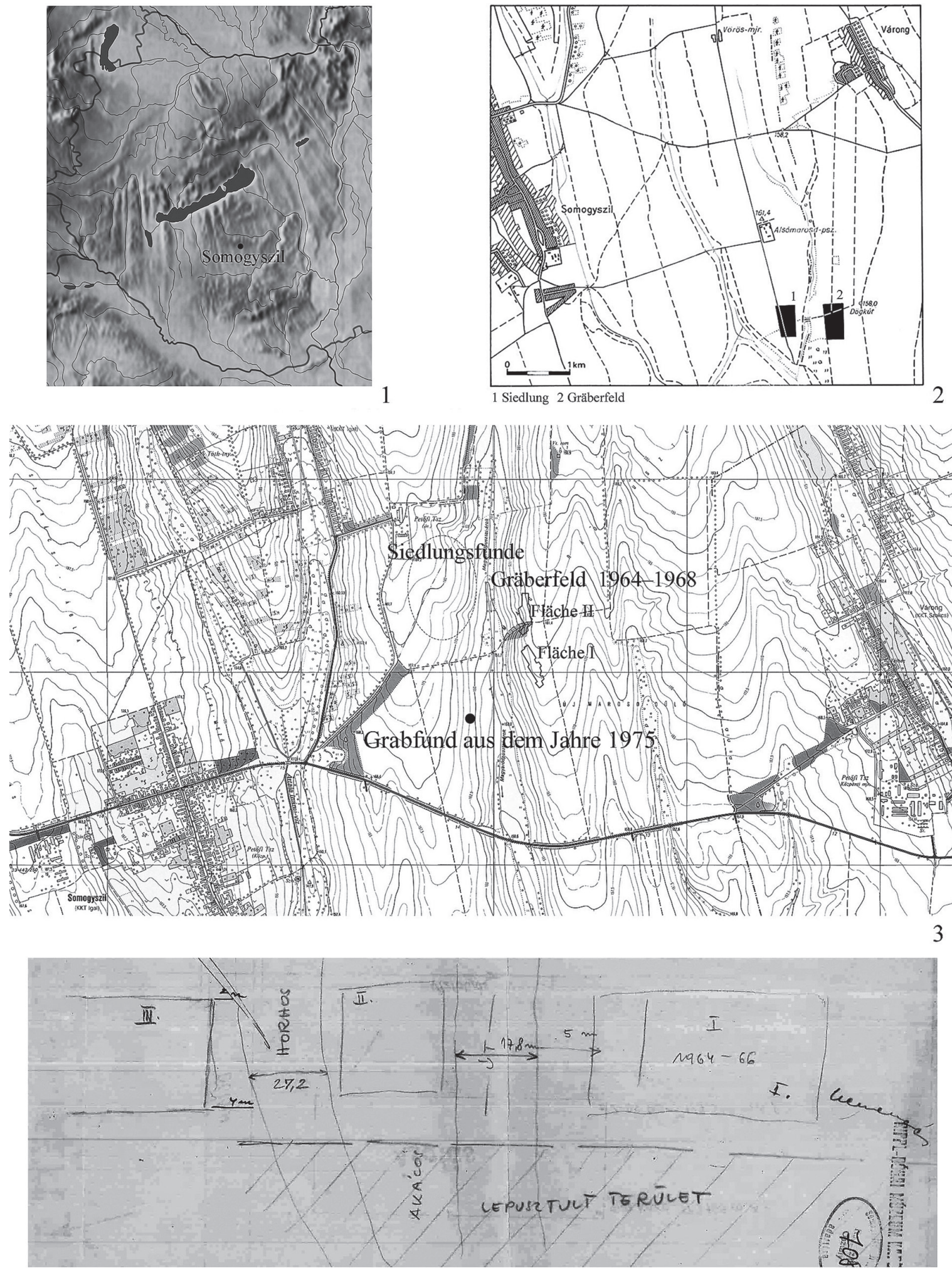

Abb. 1. 1: Übersichtskarte; 2: Lageplan des Gräberfeldes (BURGER 1979, Abb. 1);

3: Lageplan des Gräberfeldes; 4: Skizze der Grabungsflächen (RRMA IV/62/40 = 708) 

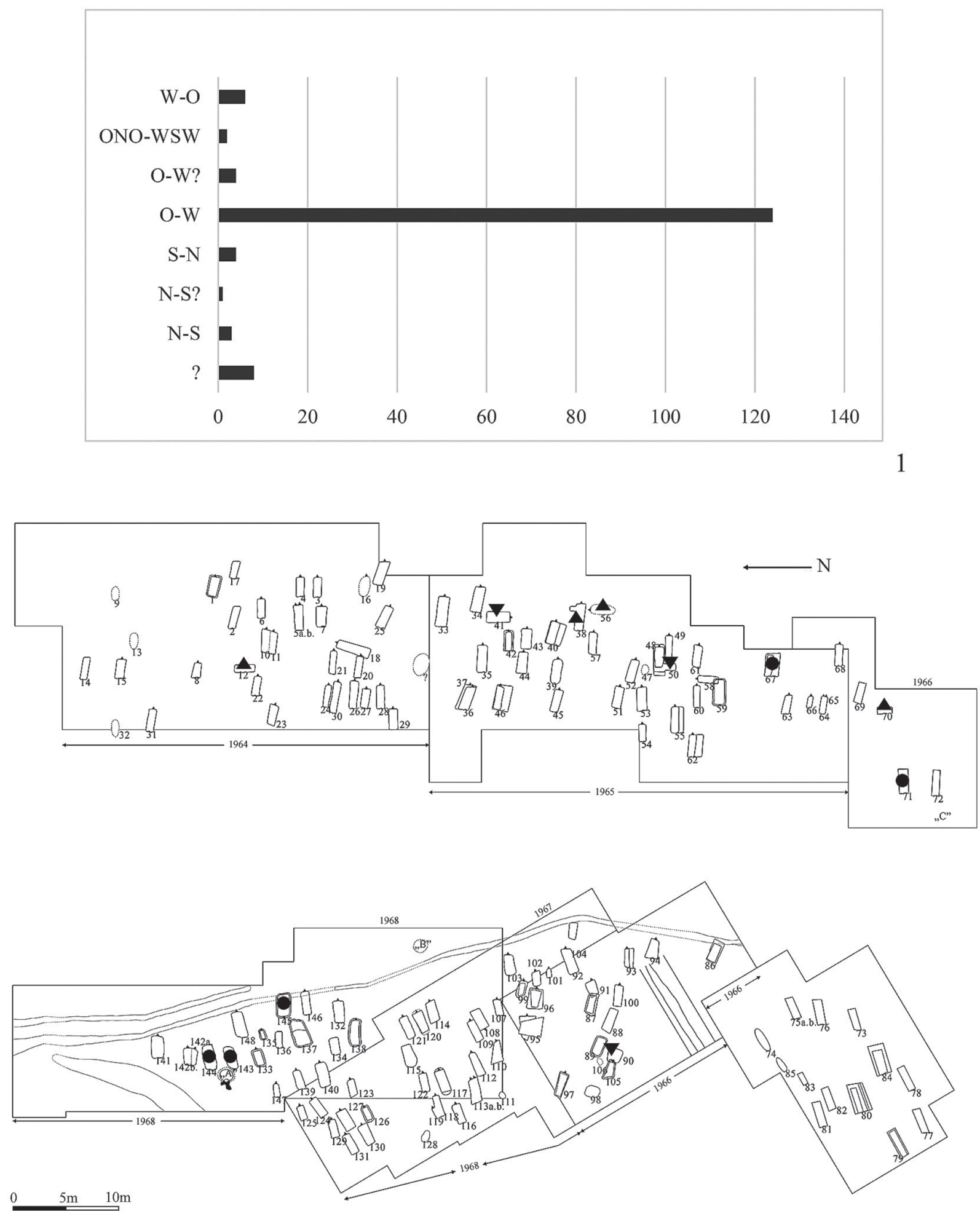

○ Ost-West $\quad$ West-Ost $\quad \boldsymbol{\Delta}$ Süd-Nord $\boldsymbol{\nabla}$ Nord-Süd

Abb. 2. 1: Verteilung der unterschiedlichen Orientierungen; 2: Verteilung der Gräber mit unterschiedlichen Orientierungen 
Grundlegend abweichende Nord-Süd- (Grab 12, 56, 58, 70) bzw. Süd-Nord-Orientierung (Grab 18, 41, 50, 90) haben wir in jeweils 4 Fällen registriert. Mit Ausnahme des Grabes 90 befinden sie sich auf der Fläche I in einer von Norden nach Süden ausgerichteten Linie. Die Gräber 18, 50, ${ }^{15} 58$ und 90 kreuzen die früheren, von Osten nach Westen orientierten Bestattungen 20, 48, 59 und 105. Eine Superposition mit den West-Ost-Gräbern konnte nicht beobachtet werden. In diesen Fällen handelt es sich um einfache Erdgräber mit ärmlichem Beigabeninventar. Im Grab 12 wurde allein ein Silberohrring mit grünem Stein und im Grab 70 eine Perlenkette mit Chalzedon und Bernsteinperlen gefunden. ${ }^{16}$ Aus Grab 41 kamen 2 ganze und ein fragmentarischer Tontopf bzw. ein Teller nebst einer Zwiebelknopffibel des Typs Keller-Pröttel 3/4 (nicht in üblicher Tragweise) sowie ein Eisenmesser zum Vorschein. Vom Geschirr befand sich der Teller in gewöhnlicher Position am Fußende. Die übrigen 3 Gefäße waren um den Kopf herum platziert. Im Fall der Zwiebelknopffibel handelt es sich um eine langlebige Variante, die dem Stück des Grabes 48 entspricht. ${ }^{17}$ Das Grab 48 wurde vom Süd-Nord orientierten Grab 50 überschnitten. In die rechte Hand des Kindes im Grab 90 legte man ein Eisenmesser, zu den Füßen wurde ein Teller hingestellt. In den Gräbern $18^{18}$ und 50 sind keine Beigaben erhalten geblieben. Das Grab 56 wurde von einer Baumwurzel und das Grab 58 durch Rigolen gestört. Münzen kamen aus keinem der Gräber zum Vorschein. ${ }^{19}$ Ihrer relativen Chronologie nach gehören sie zur späteren Bestattungsphase.

Auf den spätrömischen Gräberfeldern Pannoniens sind die Bestattungen mit West-Ost-Ausrichtung in Überzahl. ${ }^{20}$ Einheitlich Ost-West orientierte Gräberfelder hat Vera Lányi in erster Linie aus dem südpannonischen Raum aufgelistet (Kő, Fazekasboda, Bogád, Zengővárkony, Győr). Mit den Nord-Süd- und Süd-Nord-Orientierungen rechnet sie bei der Gruppe der ungleichmäßig orientierten Gräberfelder. ${ }^{21}$ In Pannonien gibt es wohl mehrere Gräberfelder ohne territorialen Schwerpunkt, auf denen neben den dominierenden Richtungen, die von Gräberfeld zu Gräberfeld variieren können, Nord-Süd- und Süd-Nord-Gräber zu finden sind (Brigetio I-II, Budapest-Bécsi út, Aquincum-canabae, Budaörs, Páty, Csákvár, Oggau, Intercisa, Majs, Dombóvár, Pécs-Széchényi tér usw.). Die Orientierungstendenzen von Somogyszil liegen den Gräberfeldern von Majs und Dombóvár aus dem südpannonischen Raum nahe. In Majs liegt die Menge der Nord-Süd- und Süd-Nord-Gräber höher. ${ }^{22}$ Superpositionen zeigen sich in zwei Fällen, bei denen die Orientierungen abweichen. ${ }^{23}$ In Dombóvár sind von 22 Gräbern 18 Ost-West orientiert und es ist mit 4 weiteren Süd-Nord-Bestattungen mit ganz wenigen Inventarstücken zu rechnen. ${ }^{24}$ In den Gräberfeldern von Intercisa zeigte sich gleichfalls ein buntes Orientierungsbild, die von Károly Sági und von den Autoren Eszter Vágó und István Bóna unterschiedlich interpretiert wurden. Im Südostfriedhof von Intercisa halten Eszter Vágó und István Bóna die Ost-West- und West-Ost-Bestattungen für zeitgleich, die seit dem Belegungsanfang häufig nachzuweisen sind. Die Mehrheit der Nord-Süd-Gräber rechnen sie eher zur früheren Übergangsphase mit Ost-Orientierung. ${ }^{25}$ Die 14 Süd-Nord-Gräber beinhalteten keine Münzen ${ }^{26}$ Demgegenüber betrachtet Sági die Ost-West-Richtung in Intercisa allgemein verbreitet, die später mit den West-Ost ausgerichteten Bestattungen ergänzt wird. Das Einsetzen der Nord-Süd gerichteten Gräber verbindet er mit den Sarmaten aus der Großen Tiefebene in der Spätphase. ${ }^{27}$

Es ist selten zu konstatieren, dass die abweichenden Ausrichtungen mit fremden Beigabensitten einhergehen. Einzelne literarische Hinweise gibt es aber dafür schon: Im Grab 163 mit Nord-Süd-Ausrichtung im vicus von

${ }^{15},[\ldots]$ ein interessantes Phänomen ist, dass das Grab 50 später ausgehoben und somit die am unteren Fußende des Grabes 48 platzierten zweimal 2 Ziegel gestört wurden [...]“; RRMA IV/62/11.

${ }^{16}$ Es kamen zwei Perlen in Kuboktaeder-Form zum Vorschein, wahrscheinlich aus Chalzedon und Bernstein. Zur Frage des barbarischen Charakters der Perlen siehe HoRvÁTH et al. 2018, 52-54

${ }^{17}$ In diesem Grab lag die Fibel in Tragweise - mit Fuß nach oben -, aber auf der linken (!) Schulter.

${ }^{18}$ Das dem Grab zugeschriebene Fundgut wurde aus der Erde des Grabes zutage gefördert. Es handelt sich nicht um Beigaben.

${ }^{19}$ Unter den Nord-Süd-, Süd-Nord-Gräbern des südöstlichen Gräberfeldes von Intercisa wurde ebenfalls keins anhand von Münzen datiert; VÁGÓ-BóNA 1976, 145.

${ }^{20}$ LÁNYi 1972, 62-63; OTTOMÁNYI 2016, 130 mit einer ergänzten Fundliste.
${ }^{21}$ LÁNYI 1972, 62-63. Die umgekehrt oder in rechtem Winkel angelegten Gräber, die sich hinsichtlich ihrer Beifunden nur selten von den übrigen Gräbern unterscheiden, sind nicht nur in Pannonien, sondern auch in anderen Donauprovinzen (Rätien und Noricum) belegt; VÁGó-BónA 1976; Puschnigg 1996, 68. Katalin Ottományi hat sich mit diesem Themenbereich eingehend beschäftigt. Sie führt die magischen oder gesellschaftlichen Gründe auch unter den möglichen Erklärungen an; OTTOMÁNYI 2016, 132.

${ }^{22}$ BURGER 1972, Abb. 37.

${ }^{23}$ Burger 1972, Abb. 2.

${ }^{24}$ BoruZs-SZABÓ 2018, 215. West-Ost-Richtung wurde in Dombóvár nicht beobachtet.

${ }^{25}$ In Intercisa war die Nord-Süd-Richtung im 3. Jahrhundert verbreiteter; VÁGÓ-BóNA 1976, 146.

${ }^{26}$ VÁGÓ-BÓNA 1976, 145-146.

${ }^{27}$ Letztere verbindet Károly Sági mit den Sarmaten der Tiefebene; SÁGI 1954, 118-119.

Acta Archaeologica Academiae Scientiarum Hungaricae 70, 2019 
Budaörs ${ }^{28}$ kamen typisch barbarische Beigaben einer germanischen Frau ans Tageslicht. ${ }^{29}$ In Oggau wurde anhand des Inventars eines Nord-Süd orientierten Grabes (Grab 9) aus dem Anfang des 5. Jahrhunderts ebenfalls auf nichtromanische Wurzeln hingewiesen. ${ }^{30}$ Im Gräberfeldabschnitt I von Csákvár sind die Gräber West-Ost orientiert. Ágnes Salamon und László Barkóczi betrachteten ihr Beigabeninventar provinzialrömisch mit sporadischem fremdem Fundgut. Im Gräberfeldabschnitt II mit Nord-Süd- und Süd-Nord-Richtung (mit Abweichungen nach Osten oder Westen) haben die Autoren bereits mit Neuankömmlingen fremder Elemente gerechnet. ${ }^{31}$ Im nördlichen, zwischen Anfang des 2. Jahrhunderts und dem letzten Drittel des 4. Jahrhunderts n. Chr. datierten Gräberfeld der Soldatenstadt von Aquincum hat Paula Zsidi mehrmals eine Situation beobachtet, wobei die West-Ost-Gräber von Nord-Süd-Bestattungen überlagert wurden. ${ }^{32}$ Aufgrund der ungewöhnlich reichen und abweichenden Zusammensetzung der Geschirrbeigabe hat sie eines der Nord-Süd-Gräber (Grab 67) als germanisch interpretiert. ${ }^{33}$ Im südlichen Gräberfeld der Canabae sagen die Forschungen von Orsolya Madarassy aus, dass es in der spätrömischen Epoche fast zeitgleich sogar von zwei, auch anthropologisch gut trennbaren Bevölkerungsgruppen benutzt wurde ${ }^{34}$ was auch an der Orientierung der Gräber abzulesen ist. Die Superposition der Ost-West- und Nord-Süd-Gräber konnte hier allerdings nicht beobachtet werden. Übereinander angelegte Bestattungen kamen nur bei Ost-West-Gräbern vor. ${ }^{35}$

In Somogyszil gehören alle fremden Fibeln zu den von Ost nach West ausgerichteten Bestattungen (Grab 75b: Fibelpaar mit umgeschlagenem Fuß; Grab 44: Stützarmfibel; Grab 122: Bügelknopffibel; Grab 140: Bügelknopffibel). Die von Sándor Évinger und Zsolt Bernert durchgeführte Revision des anthropologischen Materials ergab jedoch, dass die messbaren Werte der Skelette im Fall der Nord-Süd- bzw. Süd-Nord-Gräber sich von denen der hiesigen Bevölkerung unterscheiden. Es handelt sich um ausgesprochen groß gewachsene, robuste Individuen. Neben der Frau im maturus-Alter in Grab 70 und des Kindes der Altersgruppe infans I in Grab 90 ruhten in den übrigen 5 Gräbern Männer im adultus- und maturus-Alter.

Münzbeigaben liegen in 20 Ost-West-Gräbern vor. In 13 Fällen sind die Prägungen der konstantinischen Dynastie, in 7 weiteren Fällen die der valentinianischen belegt. Bei den mit Kopf nach Westen Bestatteten kamen Münzen nur einmal, mit Valentinian t.p.q. datiert zum Vorschein. Die Nord-Süd- bzw. Süd-Nord-Gruppe beinhaltete keine Münzen.

Allem Anschein nach sind die Gräber von Somogyszil in der Frühphase Ost-West orientiert. In der nächsten Phase treten die West-Ost-Bestattungen bei, die sich in zwei separaten Gruppen melden. Es ist jedoch zu vermuten, dass die Sitte, die Toten mit Blick nach Westen zu bestatten, dominierend blieb. ${ }^{36}$ Die Nord-Süd- und Süd-NordGräber dürfen zur jüngeren Phase gehören, von denen die Ost-West-Bestattungen in 4 Fällen überlagert wurden.

\section{GESCHLECHTS- UND ALTERSVERTEILUNG DES GRÄBERFELDES ${ }^{37}$}

Geschlechtliche Indikatoren fehlen in 10 Fällen, davon handelt es sich bei 4 Gräbern um Brandbestattungen. Die Verteilung von Männern und Frauen auf dem Gräberfeld zeigt einen etwas größeren Frauenanteil (31,6 \%

${ }^{28}$ Ein Viertel der Nord-Süd orientierten Gräber war leer oder ohne Beigaben. In Ermangelung der Datierungsanhaltspunkte wurden sie ins 3. Jahrhundert datiert; OTTOMÁNYI 2016, 130.

${ }^{29}$ An beiden Schultern wurden Fibeln mit umgeschlagenem Fuß, eine Perlenkette am Hals, an der rechten Schulter ein Nadelbehälter aus Knochen, am linken Arm ein eiserner Armreif, zwischen den Oberschenkeln ein Eisenring, ferner eine Eisenschnalle beobachtet; OTTOMÁNYI 2016, 53, Abb. 24.

${ }^{30}$ Puschnigg 1996, 67-68; Kaltofen 1984, 16-18.

${ }^{31}$ SALAMON-BARKÓCZI 1971, 71.

${ }^{32}$ Auf Fläche B wurden die West-Ost-Gräber überlagert, auf Fläche D zeigten sich unter (dreimal), über (einmal) und neben (dreimal) den West-Ost-Gräbern von Nord nach Süd ausgerichtete Bestattungen. Die West-Ost-Ausrichtung gewann im 3.-4. Jahrhundert an Bedeutung. Im Fall der Nord-Süd-Gräber konnte am Fundort keine eindeutige Periode ausgemacht werden; ZsIDI 1997, 26-29.

${ }^{33}$ ZsIDI 1997, 27, Anm. 35. Im Grab 67 befanden sich 6 Gefäße (Schleifschale, Sieb) bzw. ein Spinnwirtel.
${ }^{34}$ Anhand des anthropologischen Materials der Nord-SüdGräber waren die Verstorbenen robustere Individuen, die Orsolya Madarassy mit den hier stationierten Soldaten in Verbindung brachte; MADARASSY 2000, 37

${ }^{35}$ Madarassy 2000, 37.

${ }^{36}$ Mit der Problematik der chronologischen Lage der von West nach Ost ausgerichteten Grabgruppe hat sich Katalin Ottományi anhand des Gräberfeldes von Budaörs auseinandergesetzt. Bei der Mehrheit der Bestattungen aus der zweiten Hälfte und dem Ende des 4. Jahrhunderts hat die Autorin eine West-Ost-Richtung beobachtet, deren Anteil sich in der spätrömischen Periode im Vergleich zu den vorangehenden Jahrhunderten verdoppelte, als die Tendenz der OstWest-Bestattungen umgekehrt war. Die Anzahl der Nord-Süd- und Süd-Nord-Bestattungen war sowohl in frührömischer als auch in spätrömischer Zeit sehr gering (5 \% bzw. 2 \%); OтTOMÁNYI 2016, 129, Abb. 6.

${ }^{37}$ Die detaillierte Analyse des anthropologischen Materials siehe in ÉVINGER-BERNERT 2019. 
zu 37,5\%). Die Kindersterblichkeit beläuft sich auf $25 \%{ }^{38}$ (insgesamt 39 Gräber). ${ }^{39}$ Die Gräberfelder im Vicus von Budaörs und von Tokod weisen ähnliche Werte auf..$^{40}$

Es starben anderthalb so viele Kinder in der Altersgruppe infans II als in infans I. Allerdings liegt der Prozentsatz jener Bestattungen, in denen die zwei Gruppen nicht unterscheidbar sind, bei über $6 \%{ }^{41}$ Die Sterblichkeitswerte der Altersgruppen iuvenis und senilis stimmen hinsichtlich des kompletten Gräberfeldes überein: Beide liegen unter $4 \%$.

Die Sterblichkeitsrate der Männer stimmt innerhalb der zwei Altersgruppen adultus und maturus fast überein (41,6 \% bzw. 45,83\%). Bei Frauen im Alter adultus lag die Sterblichkeitsrate weitaus höher, als bei Frauen im maturus-Alter (68,42 \% zu 12,28 \%), ${ }^{42}$ was auf die Gebärfähigkeit der Altersgruppe adultus zurückzuführen ist. Individuen, die im senilis-Alter bestattet wurden, gibt es nur wenige. Frauen und Männer sind in demselben Anteil vertreten (je $2 \%$ ). ${ }^{43}$ Der Spitzenwert der Sterblichkeitsrate, was die Bevölkerung von Somogyszil betrifft, fällt in die Altersgruppe adultus. ${ }^{44}$ Anzeichen von Neugeborenen gab es nur in insgesamt zwei Gräbern. In den Gräbern 64-65 lagen zwei Kinder: Dabei handelt es sich um eine Nachbestattung, wo über den Leichnam des früher verstorbenen Kindes ein wenige Monate alter Säugling begraben wurde. ${ }^{45} \mathrm{Im}$ Fall der langparallelen Gräber 142a und 142b wurde im ersten Grab ein Kind, im anderen ein Säugling beigesetzt. ${ }^{46}$

\section{GRABFORMEN}

Alice Sz. Burger hat die Grabformen des Gräberfeldes kurz behandelt. Im Anhang kategorisierte sie die einzelnen Gräber in Erd-, Ziegel- und Brandbestattungen. ${ }^{47}$ In der Analyse sind 6 Gräber als „Schachtgräber“ markiert, ${ }^{48}$ die Angaben entsprechen jedoch nicht ausnahmslos den Daten der Ausgrabungsdokumentation.

Zur allgemeinen Bestattungspraxis gehören in unserem Fall die Körperbestattungen, die eine überwiegende Mehrzahl der Bestattungen ausmachen (144 Gräber mit 148 Individuen). Die Brandbestattungen mit vier Gräbern (Grab 98, 106, 111 und 128) bilden eine kleine separate Gruppe, die sich in einer Reihe geordnet am westlichen Rand der Fläche II meldet. ${ }^{49}$ Tiefenangaben liegen uns lediglich in einem Fall vor. ${ }^{50}$

Auf Gräberfeldern der ländlichen Siedlungen mit Körperbestattung handelt es sich bei den meisten Gräbern um einfache Erdgräber (Schachtgräber; 61,8 \%). ${ }^{51}$ In Somogyszil gab es keine aus Stein gebauten oder Stein-

${ }^{38}$ Im Fall des Gräberfeldes von Tác-Margittelep ist dieser Anteil wesentlich höher (33,57 \%), ebenso in der nördlichen Grenzregion Valerias (Nyergesújfalu-Sánchegy, Tokod-Erzsébetakna, Esztergom-Bánomi-dűlő, Esztergom-Kossuth utca, PilismarótÖregek-dűlő, Visegrád-Diósd). Hier ähneln die Werte allerdings eher denen von Somogyszil (28,36 \%); MercZi 2010, 70.

${ }^{39}$ Anhand der Daten von Burgers Publikation bekommt man andere Werte: Der Frauenanteil beläuft sich auf 42,8 \%, der Anteil der Männer auf $23 \%$ und der Kinderanteil liegt bei 26,3\%. Unsere Werte basieren auf den überprüften Daten von Zsolt Bernert und Sándor Évinger.

${ }^{40}$ LÁNYi 1981，182; OtTOMÁNYi 2016，135. Katalin Ottományi wies auch darauf hin, dass der Männeranteil des Gräberfeldes von Budaörs im 4. Jahrhundert im Vergleich zur Periode zwischen den 1. und 3. Jahrhunderten um $10 \%$ anstieg.

${ }^{41}$ Tác-Margittelep und die Grenzregion Valerias mit einbezogen hat Mónika Merczi im Fall der Altersgruppe infans II ebenfalls weitaus höhere Proportionen feststellen können, als anhand des von ihr Modells zitierten CoALE-Demeny 1966 zu erwarten gewesen wäre; MERCZI 2010, 71.

${ }^{42} \mathrm{Im}$ Fall von Tác-Margittelep waren in erster Linie Individuen im Alter von 15-19 und 55-59 Jahren betroffen. In der nördlichen Grenzregion konnten ebenfalls zwei Spitzenwerte zwischen 35-39 und 45-49 Jahren festgestellt werden; Merczi 2010, 71, Tabelle 7 .
${ }^{43}$ In der behandelten Periode findet man in den übrigen pannonischen Gräberfeldern ebenfalls niedrige Werte: in EsztergomBánomi-dűlő 4,28 \% (MercZi 2008, 406), in Budaörs 4 \% (OTTOMÁNYI 2016, 134, Abb. 11).

${ }^{44}$ Im Fall von Tác-Margittelep handelt es sich um die Altersgruppe 15-19 Jahren, in der nördlichen Grenzregion um die von 45-49 Jahren; MERCZI 2010, 71.

${ }^{45}$ BURGER 1979, 37.

${ }^{46}$ RRMA IV/62/11 (708), Grabkarteikarte 142b.

${ }^{47}$ BuRger 1979, 79-81.

${ }^{48}$ Burger 1979, 16. Alice Sz. Burger verwendete den Terminus Schachtgrab meistens in Verbindung mit Nischengräbern.

${ }^{49}$ Beim heutigen Forschungsstand ist es schwierig zu entscheiden, ob die Brandgräbergruppen innerhalb der spätrömischen Körpergräberfelder als späte Derivate der birituellen Übergangsphase von Brand- zu Körperbestattungen betrachtet oder eher ethnisch interpretiert werden sollen. Ohne die Frage jetzt beruhigend beantworten zu können, sprechen die meisten Beispiele im südpannonischen Raum für eine lang anhaltende birituelle Übergangsphase, sogar bis in die Mitte des 4. Jahrhunderts. Ausführlicher dazu s. HoRvÁtH et al. 2018, 42-44, Abb. 2.

${ }^{50} \mathrm{Grab}$ 128: Tiefe von $40 \mathrm{~cm}$.

${ }^{51}$ Die Form der Gräber fällt meistens rechteckig aus, vereinzelt kommen abgerundete Ecken vor. Allerdings gibt es auch recht oft trapezförmige Gruben, die zum Fußende hin enger werden, bzw. ovale Grabflecken.

Acta Archaeologica Academiae Scientiarum Hungaricae 70, 2019 
setzungsgräber. Lediglich in einem einzigen Fall haben wir zuverlässigere Informationen, ${ }^{52}$ wonach der Verstorbene in einem Holzsarg bestattet wurde (Grab 33) ${ }^{53}$ Mit seinen 8 Beigaben zählt dieses Grab zu den reicher ausgestatteten. ${ }^{54}$

Unter den Erdgräbern sind die Gräber mit schmalem Absatz in größerer Zahl vorhanden. Bei einigen kann der Absatz auf 3 Seiten beobachtet werden (Grab 79, 80, 84). Die südliche Längsseite von Grab 80 war sogar stufenförmig angelegt. Die Mehrheit vertritt allerdings die Form mit vier Absätzen: Grab 42, 44, 48, 68, 71, 86, 87, $96,97,99,133,139$. Bei Grab 42 verschmälerte sich die $90-100 \times 180 \mathrm{~cm}$ breite Grube auf $40-46 \times 150 \mathrm{~cm},{ }^{55}$ bei Grab 68 von $76 \times 200 \mathrm{~cm}$ auf $45-48 \times 180 \mathrm{~cm}$. Im Fall von Grab 97 betrug die Oberflächenbreite der Grube 71-95 cm (Fuß bzw. Kopf), unten 45-60 cm. Eine Seite von Grab 125 war senkrecht, die andere stufenförmig, mit 2 Stufen. Bei einer Gesamttiefe von $205 \mathrm{~cm}$ befand sich der erste Absatz in einer Tiefe von $60 \mathrm{~cm}$.

Ein Teil der Erdgräber wurde mit Ziegeln abgedeckt oder wurden die Wände der Gräber mit hochkant gestellten Ziegeln verkleidet. Neben einfachen Erdgräbern wurden auch die Gruben von Absatzgräbern mit Ziegeln abgedeckt (Grab 84) bzw. die Verkleidung des unteren Teils der Grube mit hochkant gestellten Ziegeln kam ebenfalls vor (Grab 87, 137). Das Grab 148 gehörte zu den Ziegelplattengräbern mit Absatzwänden. Im oberen Teil der Grube waren $6 \times 2$ randlose tegulae dachförmig aneinander gelehnt aufgestellt, während der Absatz, der entlang der zwei längeren Seiten angelegt wurde, mit Fragmenten ausgelegt war. ${ }^{56}$ Die untere, schmalere Grube wurde mit Tegula-Ziegeln bedeckt, die Längsseiten mit Randleistenziegeln verkleidet bzw. auch der Boden des Grabes wurde mit Ziegeln ausgelegt.

Klassische Ziegelplattengräber kommen in zwei Fällen vor $\left(1,{ }^{57} 59^{58}\right)$. Bei 5 weiteren kann der genaue Typ des Grabes anhand der zur Verfügung stehenden Daten nicht ermittelt werden.

Eine separate Gruppe von Erdgräbern bilden die Erdgräber mit Seitennische. Laut der Ausgrabungsdokumentation von Balázs Draveczky handelt es sich in zwei Fällen um Nischengräber (Grab $40^{59}$ und 46). Die Gräber 55, 62, 67 und 95 können ebenso dieser Kategorie angehören. Mit Ausnahme von Grab 95, das sich auf der Südseite der Fläche II befindet, zeigen sich die Gräber auf der Südseite von Fläche I einheitlich orientiert. Grab 95 ist trapezförmig, schmaler am Kopfende $(140 \mathrm{~cm})$ und breiter am Fußende $(190 \mathrm{~cm})$. Auf der einen Seite der Grube befindet sich in $100 \mathrm{~cm}$ Tiefe ein $60 \mathrm{~cm}$ breiter Absatz. Der Verstorbene wurde in $140 \mathrm{~cm}$ Tiefe gelegt, die Grube wurde senkrecht ausgehoben. ${ }^{60}$ Mit Ausnahme von Grab 67, wo der Schädel des Toten nach Westen zeigt, handelt es sich um Gräber mit Ost-West-Orientierungen. Der Verstorbene wurde ausnahmslos in die tiefere und meist schmalere, nach Norden zeigende Hälfte der Grube gelegt, samt Beigaben. Der Tiefenunterschied zwischen Absatz und Grabgrube liegt zwischen 15 und $40 \mathrm{~cm} ; 30 \mathrm{~cm}$ kommen öfter vor. Informationen darüber, ob die Grube mithilfe von Steinen ${ }^{61}$ oder Ziegeln bzw. organischem Material, wie aus mehreren pannonischen Gräberfeldern bekannt, verschlossen wurde, liegen uns keine vor. ${ }^{62}$ Nur aus einem einzigen Grab kamen Münzen der konstantinischen Dynastie zum Vorschein (Grab 40), die von Relevanz für die Datierung sein können. Diese Münzdatierung lässt das Grab auf die vorvalentinianische Periode legen.

Von 103 einfachen Erdgräbern beinhalteten 82 permanente Grabbeigaben, meistens 1-5 Gegenstände. Die höchste Anzahl von Beigaben war 14. In den mit Ziegeln verdeckten Erdgräbern sowie in den Ziegelgräbern, deren Struktur anhand der Dokumentation nicht festgestellt werden kann, kamen meist 1-8 Beigaben vor. In zwei Fällen wurden 12 Gegenstände neben die Toten gelegt. Im Fall der beiden Ziegelplattengräber kamen 3 bzw. 6 Gegen-

${ }^{52}$ Aus Kindergrab 47, das durch Rigolen gestört wurde, kamen mehrere Eisengegenstände zum Vorschein - unter anderem auch ein Nagel, der nicht auf einen Sarg hindeuten dürfte. Diese Fragestellung wurde anhand der Gräberfelder von Esztergom und Budaörs angesprochen. Ein bis zwei in Gräbern vorkommende Nägel hatten am wahrscheinlichsten magische, apotropäische Rolle; KELEMEN 2008, 193, 197; OTTOMÁNYi 2016, 220.

${ }^{53}$, ,...] bei $80 \mathrm{~cm}$ zeigen sich ringsum senkrechte, braune, holzkohleartige Spuren. Sarg? Das Grab ist $154 \mathrm{~cm}$ tief [...]“; RRMA IV/62/11 (708)

${ }^{54}$ Auf dem Nordfriedhof der Soldatenstadt von Aquincum und auf dem Südostgräberfeld von Intercisa kommen ebenfalls relativ reiche Gräber zum Vorschein; ZsIDI 1997, 33; VÁGÓ-BóNA 1976, 143-144. In Budaörs machen den größten Anteil der beigabenlosen, vermutlich aus dem 3. Jahrhundert stammenden Gräber gerade die Sargbestattungen aus; OTTOMÁNYI 2016, 143.

Acta Archaeologica Academiae Scientiarum Hungaricae 70, 2019
${ }^{55}$ RRMA IV/62/11 (708).

56 „Das Ziegelgrab war sichtlich sorgfältig gebaut worden, selbst die Spalten zwischen den Ziegeln wurden mit kleinen Ziegelscherben ausgefüllt"; RRMA IV/62/11 (708), Grabkarteikarte 148.

${ }^{57}$ RRMA 708, Ausgrabungsprotokoll 1964.

${ }^{58}$ BURGER 1979, 35

59, ,...] In einer Tiefe von $76 \mathrm{~cm}$ zeigt sich die Nischenbildung und setzt sich bis zum Grund der Grube, in $106 \mathrm{~cm}$ Tiefe, fort"; RMMA IV/62/11 (708).

${ }^{60}$ Laut Daten der Gräberkarteikarte im östlichen Teil der Grabgrube; RRMA IV/62/11 (708).

${ }^{61}$ In Budaörs: Grab 180, 225, 237, 331, 356, 370 (OTTOMÁNYi 2016, 138).

${ }^{62}$ Es mag vorgekommen sein, dass das Quartier des Verstorbenen mit organischer Substanz abgetrennt wurde; ОттомÁNYI 2016, 262. 
stände zum Vorschein, während aus dem aufwändiger angefertigten Grab 148 insgesamt 8 Beigaben zutage gefördert wurden. Keines dieser Gräber wies Zeichen der Störung auf. ${ }^{63}$ In den Nischengräbern kamen höchstens 7 Beigaben vor. In den Absatzgräbern gab es bis zu 9 Beigaben. Das mit Ziegeln verdeckte Absatzgrab 84 barg 14 Gegenstände nebst Verstorbenem.

Die Sitte der Bestattung in einfachen Erdgräbern hing unter der Bevölkerung von Somogyszil nicht zwangsläufig mit dem niedrigen sozialen Status des Verstorbenen und seiner Familie zusammen, ${ }^{64}$ da die gebauten Gräber nicht unbedingt über ein reicheres Inventar verfügten. Die meisten Beigaben wurden aus einfachen Erdgräbern zutage gefördert. ${ }^{65}$

Die Durchschnittstiefe der Gräber von Somogyszil liegt bei 110-150 cm (55 Gräber). ${ }^{66} 26$ Gräber sind tiefer, davon lagen in 2 Gräbern Kinder im Alter infans (Grab 65) bzw. infans I (Grab 66). Weitere vier sind die Ruhestätten von Kindern im Alter infans II (Grab 63, 69, 125 und 134) ${ }^{67}$ Die Übrigen weisen erhebliche Unterschiede innerhalb der erwachsenen Population, abgesehen von der Altersgruppe und Geschlechtsverteilung, auf.

Bei dem Vergleich der relativen Tiefenangaben der Gräber mit der Beigabenanzahl kann keine positive Korrelation festgestellt werden. Sowohl im Fall der seichtesten $(40-50 \mathrm{~cm}$ ) als auch im Fall den zwei tiefsten Kategorien (unter $190 \mathrm{~cm}$ ) kommen Grabinventare mit 7 Gegenständen vor. Auch die Tiefenangaben der beiden Gräber mit den höchsten Beigabenanzahlen - 12 (Grab 38, 69, 80, 96) bzw. 14 Gegenstände (Grab 34, 52, 84) - weisen wesentliche Unterschiede auf. Mit Ausnahme von Grab 84 handelt es sich um Erdgräber, deren Tiefe in einem Intervall von 113-196 cm liegt. Neben der Tiefe sollte auch das Volumen der Grabgruben in die Untersuchung mit einbezogen werden (Tabelle 1) ${ }^{68} \mathrm{Im}$ Fall von Kindergräbern können wir in den meisten Fällen - der Körpergröße entsprechend - mit Gruben unter $2 \mathrm{~m}^{3}$ rechnen, aber auch bei Erwachsenen ist das Intervall um 1-2 $\mathrm{m}^{3}$ am verbreitetsten. Die Altersgruppen adultus und maturus der Erwachsenen decken das komplette Spektrum ab. Die Grabgruben der Altersgruppe senilis fallen $1-4 \mathrm{~m}^{3}$ groß aus. ${ }^{69}$ Gruben, die größer als $5 \mathrm{~m}^{3}$ sind, fanden wir in 4 Fällen: ein Männergrab (?) (Grab 46) und drei weitere waren Gräber von Frauen (Grab 62, 67, 71). All diese Bestattungen sind hinsichtlich ihrer Beigabenanzahl nicht herausragend.

Tabelle 1

Kombination des Grabvolumens mit den Altersgruppen

\begin{tabular}{|c|c|c|c|c|c|c|c|c|c|c|c|}
\hline & \multicolumn{9}{|c|}{ Alterskategorie } & \multirow{2}{*}{ Insgesamt } \\
\hline & & Inf & $\operatorname{Inf} I$ & Inf II & $I u v$ & $A d$ & Mat & Ad/Mat & Sen & $?$ & \\
\hline \multirow[t]{8}{*}{ Grabvolumen $\left(\mathrm{m}^{3}\right)$} & $<0,5$ & 0 & 2 & 2 & 0 & 1 & 0 & 0 & 0 & 0 & 5 \\
\hline & $0,5-1$ & 2 & 5 & 2 & 1 & 7 & 7 & 1 & 0 & 0 & 25 \\
\hline & $1,1-2$ & 3 & 2 & 4 & 3 & 25 & 10 & 0 & 4 & 1 & 52 \\
\hline & $2,1-3$ & 1 & 0 & 1 & 1 & 11 & 8 & 2 & 1 & 0 & 25 \\
\hline & $3,1-4$ & 0 & 0 & 3 & 1 & 3 & 1 & 1 & 1 & 0 & 10 \\
\hline & $4,1-5$ & 0 & 0 & 2 & 0 & 3 & 1 & 0 & 0 & 0 & 6 \\
\hline & $5,1-6$ & 0 & 0 & 0 & 0 & 2 & 2 & 0 & 0 & 0 & 4 \\
\hline & $>6$ & 0 & 0 & 0 & 0 & 1 & 0 & 0 & 0 & 0 & 1 \\
\hline \multicolumn{2}{|l|}{ Insgesamt } & 6 & 9 & 14 & 6 & 53 & 29 & 4 & 6 & 1 & 128 \\
\hline
\end{tabular}

${ }^{63}$ Das Grab 1 wurde während des Pflügens gefunden. Die Knochen wurden aus der Grube entfernt, aber die Beigaben scheinen vollständig zu sein.

${ }^{64}$ VÁGÓ-BÓNA 1976, 145. István Bóna interpretiert die Erdgräber als ,ein soziales Phänomen“, da die meisten unter den einfachen Erdgräbern im Südostfriedhof von Intercisa ohne bzw. mit nur spärlichen Beigaben vorgefunden wurden. Aber auch Bóna betont, dass diese „doch nicht bettelarme Toten“ waren.

${ }^{65}$ Die Zahl der aufwendig gebauten Gräber ist in Somogyszil ausgesprochen niedrig. In Budaörs und Tokod konnte aber bestätigt werden, dass die gebauten Gräber eindeutig reicher ausgestattet worden waren (in mehreren Fällen höhere Anzahl von Beigaben); OTTOMÁNYi 2016, 188; LÁNYI 1981, 180-181.

${ }^{66}$ Wir verfügen über Tiefenangaben von 127 Gräbern.
${ }^{67}$ Die Gräber 63, 65, 66 und 69 liegen auf dem Südteil des Gräberfeldes direkt nebeneinander. Die beiden anderen Kindergräber am Nordende des Gräberfeldes befinden sich ebenfalls nahe zueinander.

${ }^{68}$ Zwischen Tiefe und Volumen der Grabgrube besteht nicht zwangsläufig ein Zusammenhang. Allerdings kann bestätigt werden, dass die seichtesten Gruben (bis $90 \mathrm{~cm}$ ) unter $2 \mathrm{~m}^{3}$ groß und die über $5 \mathrm{~m}^{3}$ tiefer als $150 \mathrm{~cm}$ waren.

${ }^{69}$ Bei den Sarmaten der Großen Tiefebene wurde beobachtet, dass die größten Gruben mit gewissen Altersgruppen zusammenhingen. Auf dem Gräberfeld von Pécel wurden bei beiden Geschlechtern Vertreter der Altersgruppe adultus in die großflächigsten Gruben gelegt, während die Gräber der Älteren schmaler ausfielen; NAGY 2014, 120-121. 


\section{MEHRFACHBESTATTUNGEN UND SUPERPOSITIONEN}

Auf dem Gräberfeld konnten einige Mehrfachbestattungen registriert werden ( $8 \%$ aller Gräber). ${ }^{70}$ Dabei handelt es sich in jedem Fall um Doppelbestattungen. Komplexere Fälle kamen nicht zum Vorschein.

1. Im Fall langparalleler Gräber (Zwillingsgrab) stimmt die Orientierung überein oder sie zeigten höchstens minimale Abweichungen, was auf eine nahe Gleichzeitigkeit zwischen den Gräbern schließen lässt. ${ }^{71}$ Es konnten drei solche Fälle ausgemacht werden: 1. Grab $10(-40 \mathrm{~cm})$ und Grab $11(-40 \mathrm{~cm})$; 2. Grab $108(-110 \mathrm{~cm}$, West-Ost) und Grab 109 (-127 cm, Ost-West) in entgegengesetzter Orientierung; 3. Grab 142a (-90-100 cm) und Grab 142b (-110 cm), ein Kind und ein Säugling.

2. Überlagerung. In Grab 64-65 wurden die Skelette zweier Kinder registriert. Über dem Kind der Altersgruppe infans $I$, das in $172 \mathrm{~cm}$ Tiefe bestattet wurde, begrub man einen paar Monate alten Säugling in einer Tiefe von $150 \mathrm{~cm}$. In den Gruben 113a und 113b ruhten zwei Erwachsene der Altersgruppe adultus. Über dem Skelett des Mannes wurde, nachdem das Grab erneut geöffnet wurde, eine Frau bestattet. Auch in diesen Fällen ist ein wesentlicher Zeitunterschied ausgeschlossen.

3. Womöglich hat das spätere Grab mit einem Zeitunterschied von einigen Jahrzehnten - den Pietätsfaktor außer Acht lassend - die anatomische Anordnung der Knochen des im früheren Grab liegenden Skeletts gestört. Im Fall der Doppelbestattung 5a und 5b kam es zur erneuten Aushebung der Grabgrube. Nach der Bestattung des Mannes im Alter adultus im Grab 5a mögen einige Jahrzehnte vergangen sein, bis in dieselbe Grube ein weiterer Mann im Alter maturus gelegt wurde. Ein ähnlicher Fall kam im Grab 75a und 75b vor, wo am Fußende des weiblichen Skeletts im maturus-Alter gehäuft ein Mann der Altersgruppe adultus begraben wurde.

4. Im Vergleich zu diesen unterscheidet sich die Orientierung der Gräber in Superposition grundlegend oft liegen sie senkrecht zueinander $-{ }^{72}$ was auf einen Zeitphasenunterschied schließen lässt (4 \% der Gräber).

\section{SKELETTLAGE}

Die meisten Toten lagen in gestreckter Rückenlage, die sich durch ihre Armhaltung unterscheiden (115 Bestattungen) (Abb. 3). Es gibt lediglich 7 Gräber, in denen die Arme des Toten ausgestreckt neben dem Körper lagen. Mit Ausnahme von Grab 58 (Nord-Süd gerichtet) handelt es sich um Ost-West orientierte Kinder- und Frauengräber. Bei den übrigen Nord-Süd- und Süd-Nord-Gräbern beugte man einen Arm oder beide Arme am Ellbogen an und platzierte sie auf das Becken bzw. im rechten Winkel darüber. In jedem Fall der West-Ost-Gräber legte man die Arme angebeugt auf das Becken oder darüber. ${ }^{73}$ Die Forschung geht im Allgemeinen davon aus, dass es sich bei der Positionierung der Arme um ein ritusunabhängiges Phänomen handelt. ${ }^{74}$ Bei den auf dem Brustkorb gefalteten Händen werden auch christliche Zusammenhänge erwogen. ${ }^{75}$ Auf dem Gräberfeld von Somogyszil handelt es sich um 13 Gräber, die - vom Grab 144 (West-Ost) abgesehen - Ost-West orientiert waren.

Das Hockergrab 116, vier weitere Beispiele mit hochgezogenen Beinen in leichter Seitenlage ${ }^{76}$ (Grab 3, 16, 45 und 51) und zwei weitere mit gekreuzten Beinen (Grab 23 und 70) melden sich als Sonderbestattungen. ${ }^{77}$ Darunter gab es lediglich zwei Gräber mit jeweils einem Tracht- und Schmuckelement. In Grab 3 kam eine Eisenschnalle und in Grab 70 eine Perlenkette vor. Die Übrigen enthielten keine andauernden Beigaben. Hinsichtlich

${ }^{70} \mathrm{Zu}$ der Frage der Doppel- und Nachbestattungen der spätrömischen Gräberfelder Pannoniens siehe zuletzt MüLLER 2010, 172-174, mit weiterer Literatur.

${ }^{71}$ Siehe dazu Zsidi 1997, 21-22.

${ }^{72} 6$ solche Fälle konnten ausgemacht werden: 1. Grab 18 (Nord-Süd) und Grab 20 (Ost-West); 2. Grab 50 (Süd-Nord) und Grab 48 (Ost-West); 3. Grab 58 (Nord-Süd) und Grab 59 (Ost-West); 4. Grab 90 (Süd-Nord) und Grab 105 (Ost-West); 5. Grab 91 (OstWest) und Grab 87 (Ost-West); 6. Grab 118 (Ost-West) und Grab 119 (Ost-West).

${ }^{73}$ Grab 67, 71, 108, 143, 144 und 145. Die Frage, ob die West-Ost orientierten Gräber mit auf dem Unterleib verschränkten Acta Archaeologica Academiae Scientiarum Hungaricae 70, 2019
Armen auf christliche Bestattungen hinweisen, muss weiter untersucht werden.

${ }^{74}$ LÁNYI 1972, 66.

${ }^{75} \mathrm{Zu}$ dieser Frage siehe ZSIDI 1997, 36; MüLLER 2010, 167. Katalin Ottományi argumentiert dagegen, dass die Gräber in Budaörs nicht einheitlich orientiert sind; OTTOMÁNYI 2016, 175.

${ }^{76}$ Diese Erscheinung wird oft mit der Beisetzung in einem Tuch eingewickelt erklärt; VÁGÓ-BóNA 1976, 157-160.

${ }^{77} \mathrm{Zu}$ den Hockerbestattungen Pannoniens siehe LÁNYI 1972, 66-69. Vor der Südmauer von Keszthely-Fenékpuszta sind diese Lagepositionen der Toten besonders für die spätrömerzeitliche Phase des Gräberfeldes charakteristisch; MüLLER 2010, 167-168. 


\begin{tabular}{|c|c|}
\hline 吊 & $37,54,58,63,110,134,137,139$ \\
\hline 吊 & 64,69 \\
\hline 吊 & 26,84 \\
\hline 巾 & $\begin{array}{l}2,25,31,34,39,45,81,82,86,88,89,90,91,95,96,97,100,101,102,104,107,112,118,123,127, \\
142,143,144,145\end{array}$ \\
\hline 吊 & $15,71,75,77,141$ \\
\hline 吊 & $8,19,28,51,52,60,62,76,83,108,114,132,140$ \\
\hline 吊 & $40,43,46,48,50,53,55,59,61,67,71,103,113,117,125,129,130,131$ \\
\hline 吊 & $21,79,87,93,146$ \\
\hline 禹 & $7,33,72,92$ \\
\hline 吊 & $5,6,27,49,80,133$ \\
\hline 吊 & 68,148 \\
\hline
\end{tabular}

Abb. 3. Übersicht zu den mehrfach belegten Armhaltungen in den Gräbern

ihrer Lage befinden sich diese Gräber etwas abseits. ${ }^{78}$ Eine mögliche Erklärung für diese Situation wird meistens in der sozialen Stellung der Verstorbenen (Armut, fremde Herkunft, diverse Krankheiten) gesucht. ${ }^{79}$

\section{MÜNZEN}

Die vollständige Erfassung und Publikation des Münzinventars aus 306 Münzen des Gräberfeldes wurde von Alice Sz. Burger durchgeführt. ${ }^{80}$ Dem Band sind Münztafeln 1-8 hinzugefügt.

Dieser Münzbestand kann 40 \% der Gräber zugerechnet werden. Aus den Brandbestattungen ist nur eine Münze des Constantius II. bekannt (Grab 128). Die anderen Münzen waren den Körperbestattungen beigelegt (insgesamt 58 Gräber). Die Münzreihe des Gräberfeldes setzt sich mit einer 314/315 geprägten Münze des Licinius ein (Grab 37 n. Chr. mit der Münze von Constantin I. aus den Jahren 317/320). Zwei Münzen von Vespasian aus dem Jahr 71 n. Chr. wurden als Einzelstücke in den Gräbern 46 und 93 entdeckt. Antoniniane stammen aus Grab 35 und 129 mit Prägungen der Jahre 335/337 (129) und 351/354 (35). Das Münzspektrum endet mit AE 3 Münze des Gratians $367 / 375$ aus Grab 82.

${ }^{78}$ Die Hockerbestattungen der Gräberfelder von Keszthely-Dobogó, Bátaszék, Esztergom, Budaörs und Halbturn befinden sich ebenso am Rand der Gräberfelder; SÁGI 1981, 96; PÉTERFi 1993, 94-95; KeLEMEN 2008, 81; OtTOMÁNyi 2016, 176; Doneus 2014, 192, Abb. 127.

${ }^{79}$ VÁGÓ-BÓNA 1976, 160; FASOLD 1992, 21. Aus Keszthely-Fenékpuszta ist ein Beispiel für ein Hockergrab mit vergoldetem Kopfschmuck bekannt (Grab 1901/85). Róbert Müller verwies aber auch darauf, dass die Leichen in echten Hockergräbern oft geknebelt wurden (oder sie kamen mit Steinpackung über der Leiche vor), da die Gemeinschaft sich vor diesen Toten schützen wollte; MÜLLER 2010, 168 .

${ }^{80}$ BuRgER 1979, 15. Die Korrektion der Bestimmungen stammt aus der Feder von Vera Lányi: Sie hat auf die Ungenauigkeiten hingewiesen; LÁNYI 1980. 
Die höchste Anzahl (18 Exemplare) der in Gräbern gefundenen Münzen stammt aus Grab 81 mit einem Zeitintervall von 351 bis 366. In insgesamt 7 Gräbern wurden 10 oder mehr Münzen entdeckt. In einem Drittel der münzführenden Gräber wurde jeweils ein Exemplar gefunden. Die Hälfte der Gräber, die mehr als 9 Münzen enthielten, waren 9 bis 11 Jahre im Umlauf. In den anderen Fällen sind längere Umlaufzeiten zu registrieren, die jedoch nicht als typisch angesehen werden können. ${ }^{81}$ Das deutliche Überwiegen von etwa 180 Prägungen der konstantinischen Periode ist besonders auffallend. Es konnten 41 Gräber registriert werden, die allein Prägungen der vorvalentinianischen Periode enthielten. Unter den bestimmbaren Münzen fallen 62 Prägungen auf die valentinianische Zeit. In den Gräbern mit valentinianischen Münzen als Schlussmünzen sind mehrfach Münzen der Zeit 355/361 (Grab 68, 132) anzutreffen und sind mehrere solche, in denen mit einer Münzreihe vom längeren Zeitraum ab den 330er Jahren zu rechnen ist (Grab 52, 60, 84). Die Gräber 82 (14 Stücke) und 141 (3 Stücke) enthalten ausschließlich mehrere Münzen der valentinianischen Dynastie.

Für Gräber mit mehreren an einer Stelle im Grab gefundenen Münzen ist die Beigabe in einem Beutel anzunehmen. Diese wurden meist in die Hände gelegt, zu den Füßen deponiert oder am Gürtel befestigt.

In chronologischer Hinsicht machen Gräber der Periode von 330 bis 355 etwa $70 \%$ der münzdatierten und statistisch auswertbaren Bestattungen aus. Die valentinianische und postvalentinianische Periode vertritt etwa $30 \%$ der Bestattungen. ${ }^{82}$ Die Intensität des Gräberfeldes geht anhand der münzführenden Gräber zurück $(A b b .4)$.
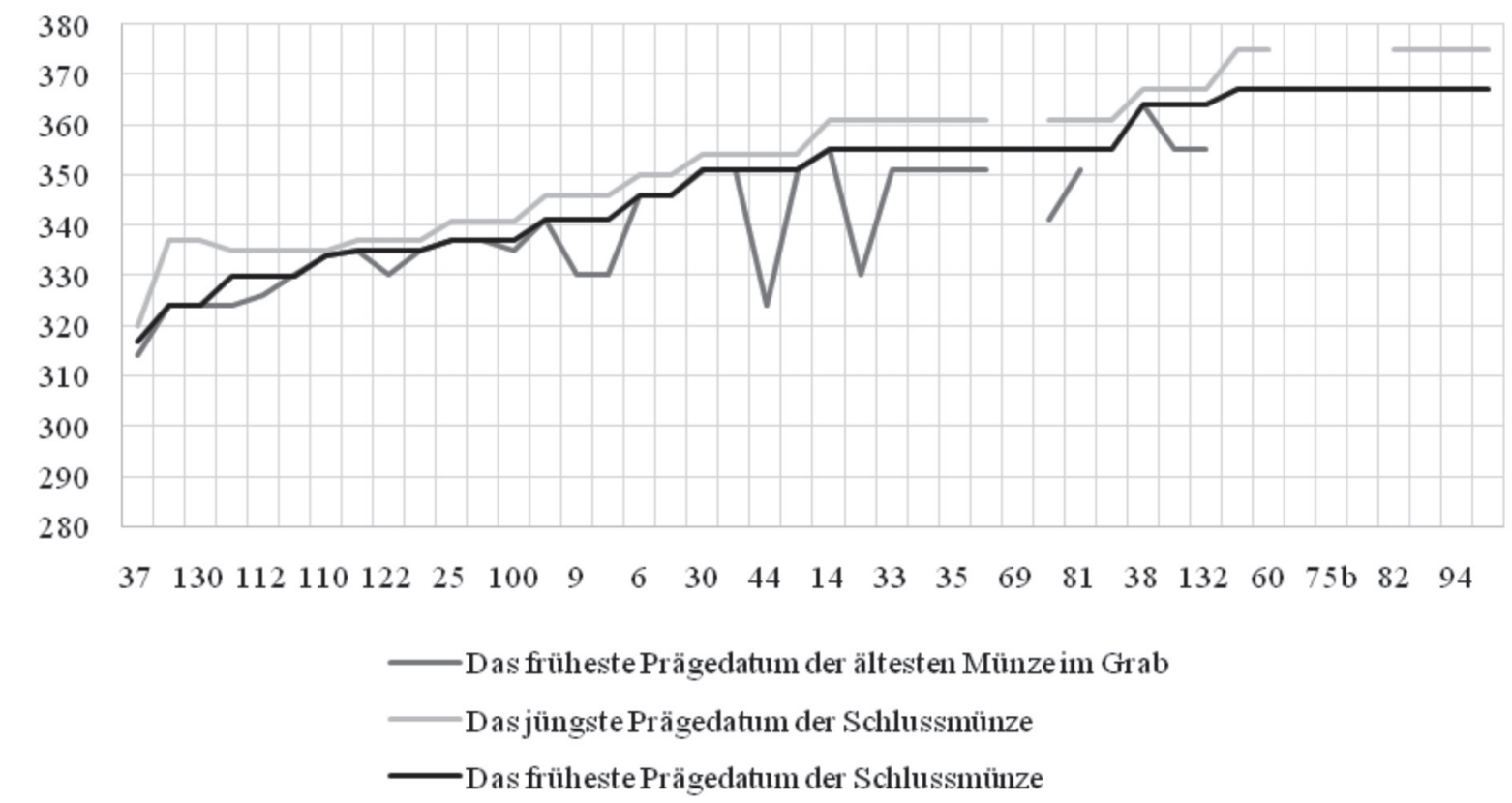

Abb. 4. Der Münzumlauf des Gräberfeldes

${ }^{81} \mathrm{Im}$ spätrömischen Gräberfeld von Hegyeshalom hat Ferenc Redő eine Umlaufsperiode von 11 bis 25 Jahren anhand der Gräber mit Münzen über zehn Exemplare registriert; REDő 1999, 188.

${ }^{82}$ Bei der absoluten Datierung wurde die von Ferenc Redö ausgearbeitete Methode berücksichtigt. Die schwarze Linie zeigt das früheste Prägedatum der Schlussmünzen, die mit der Belegungszeit des Gräberfeldes gleichzusetzen ist. Die Zone darunter bezieht sich auf den Zeitraum der Münzen im gleichzeitigen Verkehr und die Zone darüber zeigt den Unsicherheitsgrad der obersten Datierung der Schlussmünze; REDŐ 1999, 188-190. 
Bei der Analyse der rituellen Eigenheiten des Gräberfeldes wurden die Eigenschaften der Tracht- und Schmuckelemente ${ }^{83}$ der Verstorbenen bzw. die Zusammensetzung der Beigabeninventare (Speise und Trank, Werkzeuge, Münzen usw.) unter Berücksichtigung der Orientierung und Lage der Gräber unter die Lupe genommen. ${ }^{84}$

31 Gräber der 152 Bestattungen brachten keine Fundgegenstände zum Vorschein. Die prozentuale Menge der beigabenlosen Bestattungen liegt bei 20,4\%, bei denen sich eine Randlage in den einzelnen Grabgruppen nachvollziehen lässt. Hinweise auf zeitgenössische Störungen liegen uns nur in einem einzigen Fall vor, das Grab ist jedoch nicht beigabenlos (Grab 87).

Unter den Brandbestattungen am westlichen Rand der Fläche II beinhalteten drei Gräber Beigaben (Grab 111 war beigabenlos). Charakteristisch waren die Gefäßbeigaben, die auf Speise- und Trankopfer schließen lassen. In zwei Männergräbern wurde das Keramikinventar mit Gegenständen des täglichen Gebrauchs $(\mathrm{Grab} 98,106)$ und in einem Frauengrab mit einem Schmuckgegenstand ergänzt. Die Beigabenzusammensetzung dieser Bestattungen unterscheidet sich nicht von den übrigen Körpergräbern. Unter den Brandbestattungen war allein Grab 128 münzdatiert (Constantius II.). Aus Grab 98 ist eine Fibel vom Typ Pröttel 2B bekannt geworden, die nach Philipp M. Pröttel in den Jahren zwischen 300 und $340 \mathrm{n}$. Chr. zu datieren ist. ${ }^{85}$ Diese Anhaltspunkte datieren die behandelten Brandbestattungen um die Mitte des 4. Jahrhunderts, d. h. mit der Frühphase der Körperbestattungen zeitgleich.

Hinsichtlich ihrer Lage und Chronologie bilden die West-Ost-Gräber, obwohl ihre Anzahl recht niedrig ist, eine selbstständige Gruppe. In allen Gräbern wurden Trachtgegenstände oder Schmuckstücke und von einem Grab abgesehen Werkzeuge registriert. Mit Ausnahme von Grab 108 und 144 verfügten alle über Geschirrbeigabe.

Zwei der von Süden nach Norden ausgerichteten Gräber waren beigabenlos (Grab 56, 58). In Grab 12 und 70 wurde jeweils ein Schmuckgegenstand gefunden. Auch unter den Nord-Süd-Gräbern gab es zwei ohne Beigabe (Grab 18, 50). In den anderen zwei befanden sich Speisebeigaben und Werkzeuge (Grab 90). Darüber hinaus wurde aus Grab 41 noch ein Trachtelement zutage gefördert.

Knapp $90 \%$ der Frauengräber und gerade mal 70,83 \% der Männergräber beinhalteten Beigaben. In den meisten Fällen kamen Gräber mit 1-5 Beigaben vor, aber auch Bestattete mit 7 Gegenständen waren öfters beobachtet. Unter den Kindergräbern enthielten 81,5\% Beigaben. Speisebeigaben sowie Tracht- und Schmuckelemente kamen in jeweils 21 der Kindergräber vor $(65,6 \%) .{ }^{86}$ Werkzeuge wurden in $16(50 \%)$, Münzen in 15 (46,8\%) Gräbern registriert. In zwei Kindergräbern lagen Spinnwirtel und in einem eine Öllampe.

Sowohl in Männer- als auch in Frauengräbern waren Schmuck und Tracht am verbreitetsten. In geschlechtlicher Hinsicht stimmten die Werte fast überein (Frauen: 86,3 \%, Männer: 85,29 \%). Die zweithäufigste Beigabe waren Keramik- und Glasgefäße (Frauen: 70,6 \%, Männer: 67,6 \%). An dritter Stelle stehen Werkzeuge: sowohl bei Frauen als auch bei Männern 64,7 \%. Aus Kindergräbern kamen etwas weniger Werkzeuge zum Vorschein (siehe oben). Im Fall von Frauengräbern mit Beigaben fanden sich in 39,2 \% der Gräber Münzen; bei den Männern in jedem zweiten Grab (vgl. Kindergräber mit 46,8 \%). Ein definitiver Unterschied zwischen Gräbern von Männern und Frauen zeigt sich nur im Verhältnis der Gräber mit Münzbeigaben.

Unter den Frauenbestattungen gibt es viele Gräber, die ausschließlich Schmuck oder Trachtgegenstände vorführten. Männer- und Kindergräber mit demselben Inhalt kommen seltener vor. Von den Kindergräbern befinden sich Grab 136 und 142 in einer Gruppe - ebenso wie die Frauengräber 115, 118 und 120, deren Ausrichtung übereinstimmt. Solche Männergräber weisen eine große Streuung auf dem gesamten Territorium auf.

Frauengräber mit Schmuckstücken, Geschirr- und Werkzeugbeigaben sind in höherer Zahl vertreten bzw. auch solche, die darüber hinaus auch münzdatiert waren (in 9 bzw. 10 weiteren Fällen). Dieses Inventar war allerdings unter den Kindergräbern in 5 Gräbern und unter den Männergräbern in 8 Gräbern belegt. Das Münzspektrum der Kindergräber fällt auf die konstantinische Periode, während Männer- und Frauengräber ungefähr zu 50 \% konstantinische und valentinianische Münzen beinhalteten.

${ }^{83}$ Die Platzierung von Tracht und Schmuck ins Grab kann zahlreiche rituelle Bezüge haben. Allerdings können diese Gegenstände nur in gewissen Fällen als Beigaben betrachtet werden; siehe dazu KulCSÁR 1998, 48, 56.

${ }^{84}$ Auf dem Gräberfeld von Budaörs ist die Beigabensitte der spätrömischen Grabgruppen im Vergleich zur frührömischen Periode viel unbedeutender. In der Spätrömerzeit handelt es sich

strukturell viel eher um Grabreihen, die öfters über unterschiedliches Grabinventar verfügten und selbst die Gräber mit identischen Beigaben bildeten nicht immer eine Gruppe; OTTOMÁNYI 2016, 225.

${ }^{85}$ PRÖTTEL 1988, 357.

${ }^{86}$ Hinsichtlich der Relationswerte haben wir lediglich die Gräber beachtet, die permanente Fundgegenstände beinhalteten. 
In der Beigabensitte zeichnen sich in Somogyszil nur wenige Tendenzen ab, die sich chronologisch begrenzt melden: So zum Beispiel jene drei Männergräber, die außer Trachtgegenständen und Gefäßbeigaben Feuersteine enthielten, kamen allein mit konstantinischen Münzen zum Vorschein (Grab 39, 112, 114). Die beiden letzten liegen sogar in einer Grabgruppe.

\section{SPEISE- UND GETRÄNKBEIGABEN}

Im Vergleich zur Früh- und Mittelkaiserzeit steigt die Anzahl der beigegebenen Gefäße der Verstorbenen in der Spätrömerzeit deutlich an. ${ }^{87}$ Im Gräberfeld von Somogyszil wurden insgesamt 102 Tongefäße bzw. Gefäßbruchstücke als Beigaben in 73 Gräbern ( $48 \%$ der Bestattungen) sowie weitere 6 Gefäße als Streufunde registriert. ${ }^{88}$ In 51 Gräbern war nur eine Keramik. In 12 davon wurden zwei, in 7 Gräbern drei und in 3 Gräbern sogar vier Tonwaren gefunden. Der Keramikbestand besteht aus grauer Feinware, graukörniger Ware, bleiglasierter und polierter Keramik in scheibengedrehter und handgeformter Variante.

Münzbeigaben kamen insgesamt in 35 Gräbern mit Gefäßbeigaben vor. In 22 davon sind konstantinische, in 13 weiteren Gräbern valentinianische Prägungen nachzuweisen.

Unter den Ost-West ausgerichteten Gräbern sind in 59 Gräbern, die 45,38 \% dieser Gräber entsprechen, alle diese Gefäßgattungen vertreten. In 19 Fällen wurden graukörnige Gefäße registriert. Die graue Feinware und die glasierte sowie die polierte Ware in Auftragungstechnik treten in fast derselben Anzahl von Fällen auf (16-15mal bzw. 14-mal). Polierte, gedrehte Keramik wurde fünfmal, graue rauwandige Ware dreimal und tongrundige Feinware zweimal aus den Ost-West-Gräbern geborgen. Gräber mit West-Ost-Orientierung beinhalteten neben glasierten Gefäßen (Grab 67, 71, 146) in zwei Fällen graue, feinkörnige Waren (Grab 71, 143) bzw. in einem Fall ein Geschirr mit rauer Oberfläche (Grab 71). Gefäßbeigaben unter den Süd-Nord-Gräbern sind aus 2 Gräbern bekannt. Aus Grab 41 kamen graukörnige Töpfe und ein handgeformter polierter Teller ans Tageslicht. Im Grab 90 lag ein handgeformter Teller mit polierter Oberfläche.

Die graue Feinware ist insgesamt in 21 Exemplaren vorhanden. Die Mehrheit besteht aus Topfbechern/ Bechern (9 St. $)^{89}$ und Tellern (7 St.) ${ }^{90}$ es können aber auch 2 weitere Schalen/Schälchen ${ }^{91}$ zu dieser Gattung geordnet werden. Eine Subkategorie der grauen Feinware bilden polierte, gedrehte Gefäße, wovon 6 Exemplare zum Vorschein kamen. Hinsichtlich ihrer Form handelt es sich um Becher. ${ }^{92}$

Weitaus mehr Exemplare der polierten Gefäße gehören zur Gruppe von Gefäßen mit Auftragungstechnik. ${ }^{93}$ Von der Form her kommen in unserem Fall Teller/Schalen $(14 \text { St. })^{94}$ und Topfbecher $(5 \text { St. })^{95}$ vor. ${ }^{96}$ Die Mehrheit der Gräber mit polierten, aus Tonwülsten erstellten Gefäßen liegt im Gräberfeldteil I. Am südlichen Ende der Fläche II zeichnet sich eine weitere Gruppe ab, nördlich davon gibt es nur zwei Streufunde. Sie sind sowohl mit konstantinischen (Grab 6, 33, 80) als auch mit valentinianischen Prägungen (Grab 2, 68, 84) belegt.

${ }^{87}$ Ein gutes Beispiel dafür ist das langlebige Gräberfeld des Vicus von Budaörs. Die steigende Tendenz von Glasgefäßen ist bereits ab der Severus-Periode nachvollziehbar; OTTOMÁNYI 2016, 188.

${ }^{88}$ Diese Zahlenangaben sind im Vergleich zu den verschiedenen spätrömischen Gräberfeldteilen von Keszthely-Fenékpuszta ziemlich hoch. Róbert Müller sieht in den niedrigen Werten an Keramikbeigaben von Keszthely-Fenékpuszta ein Argument dafür, dass sie Christen sein könnten; MüLLER 2010, 183.

${ }^{89} \mathrm{Grab} 19,21,29,95,101,128,133,141,148$.

${ }^{90} \mathrm{Grab}$ 5b, 27, 34, 42, 69, 71, 143.

${ }^{91} \mathrm{Grab} 11,134$.

${ }^{92}$ Grab 5b, 42, 46, 100, 137, 140

${ }^{93}$ Die Warengruppe polierter, aus Tonwülsten gefertigter, meist handgeformter Keramik ist mit feinem Sand gemagert, ihre Oberfläche ist meist fleckig, von hellbraunen bis dunkelgrauen Tönen. An der Wand sind sie innen und außen mit groben Linien geglättet. Bei der Polierung der Becher/Topfbecher und Krüge ist eine entgegen- gesetzte Tendenz als bei den provinzialrömischen scheibengedrehten Varianten zu beobachten; die Schulter ist waagerecht und der Unterteil senkrecht poliert. Form und technische Merkmale dieser Gefäße erwecken einen vom provinzialrömischen Töpferverfahren abweichenden, ,barbarischen“ Eindruck; siehe dazu HoRvÁTH 2016. $80,81,90$

${ }^{94}$ Grab 1, 6, 10, 33, 40, 41, 43 (2 Exemplare), 61, 68, 79,

${ }^{95}$ Grab 2, 17, 84, 126, Streufunde.

${ }^{96}$ Diese spezielle Warengruppe der handgeformten polierten Gefäße, gegebenenfalls mit eingeglätteten Motiven, konnte bisher in den spätrömischen Gräberfeldern, Siedlungen und Befestigungen Pannoniens, östlich der Linie Keszthely-Tihany-Somodorpuszta, in vielen Fundorten registriert werden. Funktional sind Töpfe bzw. Topfbecher, Teller und Krüge bekannt, die in den voneinander in größeren Entfernungen liegenden Fundorten ein ziemlich einheitliches Bild aufzeigen; HORVÁTH 2016. 


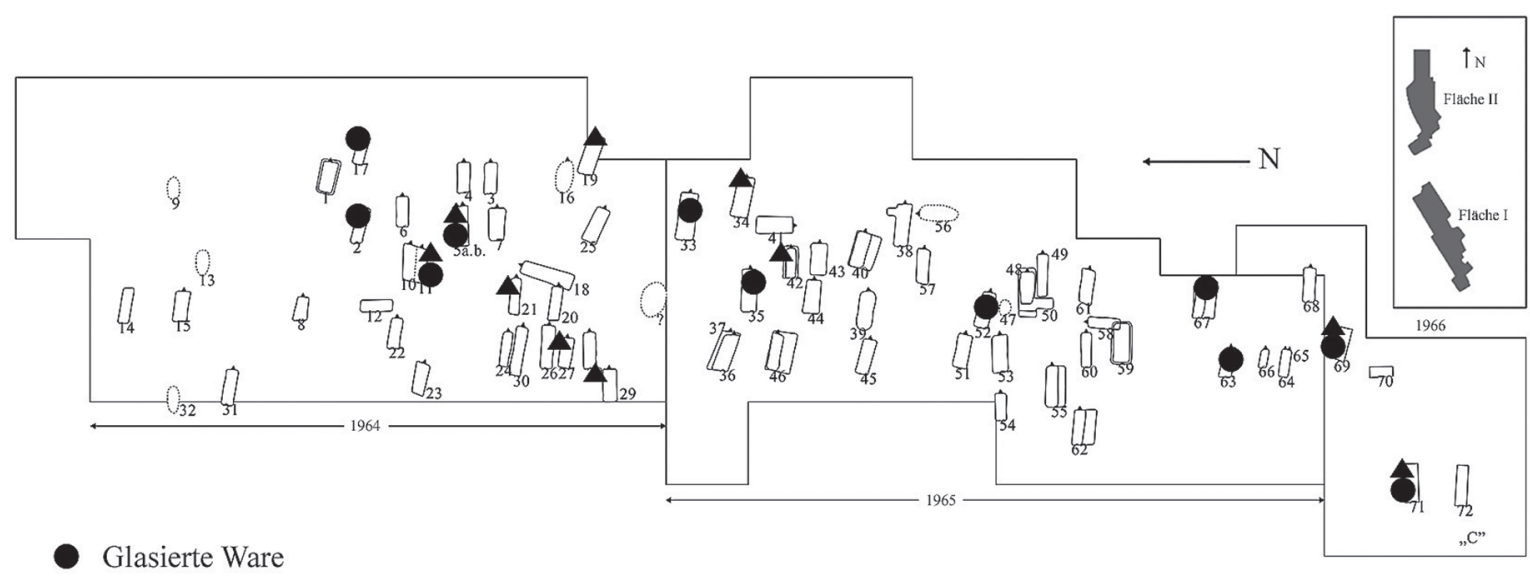

$\Delta$ Feinware

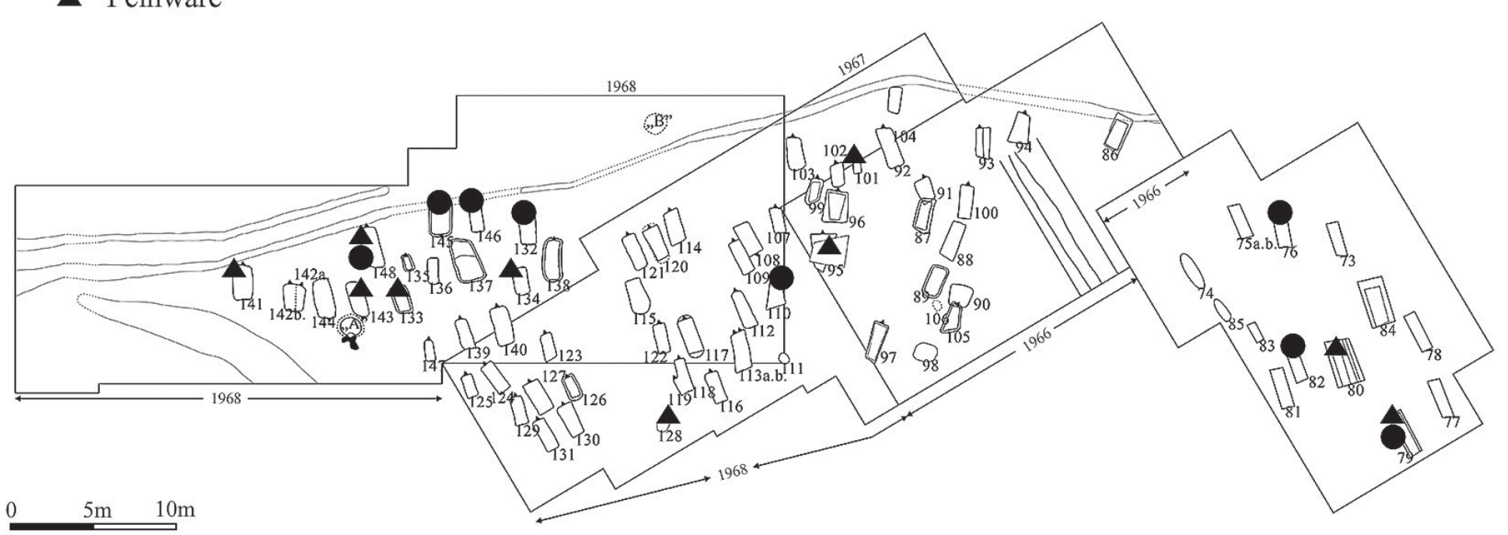

Abb. 5. Verteilung der Gräber mit glasierter Keramik und Feinware

Den graukörnigen Waren können 26 Stücke zugeordnet werden. Darunter gibt es 9 Töpfe, ${ }^{97} 8$ Teller, ${ }^{98}$ 3 Topfbecher/Becher ${ }^{99}$ und 2 Schalen. ${ }^{100}$ Als Geschirrbeigabe war diese Warengattung allgemein gebräuchlich. In den Gräbern sind sie durch Koch- und Tischgefäße vertreten, die mit allerlei anderen Warenarten variieren. Am häufigsten ist ihre gemeinsame Beigabe mit polierten Gefäßen in Auftragungstechnik zu registrieren (in 5 Fällen: Grab 2, 17, 40, 41 und 61).

Insgesamt gibt es 23 glasierte Gefäße. Die meisten davon sind Krüge (13 St.), ${ }^{101}$ sonst gibt es noch 7 Schalen ${ }^{102}$ und 2 Becher/Topfbecher. ${ }^{103}$ Die Gräber mit glasierter, bemalter und geglätteter Keramik ordnete Katalin Ottományi anhand des Gräberfeldes von Budaörs der Führungsschicht bzw. der reicheren Mittelschicht zu. ${ }^{104} \mathrm{Die}$ grauen und tongrundigen Feinwaren sollen gleichfalls dieser Gruppe hinzugefügt werden, die in mehreren Trauben jeweils eine Grabgruppe bilden ( $A b b$. 5). In Grab 5b wurden daneben ein glasierter Krug und ein Becher aus feinem grauem Ton gefunden. In den meisten Fällen - mit Ausnahme von Grab 100 - befanden sich die Bestattungen mit den grauen Feinwaren in der Nachbarschaft der Gräber mit glasierten Gefäßen, die sich in mehreren kleinen Gruppen abzeichnen: Grabgruppe 2-5b-11-17, Grabgruppe 33-35, Grabgruppe 63-67-69, Grabgruppe 79-82, Grabgruppe 110-111 sowie die Grabgruppe 132-145-146-148. Darüber hinaus kamen glasierte Waren auch in Grab 52 vor, in dessen unmittelbarer Nähe sich allerdings kein anderes Grab mit dieser Ausstattung befindet.
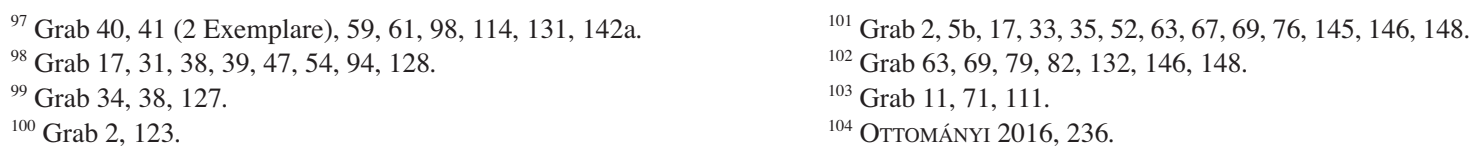
In mehreren Gräbern wurden glasierte Gefäße als zweiteiliges Set aus Krug und Schale den Verstorbenen beigefügt: nämlich in Grab 63, 69 und 146, weiterhin in Grab 148. ${ }^{105}$ Grab 69 belegt eine Julian-Prägung, Grab 63 eine der valentinianischen Dynastie. Glasierte Gefäße sind in allen Grabtypen mit einigen Exemplaren nachzuweisen, die meisten Gefäße stammen aber aus einfachen Erdgräbern (11 Stück). Eine Regelhaftigkeit hinsichtlich der Grabtiefe bzw. des Grabvolumens ist nicht erkennbar. 15 Exemplare der glasierten Ware stammen aus den Ost-WestGräbern, ${ }^{106} 3$ Gegenstände aus West-Ost-Gräbern; ${ }^{107}$ in Gräbern mit Süd-Nord- und Nord-Süd-Ausrichtung fehlen sie aber völlig. ${ }^{108}$ Die meisten Vertreter der glasierten Gefäße kamen aus den Frauengräbern zum Vorschein (insgesamt 9 Gräber). Sie sind in 5 Männer- und in 4 Kindergräbern gleichfalls belegt. Mit Ausnahme des Frauengrabes 67, wo sich ein glasierter Krug neben dem Kopf der Verstorbenen befand, wurde die Deponierung am Fußende des Grabes bevorzugt. Bemaltes Gefäß kam nur in einem einzigen Exemplar im Frauengrab 38 vor. Dieser Krug mit glänzender orangenroter Bemalung lag mit einem Ton- und Glasbecher sowie mit einem Teller zusammen bei den Füßen der Verstorbenen.

Geschirrbeigaben kommen in Kinder-, Frauen- und Männergräbern in ähnlichem Maße vor. ${ }^{109}$ Dieses Verhältnis ändert sich auch dann nicht, wenn nur Tongefäße in Betracht gezogen werden. Das Verhältnis der Gräber, die jeweils nur ein einziges Keramikgefäß beinhalteten, ist bei Kindern und Frauen ähnlich (um $43 \%$ ), bei Männern niedriger (34\%) (Tabelle 2). Die Anzahl der Gräber mit 3 Gefäßen ist im Fall von Frauengräbern etwas höher, als bei Männern. ${ }^{10}$ Die höchste Anzahl der Gefäße - 4 Stück - kommt aber im Männergrab 41 und 79 sowie im Brandgrab 128 vor. ${ }^{111}$ Im Süd-Nord-Grab des männlichen Verstorbenen im maturus-Alter lag ein größerer Topf am Fußende. Ein kleinerer Topfbecher, ein Teller und ein Bodenfragment eines Kruges lagen um den Kopf herum verteilt. ${ }^{112}$ Im Männergrab 79 fanden sich zwei ganze Tonschalen und aus dem Boden des Grabes kamen weitere Gefäßscherben ans Tageslicht. Gefäßbeigaben wurden - von einigen Ausnahmen abgesehen - am Fußende platziert. ${ }^{113}$ Weitere

Tabelle 2

Kombination der Gefäßstückzahlen in den Gräbern mit den Geschlechtern

\begin{tabular}{|c|c|c|c|c|c|c|}
\hline & & \multicolumn{4}{|c|}{ Stückzahl der Gefäße } & \multirow{2}{*}{ Insgesamt } \\
\hline & & $1 \mathrm{St}$. & 2 St. & $3 \mathrm{St}$. & $4 \mathrm{St}$. & \\
\hline \multirow[t]{5}{*}{ Geschlecht } & $?$ & 2 & 1 & 0 & 1 & 4 \\
\hline & Kind & 14 & 4 & 1 & 0 & 19 \\
\hline & weiblich & 22 & 4 & 4 & 0 & 30 \\
\hline & männlich & 11 & 3 & 2 & 2 & 18 \\
\hline & männlich? & 2 & 0 & 0 & 0 & 2 \\
\hline \multicolumn{2}{|l|}{ Insgesamt } & 51 & 12 & 7 & 3 & 73 \\
\hline
\end{tabular}

Beispiele, bei denen die Lage der Gefäße von der allgemeinen Deponierungspraxis abweicht, finden wir in zwei Frauengräbern. In Grab 61 lag auf der linken Seite des Schädels eine Kombination aus Teller und Becher. In Grab 67 fand man einen Krug rechts vom Schädel. Weiterhin im Männergrab 59 fand man ein Topffragment rechts neben dem Kopf. Bei dem Arrangement der Gefäße um den Kopf herum handelt es sich um kein geschlechtsspezifisches Charakteristikum. In zwei weiteren Gräbern platzierte man Gefäße neben dem rechten Ellenbogen. Im Frauengrab 77 legte man einen Becher und im Männergrab 114 ein Topffragment ab. Letzteres belegte man mit

${ }^{105}$ Die ersten zwei sind Kindergräber, die anderen gehören zu einem Männer- und einem Frauengrab.

${ }^{106}$ Grab 2, 5b, 11, 17, 33, 35, 52, 63, 76, 79, 82, 110, 132, $146,148$.

${ }^{107}$ Grab 67, 71, 145.

${ }^{108}$ Unter den Süd-Nord-Gräbern beinhaltete lediglich Grab 41 Gefäße. Neben grauen Gefäßen mit körniger Oberfläche fand sich auch ein handaufgebautes, poliertes Gefäß. Allerdings stammen knapp $90 \%$ aller Gefäße aus Gräbern mit Ost-West-Orientierung.

${ }^{109} \mathrm{Zu}$ ähnlichem Schluss sind Vera Lányi (LÁNYI 1972, 75-76) hinsichtlich des Gesamtbildes von Pannonien bzw. Katalin Ottományi in Verbindung mit dem Material von Budaörs gelangt (siehe dazu OTTOMÁNYi 2016, 235-236).
${ }^{110}$ Hinsichtlich der Anzahl gibt es mehr Frauengräber, ihr Anteil ist jedoch nicht größer.

${ }^{111}$ Die Gräberfelder von Budaörs (OTTOMÁNYI 2016, 235), Tokod (LÁNYI 1981, 188) und Esztergom (KELEMEN 2008, 166-167) zeigen gerade das Gegenteil.

${ }^{112}$ In Budaörs können Gefäßbeigaben am Kopf- und Fußende frühestens ab der Mitte des 4. Jahrhunderts nachgefolgt werden; OTTOMÁNYI 2016, 236.

${ }^{113}$ Ottományi wies in Budaörs auf die Unterschiede zwischen früh- und spätrömischen Gefäßplatzierungssitten hin. Statt ans Kopfende, legte man sie ans Fußende; OтTомÁNYi 2016, 236. 
einer Prägung der konstantinischen Dynastie. Im Grab 141, das auch eine Münze Valentinian I. barg, legte man der Verstorbenen im adultus-Alter den Becher in die rechte Hand. ${ }^{114}$

Ungefähr die Hälfte der Gefäße kam als einziges Gefäß im Grab zum Vorschein (in 51 Fällen). ${ }^{115}$ Darüber hinaus registrierten wir 22 Gräber, die verschiedene Gefäßkombinationen vorführten. In unserem Fall wurden gelegentlich mehrere Teller bzw. Schalen oder mehrere Töpfe, häufig mit anderen Gefäßtypen kombiniert, ins Grab gelegt. In das Frauengrab 43 legte man 2 Teller. Im Frauengrab 71 fand man neben einem unversehrten Teller ein weiteres Tellerwandfragment und ein dreihenkeliger glasierter Topf kam ebenfalls zum Vorschein. Im Männer grab 79 wurden ebenfalls zwei Teller samt glasierter Schale und einem Topfrandfragment gefunden. Aus der Brandbestattung 128 wurden ein Henkelbecher und 3 Fragmente von Tellern mit eingezogenem Rand zutage gefördert. Neben zwei Töpfe wurden in das Männergrab 41 ein Teller und das Bodenfragment eines Kruges gelegt.

Die Zusammensetzung des Geschirrinventars von Somogyszil weicht in funktionaler Hinsicht von den übrigen pannonischen Fundorten ab (s. Tabellen 15-16 im Anhang). Auf dem Gräberfeld übertrifft die Zahl der Teller bzw. Schalen (38\%) ${ }^{116}$ die Menge der Krüge bzw. der Kannen (14\% des Gesamtmaterials) ${ }^{117}$ sogar die Anzahl der Becher/Topfbecher und der Tassen (22\%). ${ }^{118}$ Im Gefäßbestand sind auch die Töpfe in bescheidener Menge vertreten (16\%). Dagegen ist die Beigabe von Krügen in den meisten pannonischen Gräberfeldern am häufigsten zu beobachten. Vera Lányi hat sogar eine steigende Tendenz in ihrem Anteil während des 4. Jahrhunderts beobachtet. ${ }^{119}$ In Somogyszil stehen die meisten Krüge in Verbindung mit Erwachsenen: In Frauengräbern kommen sie öfter vor (5 Männer- und 7 Frauengräber bzw. ein weiteres Stück mit fraglichem Geschlecht). ${ }^{120}$ In unserem Gräberfeld wurden sie in zwei Fällen aus Mädchengräbern der Altersgruppe infans II zutage gefördert. Bei einem handelte es sich um einen engmündigen glasierten Krug (Grab 69), der andere war eine glasierte Kanne mit kleeblattförmiger Mündung (Grab 63). ${ }^{121}$ Beide befanden sich am Fußende der Verstorbenen. Vom Exemplar aus Grab 38 abgesehen, das zu den bemalten tongrundigen Feinwaren gehört, sind alle andere Vertreter glasiert. Polierte und eingeglättete Krüge sind in unserem Fall nicht belegt.

Als charakteristischste Gefäßbeigabenkombination der spätrömischen Gräberfelder Pannoniens können der Krug und der Becher angesehen werden. ${ }^{122}$ Diese Kombination ist in Somogyszil in insgesamt 3 Frauengräbern (Grab 2, 38, 148) und in 2 Männergräbern (Grab 5b, 17 [Kanne]) mit einem Teller oder Schale zusammen belegt. In Grab 63 befanden sich eine glasierte Kanne und eine glasierte Schale, die mit den valentinianischen Prägungen t.p.q. datiert sind. Diese Kombination wurde auch im Männergrab 146 bestätigt. Im Grab 33 wurde das Keramikinventar aus Krug und Teller mit einem Glasbecher, im Kindergrab (Krug, Teller und Schale aus Ton) mit einer Glasschale ergänzt. Die Vergesellschaftung von Tellern/Schalen und Bechern (sowie von Töpfen) ohne Krüge ist ebenfalls in mehreren Fällen bekannt (Grab 39, 40, 41, 42, 128). Alle Gefäßkombinationen von Somogyszil erwiesen sich weder als geschlechts- noch als zeitspezifisch.

Glasgefäße wurden in 24 Gräbern registriert (15,79\% der Bestattungen). ${ }^{123}$ In 8 Gräbern kamen allein Glasgefäße ohne Beigabe von Tongeschirr zum Vorschein; 6 davon waren Becher (Grab 8, 14, 15, 25, 32, 57), 2 waren Schälchen (Grab 97 und 99) (Tabelle 3).

${ }^{114}$ Die in Budaörs gesammelten Erfahrungen belegen ebenfalls, dass die am Becken befindlichen Gefäße nicht früher als auf die Mitte des 4. Jahrhunderts datiert werden können; OTTOMÁNYI 2016, 236.

${ }^{115}$ Wir zählten auch Gefäßfragmente dazu. Hinweise auf Grabraub bemerkte der Ausgräber nur in einem einzigen Fall.

${ }^{116}$ Im Material von Esztergom sind diese niedrigen, steilwandigen Formen gar nicht vorhanden; KELEMEN 2008, 87.

${ }^{117}$ Ihre Anzahl auf dem Gräberfeld von Budaörs ist - von der Form her als Schalen betrachtet - recht niedrig: Gerade mal 12 Stück wurden zutage gefördert. Katalin Ottományi wies darauf hin, dass ihre Menge im ganzen Pannonien allgemein niedrig ist (LÁNYI 1972, 75), mit Ausnahme der Gräberfelder in der Umgebung von Pécs, die auf die erste Hälfte bis zur Mitte des 4. Jahrhunderts datiert werden können; OTTOMÁNYI 2016, 236.

${ }^{118}$ Katalin Ottományi bemerkte während der Bearbeitung von Budaörs nur im Fall von Frauen, dass die Menge der Becher/
Topfbecher die der Krüge übersteigt, sonst sind die Krüge in Budaörs und auf den meisten pannonischen Gräberfeldern weitaus verbreiteter; OTTOMÁNYI 2016, 236. Vera Lányi rechnet hinsichtlich des 4. Jahrhunderts mit einer sinkenden Anzahl; LÁNYI 1972, 75.

${ }^{119}$ LÁNYI 1972, 73-75.

${ }^{120}$ Die gleiche Tendenz kann in Budaörs bei Männern nachgewiesen werden; OTTOMÁNYi 2016, 236.

${ }^{121}$ Im Material der Gräberfelder von Budaörs und Bátaszék wurden solche Krüge/Kannen mit kleeblattförmiger Ausgusstülle grundsätzlich in Männergräbern registriert; OTTOMÁNYI 2016, 236; PÉTERFI 1993, 88.

2016,237-243

${ }^{122}$ LÁNYi 1972, 134; KELEMEN 2008, 166-167; OTTOMÁNYI

${ }^{123}$ Ähnelt dem Verhältnis, was das Gräberfeld von Budaörs charakterisiert (13\%); OTTOMÁNYI 2016, 268.

Acta Archaeologica Academiae Scientiarum Hungaricae 70, 2019 
Tabelle 3

Verteilung der Glasgefäße nach Typen in Kombination mit dem Münzspektrum

\begin{tabular}{|l|l|c|c|c|c|c|c|}
\hline \multicolumn{2}{|c|}{} & $\begin{array}{c}\text { Becher Typ } \\
\mathbf{4 7 a}\end{array}$ & $\begin{array}{c}\text { Becher Typ } \\
\mathbf{4 7 c}\end{array}$ & $\begin{array}{c}\text { Becher Typ } \\
\mathbf{3 5 b}\end{array}$ & $\begin{array}{c}\text { Schale Typ } \\
\mathbf{1 3 a}\end{array}$ & $\begin{array}{c}\text { Schale Typ } \\
\mathbf{1 3 b}\end{array}$ & $\begin{array}{c}\text { Balsamarium } \\
\text { Typ 86/87 }\end{array}$ \\
\hline \multirow{2}{*}{ Münzspektrum } & konstantinisch & 3 & 7 & 1 & 2 & 1 & 1 \\
\cline { 2 - 8 } & valentinianisch & 1 & 3 & 1 & 0 & 0 & 0 \\
\hline Insgesamt & $\mathbf{4}$ & $\mathbf{1 0}$ & $\mathbf{2}$ & $\mathbf{2}$ & $\mathbf{1}$ & $\mathbf{1}$ \\
\hline
\end{tabular}

In Somogyszil kommt je Grab höchstens ein Glasgefäß vor. Die einzige Ausnahme bildet Grab 80, worin sich laut ursprünglicher Dokumentation in der rechten Hand des Verstorbenen ein zusätzlicher Glasbecher in nicht mehr zu bergendem Zustand befand. ${ }^{124}$ Glasgefäße wurden in 5 Kinder-, 11 Frauen- und 9 Männergräbern registriert. In 16 Gräbern kamen Funde sowohl aus Glas als auch aus Keramik zum Vorschein. Mehrmals wurden die Kombinationen von Keramikgefäßen aus Krug, Becher, Teller bzw. Schale mit einem Glasbecher ergänzt (Grab 2, 38). Vereinzelt kam eine Glasschale dazu (Grab 5b). In einigen Gräbern ergänzte man die Gefäßkombination von Krug, Teller und Schale mit einer weiteren Glasschale (Grab 33, 69) bzw. in Grab 52 den glasierten Krug mit einem Glasbecher. In 8 Gräbern befand sich neben dem beigelegten Teller (Schale) ein Glasbecher (Grab 6, 7, 31, 34, 80, 81, $82,86,94)$, in Grab 80 ein Balsamarium.

Die Verstreuung der Gräber mit Glasfunden in Betracht nehmend stellt sich heraus, dass im nördlichen Drittel der Fläche II keine einzige Bestattung über Glasbeigaben verfügte - ebenso wie unter den Gräbern mit WestOst-, Nord-Süd- bzw. Süd-Nord-Orientierung.

Vorherrschende Form der Glasgefäße vom Somogysziler Gräberfeld ist der Becher. ${ }^{125}$ Bei den meisten Exemplaren handelt es sich um höhere Gefäße (Barkóczi 47a=Dévai 2012 P8 ${ }^{126}$; Barkóczi 47c ${ }^{127}=$ Dévai 2012 P9 ${ }^{128}$ ). Darunter ist die Variante mit schmalem Boden verbreiteter. Lediglich ein Viertel der Funde (4 Exemplare) sind gedrungene Becher (Barkóczi 35b = Dévai 2012 P6; ${ }^{129}$ Barkóczi 37b = Dévai 2012 P7 ${ }^{130}$ ). Halbkugelige Schalen (Barkóczi 13a, 13b; Dévai 2012 T1) ${ }^{131}$ gab es ebenfalls 4 Stück. ${ }^{132}$ Des Weiteren wurde aus Grab 80 eine Parfümflasche zutage gefördert (Barkóczi 86/87). Flaschenformen kamen im Material des Friedhofs keine vor, gleichwohl ihre Zahl auf dem gesamten pannonischen Gebiet höher, als die der Schalen ist. ${ }^{133}$

Die hohen, konisch geformten Glasbecher kommen sowohl in Frauengräbern als auch in Männergräbern vor. Der halbkugelige Becher vom Typ Barkóczi 35b und die Schale vom Typ Barkóczi 13b zeigten sich in Frauengräbern, während der Becher vom Typ Barkóczi 37b und der Becher/Schale Barkóczi 13a in Männergräbern vorkam. Letzterer kam auch in einem Kindergrab vor. Das Balsamarium (Typ Barkóczi 86/87) stammt aus einem Frauengrab (Grab 80). ${ }^{134}$

Die halbkugeligen Schalen/Becher (Typ Barkóczi 13a und 13b) und das Balsamarium (Typ Barkóczi 85/86) sind mit konstantinischen Münzen t.p.q. datiert. Die konischen Becher (Typ Barkóczi 47a und 47c) ${ }^{135}$ sowie der Becher mit geschweifter Wandung und Standring (Typ 35b) sind sowohl mit konstantinischen als auch mit valentinianischen Prägungen belegt. Der einzige halbeiförmige, schmucklose Becher des Gräberfeldes (Barkóczi 37b = Dévai 2012 Typ P7) stammt aus einem Männergrab (Grab 86) und wurde nicht mit Münzen belegt. Dem

\footnotetext{
${ }^{124}$ RRMA IV/62/11 (708).

${ }^{125}$ In Bezug auf die spätrömische Periode ist besonders in den Grenzprovinzen auffallend, dass die Menge der Trinkgefäße aus Glas wesentlich ansteigt und die der Tischgefäße (Schalen) sinkt; DÉvaI 2012, 34.

${ }^{126}$ DÉvAI 2012, 161-162.

${ }^{127}$ BARKÓCZI 1988, 82-83.

${ }^{128}$ Bei dieser Form wurde bereits die Frage der multifunk-
} tionalen Verwendung in Erwägung gezogen (Öllampe, Würfelspiel); DÉVAI 2012, 162-168.

${ }^{129}$ BARKÓCZI 1988, 73.

${ }^{130}$ BARKÓCZI 1988, 75-76.

${ }^{131}$ BARKÓCZI 1988, 56-59.

${ }^{132}$ Die Funde von Somogyszil zählte Katalin Dévai anhand des Verhältnisses von Randdurchmesser zur Höhe eher zu den BeActa Archaeologica Academiae Scientiarum Hungaricae 70, 2019 cherformen, mit Ausnahme des Gefäßes aus Grab 97 mit drei geschliffenen Zonen; DÉVAI 2012, 118.

${ }^{133}$ Die bei Katalin Dévai erwähnte Glasflasche ist das Parfümfläschchen aus Grab 80, das der Ausgräber auf der ursprünglichen Grabkarteikarte fälschlicherweise als Flasche vermerkt hat. Gefäße für das Servieren von Getränken registrierte Katalin Dévai in Pannonien in erster Linie in urbanen Siedlungen; DÉvAI 2012, 39, 117.

${ }^{134}$ Vera Lányi bemerkte, dass lediglich $60 \%$ der Parfümfläschchen Frauengräbern zugeschrieben werden können. Sie kamen in zahlreichen Fällen auch aus Männergräbern zum Vorschein; LÁNYI $1972,78$.

${ }^{135}$ László Barkóczi datiert diese Becher auf die Zeit zwischen dem zweiten Drittel des 4. Jahrhunderts und dem Beginn des 5. Jahrhunderts. Ihre Anzahl geht erst nach den 380er Jahren, mit dem Erscheinen des halbeiförmigen Bechers, zurück; BARKóCZI 1988, 80. 
allgemeinen Forschungsstand zufolge verbreitete sich diese Form und drängte die übrigen Becherformen ab den 380er Jahren zurück. ${ }^{136}$

Die Mehrheit der Glasgefäße aus dem Gräberfeld von Somogyszil wurde am Fußende der Grabgrube deponiert. In Körpermittenhöhe kamen ausschließlich Becher vor (Grab 9, 81, 82) ${ }^{137}$ In den Gräbern 80 und 99 befand sich jeweils ein Becher in der rechten Hand. Da die Münzen in diesen Gräbern unmittelbar neben den Bechern zum Vorschein kamen, kann davon ausgegangen werden, dass sie in die Gefäße gelegt worden waren.

$80 \%$ der Glasgefäße stammen aus einfachen Erdgräbern bzw. in einem Fall wahrscheinlich aus einer Sargbestattung. 3 Gefäße können mit Erdgräbern in Verbindung gebracht werden, die mit Ziegeln abgedeckt waren. Da Glasprodukte teuer waren, konnte sich nur die wohlhabendere Schicht Glasgefäße leisten. ${ }^{138}$ Die Gräber mit Glasbeigabe können nicht von den anderen Bestattungen durch ihre Grabtypen getrennt werden. ${ }^{139}$ Dass Gräber mit Glasgefäßen auch reich an weiteren Beigaben gewesen wären, kann man nicht eindeutig behaupten, jedoch gibt es unter ihnen besonders viele mit Münzbeigaben. In den meisten Gräbern kommen sie mit Trachtgegenständen und Schmuck zusammen vor. Von 24 Gräbern kamen in 20 Münzfunde zum Vorschein. Der Großteil davon wird der konstantinischen Dynastie zugeordnet (in 15 Fällen), ${ }^{140}$ bei 5 weiteren Münzen handelt es sich um Prägungen der valentinianischen Dynastie (Grab 2, 52, 81, 82, 94).

Im Frauengrab 43 wurden eiserne Reifenbruchstücke mit Holzfaserspuren gefunden. Die $1 \mathrm{~cm}$ breiten Eisenbandüberreste lagen mit zwei Tellern an rechten Füßen der Verstorbenen. Solche Eisenbandfragmente sind von einigen pannonischen Fundorten - besonders aus den südosttransdanubischen Gräberfeldern (Zengővárkony, Márok und Bátaszék) - bekannt. Unsere Stücke stimmen in ihrer Breite mit den von Márta Kelemen aus dem Material des Friedhofs von Esztergom veröffentlichten Exemplaren überein (Grab 27, 149, 168). ${ }^{141}$ Die Autorin definierte diese als Eisenbandfassung von Holzbechern mit einem Durchmesser von $10-12 \mathrm{~cm},{ }^{142}$ deren Vorbilder sie unter den zeitgenössischen Lavezbechern sucht. ${ }^{143}$ Andere Hinweise auf Holzgefäße sind in Somogyszil nicht bekannt geworden.

Verkohlte Samenfunde kamen in zwei Gräbern vor (Grab 54 und 141). Bei den Samen, die neben dem Schädel in Grab 141 gelegt wurden, handelt es sich um Kräuterpflanzen gegen rheumatische und Atemwegserkrankungen. ${ }^{144}$ Die verkohlten Samen unter dem Schädel in Grab 54 konnten nicht genau bestimmt werden.

Auf dem Gräberfeld von Somogyszil befinden sich ausgesprochen viele Gräber (Grab 26, 34, 43, 44, 79, 80 , 84, 124, 134 und 143), ${ }^{145}$ die jeweils ein tierisches Körperteil ${ }^{146}$ als Opfergabe oder als Totenmahl (Fleischbeigabe) für den Verstorbenen beinhalteten. ${ }^{147}$ Während der Bearbeitung des Fundguts wurden die Tierknochen nicht bestimmt. ${ }^{148}$ In einem Fall, beim Männergrab 124, wurden die Tiergebeine - eines war ein Wildschweinhauer - aus der Graberde zutage gefördert, was eher auf ein symbolisches Tieropfer schließen lässt. ${ }^{149}$ In den übrigen Fällen wurden die tierischen Überreste in erster Linie als Totenmahl in Grab gelagert. In lediglich zwei Gräbern liegen uns Angaben vor, wonach die Fleischbeigabe in ein Gefäß hingelegt wurde. Im Männergrab 79 der Altersgruppe maturus befanden sich die Knochen in einem Teller, auf dem der Ausgräber Rückstände von Asche fand. ${ }^{150} \mathrm{Im}$ bereits erwähnten Frauengrab $43 \mathrm{im}$ maturus-Alter fand man am rechten Fuß Holzgefäßüberreste mit Tierknochen als Inhalt. In den übrigen Gräbern kamen Tierknochen ohne Geschirr, ${ }^{151}$ in mehreren Fällen neben den Füßen und um die Unterschen-

${ }^{136}$ Laut der Revision des Exemplars aus Somogyszil gehört es zu den grünen Glaswaren, was auf die Periode ab Mitte des 4. Jahrhunderts schließen lässt; DÉVAI 2012, 150. Auf dem Gräberfeld von Budaörs kam auch nur ein einziges Exemplar zum Vorschein (Grab 446, weiblich). Anhand der Qualitätsmerkmalen kann es der Jahrhundertwende des 4. und 5. Jahrhunderts zugeschrieben werden; BoRUZs 2016, 376, mit weiterer Literatur.

${ }^{137}$ Dieses Phänomen passt in die Reihe der übrigen Charakteristika, die auf den Gräberfeldern Pannoniens notiert wurden; DÉVAI 2012, 221.

${ }^{138}$ DÉVAI 2012, 222, mit weiterer Literatur.

${ }^{139} 63 \%$ der Gräber mit Glasbeigaben von Budaörs waren irgendwie gebaut; OTTOMÁNYI 2016, 268.

${ }^{140}$ Grab 6, 7, 9, 14, 15, 25, 31-34, 38, 69, 80, 97, 99.

${ }^{141}$ KeLEMEN 2008, 147-148.

${ }^{142}$ Kelemen 2008, 148; siehe dazu Keller 1971, 131-132.

${ }^{143}$ KeLEMEN 2008, 148; zur Provenienzfrage weiterhin HORVÁTH et al. 2018, 55.
${ }^{144}$ Anhand der Samenfunde wurde der Zeitpunkt der Bestattungszeremonie auf die Sommermonate gelegt; BURGER 1979, 14, Anm. 30; zur Beschreibung der Samenfunde siehe HARTYÁNINOVÁKI 1975, 34

${ }^{145}$ Auf dem Gräberfeld des Vicus von Budaörs wurde lediglich ein spätrömisches Grab dieser Art gefunden; OTTOMÁNYI 2016, 259.

${ }^{146}$ Das Material der Tierknochen blieb unbestimmt, wir müssen uns auf die Beobachtungen des Ausgräbers verlassen.

${ }^{147}$ Unter den spätrömischen Gräberfeldern Pannoniens gibt es einige Beispiele für die Beigabe von verarbeiteten Tieren als Speise in Gefäßen bzw. ohne Gefäße.

${ }^{148}$ Die Verfasserin deutet auf den schlechten Erhaltungsstand der Tierknochen hin und ein Großteil wurde vernichtet; BURGER 1979, Anm. 31.

${ }^{149}$ RRMA IV/62/11 (708).

${ }^{150}$ RRMA IV/62/11 (708); BURGER 1979, 42.

${ }^{151}$ Es besteht die Frage, ob wir mit Holzgefäßen rechnen können. Der Ausgräber vermerkte keinerlei Spuren diesbezüglich. 
kel herum zum Vorschein (Grab 34: am rechten Fuß über einer Kombination aus Becher, Schale und Eisenmesser; Grab 80: zwischen den Unterschenkeln über einer Schale und weiteren Gefäßfragmenten; Grab 84: neben dem rechten Fuß, unter einem Becher; Grab 134: auf dem linken Unterschenkel). Davon abweichende Positionen konnten im Frauengrab 26, unter den Knien, im Frauengrab 44 neben dem linken Ellenbogen und im Kindergrab 134 eines Verstorbenen der Altersgruppe infans II unter dem Kiefer nachgefolgt werden. Anhand der Beobachtungen des Ausgräbers wurden Geflügelknochen in folgenden Gräbern gefunden: Grab 34 (infans II, Mädchen), 134 (infans II, ?), 143 (adultus, Frau).

Auf dem Gräberfeld von Somogyszil kamen tierische Überreste sowohl in Männer- als auch in Frauengräbern bzw. in Gräbern von Kindern der Altersgruppe infans II vor, deren Münzbeigaben die gesamte Epoche abdecken (konstantinische Prägungen: Grab 34, 44, 134; valentinianische Prägungen: Grab: 26, 84, 124).

\section{GERÄTE UND WERKZEUGE}

Es gibt eine beträchtliche Anzahl von Gegenständen in Somogyszil, die sich auf den Prozess der Textilherstellung beziehen und folglich als von Frauen verwendete Geräte betrachtet werden. Unter diesen Funden treten die von Alice Sz. Burger als „spießförmige Eisengegenstände“ definierten Objekte besonders häufig auf. Auf dem Gräberfeld wurden in insgesamt 25 Gräbern solche Eisenobjekte registriert, deren Funktion in der Fachliteratur viel erörtert wurde. Anstatt der früheren Interpretation als „Fleischspieß“152 wird ihre Definition anhand der Arbeit von Károly Sági, ${ }^{153}$ Judit Pásztókai-Szeőke ${ }^{154}$ und Róbert Müller ${ }^{155}$ als ein Spinnwerkzeug (sog. Spinnrocken) ${ }^{156}$ heutzutage bereits allgemein anerkannt. Dabei handelt es sich um eiserne, kompakte, stabförmige Objekte, die zu einem Ende hin schmaler werden. Ihre Länge liegt bei $17-30,5 \mathrm{~cm}$, ihr Durchmesser bei $0,5-1,4 \mathrm{~cm} .{ }^{157}$

Róbert Müller registrierte in seiner Sammlung im Jahr 201131 spätrömische pannonische Fundorte, wo Spinnrocken - meist nur ein-zwei Exemplare - zum Vorschein kamen. ${ }^{158}$ Die Eisenstäbe kennen wir fast ausschließlich aus Gräberfeldern - mit Ausnahme der Eisengerätfunde aus Tatabánya, die János László aus einer römischen Villenwirtschaft veröffentlichte. Dieses Fundgut umfasste weitere Webewerkzeuge (Hechel und Webkamm), die die Funktion der Eisenstäbe im Themenbereich Weben und Flechten weiter bekräftigen. ${ }^{159}$ Die Fundorte der behandelten Objekte liegen südlich der Linie Donauknie und Balaton-Hochland, mit zwei bedeutenderen Zentren (BalatonHochland und Südosttransdanubien). ${ }^{160}$

Das Material aus Somogyszil ist in zweierlei Hinsicht besonders bemerkenswert. Einerseits wegen der hohen Anzahl an Spinnrocken, ${ }^{161}$ andererseits, weil diese nicht nur in Frauengräbern, ${ }^{162}$ sondern auch in Männergräbern zum Vorschein kamen. Laut der von Alice Sz. Burger veröffentlichten Geschlechtsbestimmung wurde in Grab 130 ein Mann der Altersgruppe adultus beigesetzt, auf dessen rechter Schulter eine Fibel vom Typ KellerPröttel 3/4B lag. Während der Überprüfung des anthropologischen Materials wurden noch zwei weitere Gräber dazugerechnet (Grab 15, ${ }^{163}$ Grab $94^{164}$ - beide im adultus-Alter). Im Vorigen wurde neben weiteren Beigaben eine Zwiebelknopffibel, im Letzteren eine ovale Eisenschnalle gefunden.

Spinnrocken mit Frauengräbern in Verbindung zu bringen betont die Symbolik der in die Gräber gelegten Gegenstände. In diesem Fall handelt es sich einerseits um ein Zeichen der Macht über das menschliche Schicksal - man denke nur an die den Lebensfaden spinnenden Parzen. Andererseits spielten sie hinsichtlich weiblicher Fruchtbarkeit, Gebärfähigkeit, Fleiß etc. eine ebenso wichtige Rolle. ${ }^{165}$ Als Gegenargument zur apotropäischen

${ }^{152}$ Dombay 1957, 289; VÁGÓ-BÓNA 1976, 182.
${ }^{153}$ SÁGI 1973, 293; SÁGI 1981, 103.
${ }^{154}$ PÁszTóKAI-SZEÖKe 2012b.
${ }^{155}$ Zuletzt MÜlLER 2011, 194, Fundliste 1; MÜLLER 2017.
${ }^{156}$ Judit Pásztókai-Szeöke ging bei dem Eisenstab zuletzt davon aus, dass es sich um einen radius handelt, der dem Anheben des Kettfadens dient (PÁsZTóKAI-SZEÖKE 2012b, 18-20), was Róbert Müller in seiner Studie (MÜLLER 2017) anzweifelt.

${ }^{157}$ Hohle oder tüllenartige Versionen betrachtet Róbert Müller als Gürtelrocken. Solche sind uns aus Grab 111 in KeszthelyDobogó bekannt, wo sie mit einem Gatterkamm und einem Spinnwirtel aus Knochen zusammen ins Grab gelegt wurden; SÁGI 1981, 103,
Abb. 57. Siehe dazu PÁsZTóKAI-SZeŐKE 2013, 262, Abb. 10; MÜLLER 2017, 147-148.

${ }^{158}$ MÜLLER 2011.

${ }^{159}$ LÁSZLÓ 2011, 153, Taf. 4. 4-8.

${ }^{160}$ MÜLler 2009, Karte 1; PÁSZTÓKAI-SZEŐKE 2012b, fig. 11.

${ }^{161}$ Uns sind 12 Exemplare aus dem Gräberfeld von Keszthely-Dobogó (SÁGI 1981) und 18 aus dem von BátaszékKövesdpuszta bekannt (PÉTERFI 1993).

${ }^{162}$ In der Forschung ist allgemein anerkannt, dass sie ausschließlich in Frauengräbern vorkamen; siehe dazu MÜLLER 2014, 67.

${ }^{163}$ In der Publikation wurde es als Kind bestimmt.

${ }^{164}$ Früher wurde als Frau im adultus-Alter bestimmt.

${ }^{165}$ Bíró 2011, 69-73; PÁSZTóKAI-SZEÖKe 2012a, 17-19. 
Rolle der spitzen Eisengegenstände trägt Róbert Müller gerade die Tatsache vor, dass er aus Männergräbern fehlt, und bezieht somit Stellung für ihre Rolle als Nutzgegenstand. ${ }^{166}$

In der Veröffentlichung des Gräberfeldmaterials von Brigantium in Rätien kommt bei der Erklärung des Vorkommens der Spinngeräte im Grab ein anderer Aspekt auch zu. Michaela Konrad wies darauf hin, dass die Spindeln und Kämme sowohl als bildliche Darstellung auf Grabsteinen als auch als Grabbeigaben im östlichen Mittelmeerraum bereits im 2. Jahrhundert n. Chr. registriert werden konnten. ${ }^{167}$ Auf den bithynischen Grabsteinen der mittleren Kaiserzeit handelt es sich nicht um ein geschlechtsspezifisches Attribut, sondern wurden von Christen ebenfalls als Symbole des Schicksals und der Ewigkeit übernommen. ${ }^{168}$ Im westlichen Teil des Imperiums sind auch einige Beispiele bekannt, die auf die religionsbedingten, ostmediterrane Traditionen widerspiegelnden Zusammenhänge (christliches Symbolgehalt) hinweisen. ${ }^{169}$

In Somogyszil stammen die meisten Exemplare aus Gräbern von Erwachsenen im adultus-Alter und jeweils drei aus infans II- und iuvenis-Gräbern. Drei weitere können den Frauen im maturus- bzw. zwei im senilisAlter zugeschrieben werden. Auf jeden Fall dürfen die Gegenstände in diesem Gräberfeld nicht als symbolisches Zeichen für volljährige Frauen betrachtet werden. Infolgedessen müssen mehrere Möglichkeiten bei den Interpretationen des Phänomens berücksichtigt werden, die noch weitere Untersuchungen erfordern. 17 Exemplare des Materials aus Somogyszil stammen aus münzdatierten Gräbern: Darunter gehören 12 der konstantinischen und 5 der valentinianischen Dynastie an. Ein Indiz dafür, dass es sich um eine Sitte handelt, die die gesamte Periode begleitete. Die Eisenstäbe wurden fast ausnahmslos gekreuzt auf die Unterschenkel gelegt, nur selten parallel dazu (Grab 40, 46, 94 und 130). In einem Fall befand sich einer über den Knien (Grab 43).

Nähnadeln aus Eisen gelten als seltene Grabfunde. Im Material von Somogyszil gab es insgesamt zwei, die aus Frauengräbern stammten: eine in Grab 97, am rechten Knöchel und die andere in Grab 141, neben dem rechten Unterschenkel. Letztere wurde zusammen mit einem eisernen Spinnrocken, der auf die Schenkel gelegt wurde, zutage gefördert. ${ }^{170}$

Ein weiteres Textilwerkzeug wurde aus Grab 67 neben einer Frau der Altersgruppe adultus geborgen. Der so genannte Gatterkamm (Weberkamm) ${ }^{171}$ aus Eisen, noch mit Textilfasern auf der Oberfläche, lag an den Füßen der Verstorbenen. Trotz der erheblichen Anzahl der Spinnrocken gab in diesem Grab kein einziges Stück. ${ }^{172}$ Die pannonischen Exemplare wurden von Judit Pásztókai-Szeőke mit 5 Stücken aus Grabzusammenhängen beurteilt. ${ }^{173}$ Das behandelte Grab ist hinsichtlich weiterer Beigaben nicht herausragend. ${ }^{174}$ Was sein Volumen anbelangt, handelt es sich dabei jedoch um das größte Grab des Gräberfeldes, mit über $6 \mathrm{~m}^{3}$.

Auf dem Gräberfeld wurden insgesamt nur 3 Spinnwirtel in die Gräber gelegt. In Grab 17 lag er neben dem rechten Unterschenkel, in Grab 63 am rechten Fuß und in Grab 96 am rechten Knie. Sie kamen nie in einem Grab mit Spinnrocken zusammen vor. Spinnwirtel als Beigabe ins Grab zu legen gehört auch zu den Phänomenen, die im provinziellen Umfeld der Zeit nicht allzu verbreitet waren. ${ }^{175}$ Dabei handelt es sich viel eher um eine unter Germanen und Sarmaten bekannte Sitte, ${ }^{176}$ die sich während des letzten Abschnitts des 4. Jahrhunderts weiter verbreitet und öfter mit anderem, barbarisch anmutendem Fundgut erscheint. ${ }^{177}$ In den drei besagten Gräbern haben wir

\footnotetext{
${ }^{166}$ MÜLLER 2009, 44-45.

${ }^{167}$ KONRAD 1997, 164-165.

${ }^{168}$ KONRAD 1997, 164, mit weiterer Literatur.

${ }^{169}$ KonRad 1997, 94, 165.

${ }^{170}$ In Esztergom wurde eine Nähnadel in Grab 227 registriert; KELEMEN 2008, 116

${ }^{171}$ Im archäologischen Kontext wurde dieses Gerät zuerst von Károly Sági identifiziert; SÁGI 1973, 293-294; SÁGI 1981, 75-76.

${ }^{172}$ Mit Ausnahme des Grabes von Somogyszil wurde der Gatterkamm in den übrigen Fällen samt Spinnrocken in die Gräber gelegt: Bátaszék-Kövesdpuszta Grab 56, 102; Keszthely-Dobogó Grab 111; Tác-Margittelep Grab 216; PÁsZTÓKAI-SzEŐKE 2012b, 15 $16,18$. 2012b, 15-16.

${ }^{173}$ Das sind $10 \%$ der Exemplare; PÁszTÓKAI-SzEŐKE

${ }^{174}$ Der ins Grab gelegte glasierte Krug lässt auf den relativen Wohlstand des Verstorbenen und seiner Familie schließen.
}

${ }^{175}$ Für die pannonischen Daten siehe MüLLER 2009, 45 46. Auch auf dem Vicus-Gräberfeld von Budaörs wurden lediglich zwei spätrömische Exemplare registriert; Оттоми́NYI 2016, 209. Gleichzeitig sind aus dem Material von Solva 18 Gräber bekannt, was Márta Kelemen damit erklärt, dass diese Gräber mit Spinnwirteln mit der zweiten Hälfte des 4. und Anfang des 5. Jahrhunderts verbunden werden können, als schon mit einer wesentlichen barbarischen Präsenz zu rechnen ist; KELEMEN 2008, 144.

${ }^{176}$ KeLler 1971, 113-114; KulcsÁr 1998, 57. Róbert Müller kommt zu dem Schluss, dass die Beigabe von Spinnrocken und Spinnwirteln teils unterschiedlichen Glaubensvorstellungen zuzuschreiben ist; MÜLLER 2009, 46

${ }^{177}$ Márta Kelemen weist darauf hin, dass doppelkonische Spinnwirtel in erster Linie dort vorkommen, wo die Forschung barbarische Präsenz vermutet. Dabei erwähnt sie auch das Material von Somogyszil; KelEMEN 2008, 144, Anm. 690; OTTOMÁNYI 2016, 209, Anm. 839.

Acta Archaeologica Academiae Scientiarum Hungaricae 70, 2019 
keine weiteren barbarischen Phänomene beobachtet. In Grab 17 ruhte ein Mann im adultus-Alter, ${ }^{178}$ in Grab 63 ein Mädchen im Alter infans II, in Grab 96 ein Mädchen im Alter infans II - alle drei von Ost nach West ausgerichtet. Ein Münzfund kam nur in Grab 63 zum Vorschein (valentinianisch), das mit seiner Tiefe von $215 \mathrm{~cm}$ das tiefste des Gräberfeldes ist.

Eisenscheren kommen als Beigaben in den nicht allzu reich ausgestatteten Männergräbern 117 und 124 vor. In Grab wurde die Schere mit anderen Eisengegenständen wie Messer und eine eiserne Pinzette zu den Füßen des Verstorbenen ins Grab gelegt. In Männergräbern sind sie meist als Toilettengeräte zur Haar- und Bartpflege interpretiert. Beide Exemplare von Somogyszil gehören aber nach ihrer Größe zu den größeren Kategorien (beide sind länger als $15 \mathrm{~cm}$ ), bei denen eine handwerkliche oder landwirtschaftliche Nutzung nicht auszuschließen ist. ${ }^{179}$

Bereits Alice Sz. Burger wies darauf hin, dass die Eisenmesser als tägliche Gebrauchsgegenstände in beachtenswerter Zahl belegt sind (55 St.). ${ }^{180}$ Sie teilen sich unter den Kinder- (17 St.), Frauen- (17 St.) und Männergräbern (19 St.) fast gleichmäßig auf. Die vorhandenen Stücke sind mehreren Varianten zuzuordnen: mit einer oder mit zwei Schneiden, in schmaler oder lorbeerblattförmiger Ausführung. Die Messer mit schlaufenförmigem Ende sind durch 2 Exemplare vertreten. Eine Hälfte des Typs von einschneidigen Messern mit schmaler Klinge gehört zu den Kinderbestattungen. ${ }^{181}$ In den Gräbern mit Spinnrocken sind Messer in 9 Frauen- (Grab 1, 8, 25, 26, 31, 35, 52, 80, 148), in 3 Kinder- (Grab 34, 69, 102) und in 2 Männergräbern (Grab 46?, 130) belegt. Die Messer wie die Eisenstäbe wurden meist quer über den Beinen ins Grab gelegt oder treten mindestens bei den Füßen der Bestattung ${ }^{182}$ mit Gefäßbeigaben zusammen ${ }^{183}$ vor. Im Frauengrab 8 wurden das Messer am Beckenknochen und der Spinnrocken zwischen den Unterschenkeln vorgefunden. In drei weiteren Kindergräbern (Grab 6, 90, 99) wurde das Messer am Beckenknochen entdeckt, was in diesen Fällen wohl am Gürtel getragen wurde (Tabelle 4).

Tabelle 4

Fundlage der Gürtelgarnituren im Grab und ihre Vergesellschaftung mit Fibeln und Münzen

\begin{tabular}{|c|c|c|c|c|}
\hline Grabnummer & Geschlecht & Fundlage & Fibel & Münzspektrum \\
\hline 110 & Kind & \multirow[t]{3}{*}{ rechts parallel dem ganzen Körper } & - & \multirow[t]{2}{*}{ konstantinisch } \\
\hline 114 & \multirow[t]{6}{*}{ männlich } & & Zwiebelknopffibel & \\
\hline 144 & & & - & - \\
\hline 112 & & \multirow[t]{2}{*}{ parallel dem rechten Bein } & Zwiebelknopffibel & \multirow[t]{2}{*}{ konstantinisch } \\
\hline $\begin{array}{l}122 \\
\text { (ohne Schnalle) }\end{array}$ & & & Bügelknopffibel & \\
\hline 72 & & quer über dem linken Bein & - & - \\
\hline 84 & & quer über dem rechten Bein & Zwiebelknopffibel & konstantinisch-valentinianisch \\
\hline 140 & & quer über den Beinen & Bügelknopffibel & konstantinisch \\
\hline 86 & & beim rechten Fuß gefaltet & - & - \\
\hline
\end{tabular}

In drei Männergräbern (Grab 46, 81 [Oberschenkel], 114) sowie in zwei Kindergräbern (Grab 107, 110: infans II) kamen Gürtelgarnituren mit Messer und Schnallen parallel auf der rechten Seite des Verstorbenen oder quer über dem Oberkörper (Grab 46) gelegt vor. Zwei davon sind mit konstantinischen Münzen, ein mit der Prägung Gratian datiert. Ins Grab 39 wurde ein Gürtel mit Eisenmesser (Feuerschlagmesser) und 16 Feuersteinen ${ }^{184}$ voraussichtlich in einem Beutel auf die linke Seite des männlichen Unterkörpers niedergelegt. Im Männergrab 112 mit

${ }^{178}$ In der Publikation als Frau im maturus-Alter erwähnt, nach der anthropologischen Überprüfung aufgrund des guten Erhaltungsstandes des Skeletts und dessen stark maskuliner Züge jedoch geändert; BURGER 1979, 24.

${ }^{179}$ Weitere Exemplare sind aus spätrömischen Gräberfeldern von Esztergom-Bánomi-dülő, Majs, Intercisa und Csoma bekannt; siehe dazu RUPNIK 2016, 548, mit weiterführender Literatur.

${ }^{180}$ Demgegenüber im Gräberfeldmaterial von Solva wurden allein 5 Stücke registriert, von denen 4 aus Männergräbern stammen; Kelemen 2008, 110, 145.

${ }^{181} \mathrm{Vgl}$. BuRger 1979, 13.
1972,103

${ }^{182}$ Siehe dazu weitere pannonische Beispiele bei LÁNYI

${ }^{183}$ Die Fruchtreste, Messer und Tongefäße bildeten nach dem heidnischen Glauben den letzten Mundvorrat; SÁGI 1973, 295. Die Sitte, wonach das Messer quer über einer Schüssel ins Grab hingelegt ist, verbindet Vera Lányi mit dem Gräberfeld Zengővárkony II; LÁNYI 1972, 110.

${ }^{184}$ In Valeria und Pannonia Prima sind Beispiele für Feuersteine aus spätrömischen Gräbern in verhältnismäßig großer Zahl bekannt: Bogád, Csákvár, Majs, Somodorpuszta, Intercisa, Keszthely-Dobogó, Keszthely-Vásártér und Esztergom; KELEMEN 2008, 108, mit betreffender Literatur. 
konstantinischen Münzen fand man an der Außenseite des rechten Fußknöchels ein Feuerstahl mit Feuerstein und Eisenahle, die dem Inhalt einer auf einen Gürtel befestigten Tasche angehören könnten. Diese Gürtelgarnitur mit Feuerzeug an den Füßen und einer fragmentarisch erhaltenen Riemenplatte in der Beckengegend lag ebenfalls auf der rechten Seite des Verstorbenen. Ein weiterer Hinweis auf eine Gürtelgarnitur mit dem Feuerzeug stammt aus Grab 114 (in einer Grabgruppe mit Grab 112), in dem sich eine nierenförmige Bronzeschnalle auf der rechten Seite des Schädels und das Feuerzeug aus eiserner Ahle, Messer und Feuerstein neben dem rechten Unterschenkel befanden. Der Grabkontext der Gräber 39 und 114 wurde - wie das Grab 112 - mit Münzen der konstantinischen Dynastie (Constantius II.) datiert. Außer den Gürtelgarnituren mit Feuerzeug tragen alle drei Männer Zwiebelknopffibeln (Grab 112, 114: Keller-Pröttel 3/4B; Grab 39: Keller-Pröttel 3/4D), was auf ihre zivile oder militärische Amtstätigkeit hinweist.

Der Löffelbohrer aus Grab 84 kam quer über dem rechten Bein mit einer eisernen Ahle vergesellschaftet vor. Es ist zu vermuten, dass beide am Gürtel befestigt waren. ${ }^{185}$ Das Grabinventar ist mit valentinianischen Münzen t.p.q. datiert.

In Somogyszil kamen insgesamt 13 von Alice Sz. Burger als Eisenahlen definierte Gegenstände vor. Sie sind in 3 Fällen zum Inventar der Kinder-, in einem einzigen Fall der Frauen- und in 8 weiteren Fällen der Männerbestattungen zuzuordnen. Aus drei Gräbern ist die Variante mit Ringöse bekannt (Grab 86, 112, 140). Aus funktionaler Sicht sind mit mehreren Anwendungsmöglichkeiten im handwerklichen Bereich zu rechnen. ${ }^{186}$ In Somogyszil dürften die meisten Exemplare anhand der Fundsituation im Grab der Taschengarnitur am Gürtel zugezählt werden.

Aus dieser Zusammenstellung stellt es sich heraus, dass die männlichen Verstorbenen meist nicht in gegürtelter Tracht zur Ruhe gelegt wurden. ${ }^{187}$ Die Gürtel mit statusanzeigender Bedeutung kamen meist separat, parallel oder quer über dem Körper gelegt sowie gefaltet vor.

Ebenfalls zu dieser Fundkategorie sind die Schleifsteine zu rechnen. In unserem Material ist er nur durch ein Exemplar mit Eisenabdrücken auf seiner Unterseite vertreten. Es stammt aus dem Frauengrab 44 mit einer germanischen Stützarmfibel. ${ }^{188}$ Der Grabkontext ist durch konstantinische Prägungen t.p.q. datiert. Einige Beispiele für Schleifsteine sind aus mehreren spätrömischen Gräberfeldern Pannoniens, ${ }^{189}$ in zwei Fällen mit konstantinischen Münzen, bekannt: in Budaörs (Grab 166), wo es dem Zubehör eines männlichen Gürtels gehörte, ${ }^{190}$ und in Grab 24 sowie 112 von Keszthely-Dobogó. ${ }^{191}$

Die ethnische Interpretation der Feuerzeuge stellt ein viel diskutiertes Thema dar. Auf jeden Fall sind diese Gegenstände $\mathrm{ab}$ dem 5. Jahrhundert in größerer Zahl in den Gräbern zu finden. In den römischen Fundkontexten ist die Kombination aus Messer und Eisenahle oft zu registrieren. Sie waren in Budaörs in allen bekannten Fällen mit Zwiebelknopffibel vergesellschaftet, was nach der Meinung von Katalin Ottományi eher auf einen Kreis der Beamten und keineswegs auf barbarische Tracht verweist. ${ }^{192}$ Márta Kelemen vertritt eher die Meinung, dass es sich um keine westgermanische Sitte handelt. Es könnte eher mit den östlichen Volkselementen ohne nähere ethnische Zuordnung in Zusammenhang gebracht werden. ${ }^{193}$ Diese Elemente, die eine nichtrömische Sachkultur demonstrieren, erscheinen als Trachtbestandteile der sozialen Elite. Sie bestätigen die Ansicht, dass man unter ihnen mit zahlreichen Vertretern von barbarischer Abstammung rechnen sollte.

Diesen letztgenannten Eisengegenständen kommt eine Bedeutung als alltägliche Gebrauchsgegenstände zu. Andererseits fungierten sie bereits als Trachtelemente, die wohl an oder in einer am Gürtel befestigten Tasche getragen wurden.

${ }^{185}$ Da es sich um ein alltägliches Zimmereiwerkzeug handelt, sind die meisten Exemplare aus den Werkstätten des Militärs und der Villenwirtschaften bekannt. Ihre Funktion wurde anhand der Stücke aus dem Vicus von Budaörs ausführlich behandelt; RUPNIK 2012, 556-557.

${ }^{186}$ Weitere Belege als spätrömische Grabfunde kamen in Budaörs, Esztergom, Gödrekeresztúr, Keszthely-Dobogó und Zengővárkony vor; siehe dazu RUPNIK 2016, 548-549, mit weiterer Literatur.

${ }^{187}$ SÁGi 1960, 236; KELEMEN 2008, 109, mit mehreren Belegen aus Esztergom.
${ }^{188}$ Da dieses Stück am rechten Fuß zum Vorschein kam, könnte es nicht unbedingt in einem Beutel ins Grab gelegt werden.

${ }^{189}$ Intercisa (VÁGÓ-BÓNA 1976, 204-205, mit weiterer Literatur, Grab 1294, 1333; 27/1949 und 14/1952), Adony (BARKócZIBóNIS 1954, 179, Grab 6 mit Zwiebelknopffibel), Keszthely-Dobogó (SÁGi 1981, Grab 4 mit Zwiebelknopffibel, 24, 52, 112), BudapestGazdagrét (ZsidI 1997, Grab 29).

${ }^{190}$ OTTOMÁNYi 2016, 53, 219.

${ }^{191}$ SÁGI 1981, 16, 77.

192 OtTOMÁNYi 2016, 219.

${ }^{193}$ KeLEMEN 2008, 106.

Acta Archaeologica Academiae Scientiarum Hungaricae 70, 2019 


\section{TRACHT- UND SCHMUCKGEGENSTÄNDE}

\section{Fibeln}

Im Fibelbestand des Gräberfeldes sind zwei Gruppen abzusondern. Die allgemein verbreiteten provinzialrömischen Typen vertreten die Zwiebelknopf-, Ring- und die Scheibenfibel (insgesamt 25 Exemplare). Unter den so genannten ,fremden“ Fibeln kommen Bügelknopf- und Stützarmfibeln sowie Fibeln mit umgeschlagenem Fuß vor (5 Exemplare in 4 Gräbern) (Abb. 6).

\section{Zwiebelknopffibeln}

Im Fundstoff des Gräberfeldes machen die Zwiebelknopffibeln den größten Anteil unter den Fibeln aus. Bei 152 Bestattungen kamen insgesamt 17 Stücke zutage: Es handelt sich um etwas mehr als $10 \%$ aller Bestattungen. ${ }^{194}$ Im behandelten Material sind die Zwiebelknopffibeln in vier Typen vorhanden, ${ }^{195}$ unter denen der Typ Keller-Pröttel 3/4B den pannonischen Tendenzen entsprechend am häufigsten vorkommt (Tabelle 5). ${ }^{196}$

Tabelle 5

Verteilung der Zwiebelknopffibeln nach den Typen und ihre Datierung

\begin{tabular}{|l|l|l|}
\hline Typ* & Grabnummer & Datierung nach PRöTTEL 1988 \\
\hline Pröttel 2B & 98 & ca. $300-$ ca. $340 \mathrm{n}$. Chr. \\
\hline Keller 3B-Pröttel 2C & 33 & ca. $300-$ ca. $340 \mathrm{n}$. Chr. \\
\hline Keller 3B/4A-Pröttel 3/4B & $5 \mathrm{a}, 14,15,19,41,48,79,81,84,112,114,130$ & $330-$ um $400 \mathrm{n}$. Chr. \\
\hline Keller 4C-Pröttel 3/4D & $39,60,65$ & $330-$ um $400 \mathrm{n}$. Chr. \\
\hline
\end{tabular}

* Keller 1971, 26-55, Abb. 11; PRÖTtel 1988.

Alle Exemplare sind aus Bronze gegossen. Die Mehrheit der Stücke aus Somogyszil stimmt sowohl in Form als auch im Material miteinander überein. Erhebliche Unterschiede sind vor allem in der Größe bzw. der Verzierung festzustellen. ${ }^{197}$ Die einzelnen Typen werden grundsätzlich anhand der Verzierung der Fußplatte bzw. der damit nur selten identischen Verzierung des Bügels definiert ( $A b b$. 7). Über den Bügel und den Fuß hinaus wurde manchmal auch der Kragen der Knöpfe oder die mit den Knöpfen mitgegossenen Ringe verziert (Grab 33, 41, 112 und 130). ${ }^{198}$

Im Nadelhalter einiger Fibeln von Somogyszil ist die für die behandelte Periode und das Gebiet typische Versicherungskonstruktion für den Nadelverschluss in zwei verschiedenen Ausführungen erhalten geblieben. Die eine bestand darin, dass eine bewegliche Niete das Öffnen des Verschlusses im Bügelbereich verhinderte; in diesem Fall hinterließ die Niete deutliche Spuren am Fußende. Nach anderer Lösung wurde die Nadel mit einer drehbaren, dünnen, gebogenen sperrenartigen Platte, die mit einer Niete am Fußende der Fibel befestigt wurde, fixiert. ${ }^{199}$ An zwei Fibeln sind Spuren eines Eisendrahtes (Grab 5a und 98), an einer anderen eine Eisenniete mit rechteckigem Kopf zu sehen (Grab 48). Bei der Fibel aus Grab 60 wurde die Eisenniete zwischen Bügel und Fußplatte angebracht (Abb. 6).

${ }^{194}$ Einen ähnlich hohen Anteil hat Róbert Müller im Gräberfeld vor der südlichen Festungsmauer von Keszthely-Fenékpuszta registriert; MÜLLER 2010, 204. Nach seiner Zusammenstellung ist in den pannonischen Gräberfeldern eine große Streuung in der Anteilnahme der Gräber mit Zwiebelknopffibeln festzustellen (Intercisa, Südostfriedhof: $3 \%$, Intercisa XXIII: $49 \%$, Tokod: 5,8 \%, Solva, castellum: $41 \%$ und vicus: 22,4\%, Gorsium: 5,1\%, Ságvár: 11,9\%).

${ }^{195}$ Ausführlicher zu den Typenvarianten siehe SwIFT 2000, 14, Table A; Merczi 2012, 501, 503-504; neuerlich Merczi 2016, $465-468$.

Acta Archaeologica Academiae Scientiarum Hungaricae 70, 2019
${ }^{196}$ MerCZi 2012, 503.

${ }^{197}$ Die Länge der Fibeln bewegt sich zwischen 6,4 und $9,1 \mathrm{~cm}$, ihre Breite zwischen 4,2 und 6,1 cm und sie wiegen 34 bis $62,8 \mathrm{~g}$.

${ }^{198}$ An zwei Fibeln sind nur die beiden Seitenknöpfe erhalten (Grab 41 und 112). Bei weiteren zwei Fibeln kommt eine Kerbung trotz der vorhandenen drei Knöpfe allerdings nur an den beiden Seitenknöpfen vor (Grab 79 und 130). Allein bei der Fibel aus Grab 33 wurden alle drei Knöpfe gekerbt.

${ }^{199}$ Ausführlicher siehe PATEK 1942, 74; PATEK 1950, 502, 504-508, Abb. 1-4; MERCZI 2016, 466. 

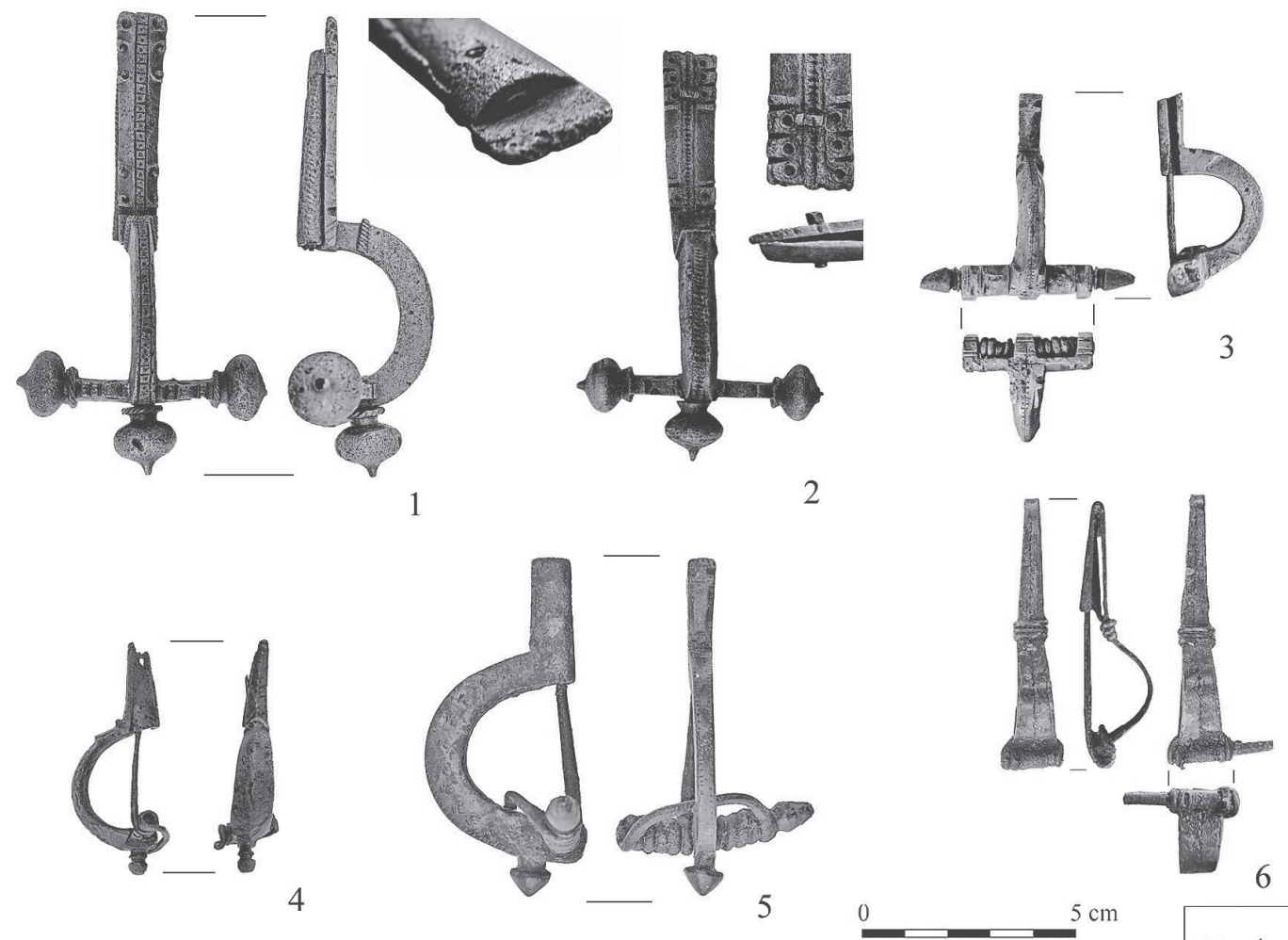

4

2

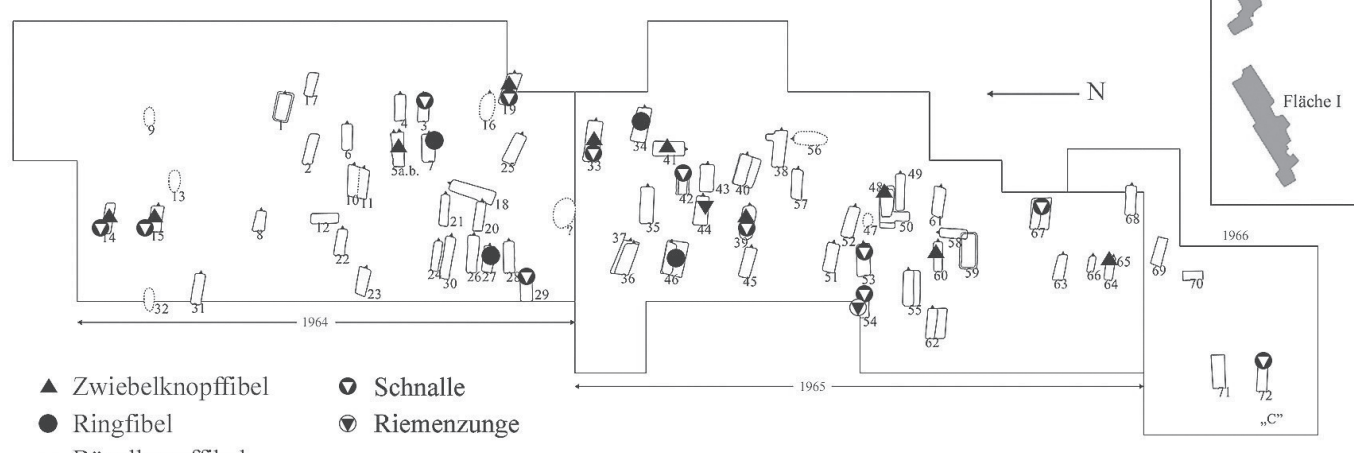

- Bügelknopffibel

V Stützarmfibel

Fibelpaar mit umgeschlagenem Fuß
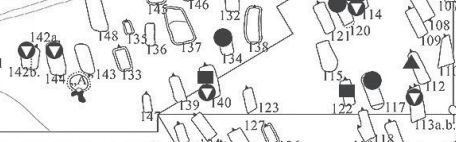

$\int_{1251}^{127} \int_{130}^{126}$
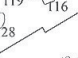

Abb. 6. 1: Zwiebelknopffibel mit Nadelsicherung aus Grab 33; 2: Zwiebelknopffibel mit Nadelsicherung aus Grab 48; 3: Stützarmfibel aus Grab 44; 4: Bügelknopffibel aus Grab 122; 5: Bügelknopffibel aus Grab 140;

6: Fibelpaar mit umgeschlagenem Fuß aus Grab 75b; 7: Verteilung der Gräber mit Fibeln, Schnallen und Riemenzungen 

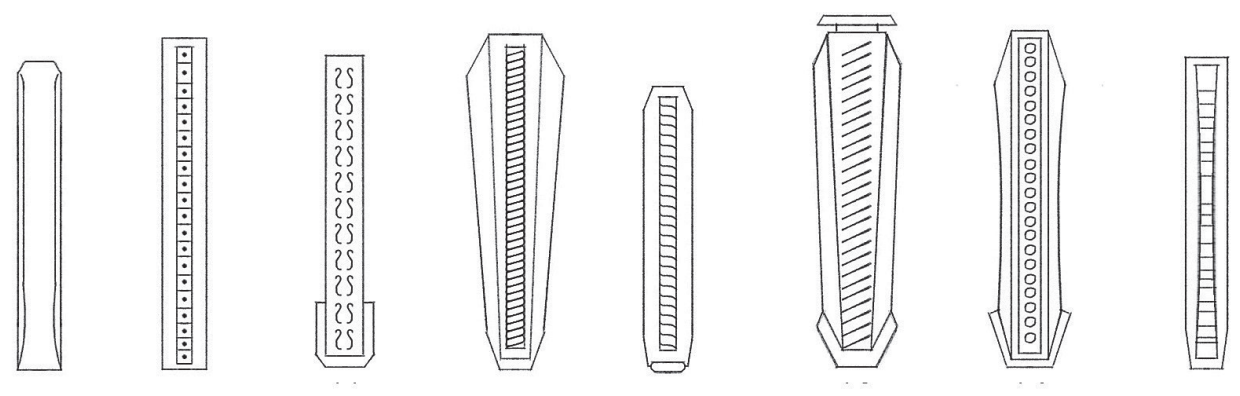

1

2

3

4

5

6

7

8
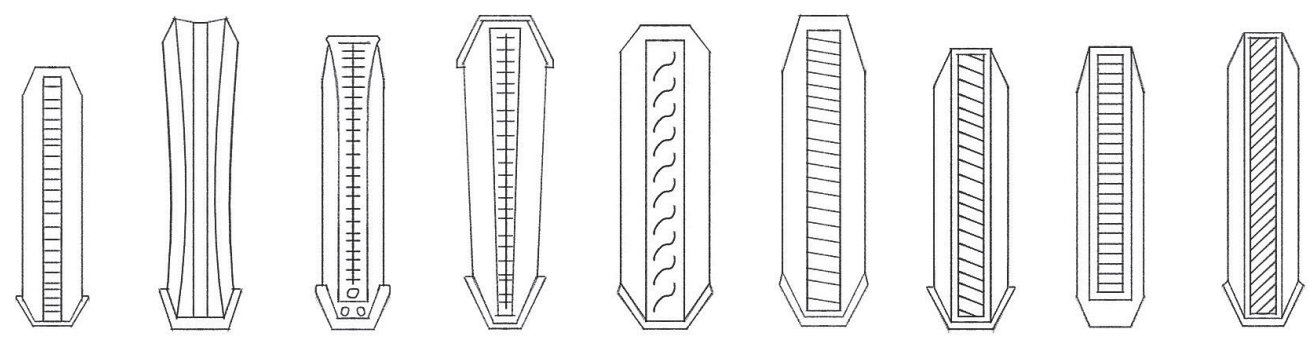

9

10

11

12

13

14

15

16

17

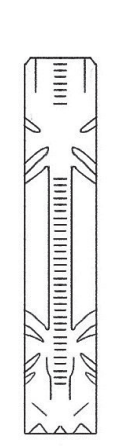

1

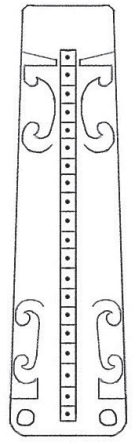

2

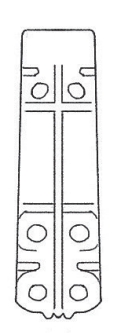

3

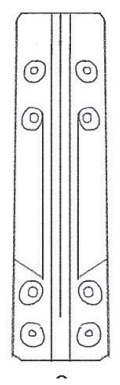

4

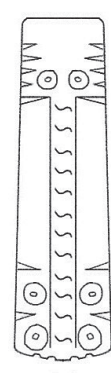

5

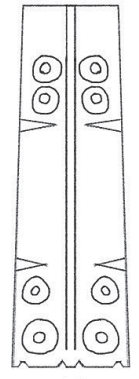

6

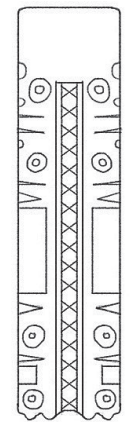

7

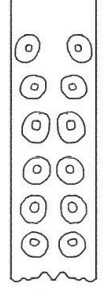

8

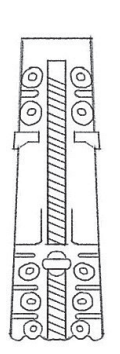

9

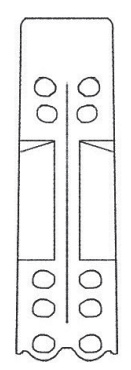

10

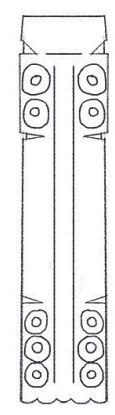

11

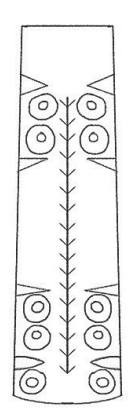

12

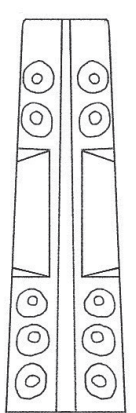

13

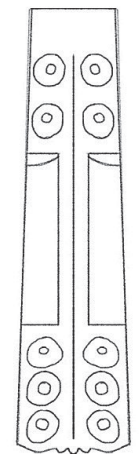

14

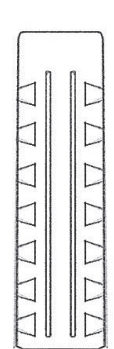

15
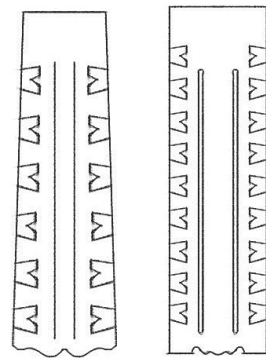

16 3: Grab 112; 4: Grab 14; 5: Grab 41; 6: Grab 15; 7: Grab 130; 8: Grab 114; 9: Grab 48; 10: Grab 81; 11: Grab 5a; 12: Grab 19; 13: Grab 84; 14: Grab 79; 15: Grab 65; 16: Grab 60; 17: Grab 39 
Zwiebelknopffibeln kamen fast ausschließlich in Männergräbern zum Vorschein. ${ }^{200}$ Lediglich ein Exemplar stammt aus einem Brandgrab (Fibel vom Typ Pröttel 2B aus Grab 98). Sie kamen meistens in Gräbern von Erwachsenen der Altersgruppen maturus und adultus vor. Andere Beispiele meldeten sich in einem Kindergrab (Grab 65, Altersgruppe infans), in einem Grab einer jugendlichen Person (Grab 81, iuvenis) und eventuell in Grab 112 (iuvenis) belegt.

Nach der typischen Tracht der Periode wurde von den Männern Mantel, an der rechten Schulter mit einer Zwiebelknopffibel befestigt, getragen. ${ }^{201}$ In der Mehrheit der Gräber von Somogyszil wurde die Fibel an der rechten Schulter mit dem Fuß nach oben registriert, was die übliche Tragweise widerspiegelt (Grab 5a, 14, 19, 39, 81, 84, 112, 114 und 130). ${ }^{202}$ Davon weicht die Lage der Fibel neben dem Kind in Grab 65 ab: ${ }^{203}$ Sie liegt auf der rechten Schulter ohne Nadel mit dem Fuß nach unten. Da das Tragen eines Mantels mit Zwiebelknopffibel nur Männern mit einem bestimmten Status zustand, besteht die Möglichkeit, dass die Fibelbeigabe bei einem Kind lediglich ein Element der Totentracht war. ${ }^{204}$ Bei der männlichen Bestattung der Altersgruppe maturus in Grab 79 fand man die Fibel ebenfalls an der rechten Schulter mit dem Fuß nach unten vor. In Grab 41 lag sie an der rechten Seite, jedoch mit dem Fuß nach unten am Ellenbogen des männlichen Skeletts. ${ }^{205}$ Mit dem Fuß nach oben, aber an der linken Schulter wurden zwei Stücke gefunden: in Grab 15 bzw. 48 (beide Typ Keller-Pröttel 3/4 B). ${ }^{206}$ In Grab 60 lag die Fibel in der linken Hand des Skeletts, ${ }^{207}$ ebenfalls mit dem Fuß nach oben (Typ Keller 4C Pröttel 3/4 D).

Der gesellschaftliche Status der Träger von Zwiebelknopffibeln bzw. ihre Zugehörigkeit zum Militär oder zum Verwaltungsapparat stellt ein viel diskutiertes Thema dar, das zuletzt von Marcus Zagermann eingehend behandelt wurde. ${ }^{208}$ Die Mitglieder des Staatsapparates leisteten einen mit dem Militärdienst vergleichbaren Dienst, führten militärische Titel und besaßen entsprechende Rechte, was auch ihren gesellschaftlichen Status begründete. Die spezielle Männertracht der Staatsbediensteten umfasste einen Mantel (chlamys, paludamentum, sagum), ${ }^{209}$ eine Fibel (in Spätrömerzeit Zwiebelknopffibel) und einen Gürtel.

Mit den Zwiebelknopffibeln - es handelt sich dabei um den Typ Keller-Pröttel 3/4B - wurden in 5 Fällen Schnallen ins Grab gelegt. In drei Gräbern wurden sogar je zwei Schnallen gefunden (Grab 14, 81 und 114). Zwiebelknopffibeln mit Schnallen und Riemenzungen vergesellschaftet sind in 3 Fällen belegt (Grab 79, 81 und 84).

Was die Chronologie der Zwiebelknopffibeln von Somogyszil anbelangt, ist mit der Verbreitung vom Typ Pröttel 2 am frühesten, und zwar etwa zwischen 300 und 340 n. Chr., zu rechnen (Grab 33 und 98). Dieser Typ kommt in unserem Gräberfeld in einem einzigen Grab mit Münzbeigaben vor (Grab 33), wo die t.p.q. Datierung anhand der Münzen von Constantius Gallus in den Jahren 351-354 erfolgt. Die Vertreter des Typs Pröttel 3/4B blieben länger im Umlauf. Die Mehrheit dieser Fibeln von Somogyszil kam mit Münzen der konstantinischen Dynastie (Grab 5a, 14, 15, 112, 114 und 130) zutage. In zwei Fällen liegen Münzen von Valens (Grab 84) bzw.

${ }^{200}$ Im Gräberfeld von Ságvár sind die Zwiebelknopffibeln siebenmal auch in Frauengräbern belegt (Grab 11, 18, 42, 114, 174, 218, 306, 333); SchMidT 2000, 399. Das Vorkommen in Frauen- oder Kindergräbern ist zwar nicht einzigartig, aber im Verhältnis des gesamten Reiches nur gering. Auf den Darstellungen kommen sie nicht als Teil der Frauentracht vor; ZAGERMANN 2014, 342-343.

${ }^{201}$ Das Sagum bzw. die Chlamys waren im 4. Jahrhundert bereits im gesamten mittleren Donaugebiet verbreitet. Zur antiken Bezeichnung siehe ausführlich ZaGermann 2014, 342, Anm. 25, 345-348. Die unterschiedlichen Typen von Zwiebelknopffibeln bewirkten keine Veränderungen der Tracht; TóTH 2015, 350.

${ }^{202}$ Von den 25 Zwiebelknopffibeln in Keszthely-Fenékpuszta kamen lediglich 7 Stücke auf der rechten Seite des Skeletts, in Trageposition zum Vorschein; MüLLER 2010, 204-205.

${ }^{203}$ In unserem Fall lässt sich das Alter des Kindes nicht näher bestimmen. Marcus Zagermann weist jedoch darauf hin, dass sogar Kinder unter 10 Jahren in der Funktion puer notarius in den administrativen Personalbestand des Staates aufgenommen werden konnten; ZAGERMANN 2014, 343, mit weiterer Literatur.

${ }^{204}$ Vera Lányi vertritt anhand von SÁGI 1954 und VÁGÓBóNA 1976 den Standpunkt, dass gegen Ende des 4. Jahrhunderts die Zahl der Männergräber zunimmt, in denen die Trachtgegenstände nicht der eigentlichen Tragweise entsprechend vorkommen; LÁNYI 1990, 249-250

${ }^{205}$ Im Süd-Nord ausgerichteten Grab waren Geschirrbeigaben an den Füßen und auch um den Schädel herum hingelegt worden.

206 Ähnliche Fälle sind auch aus anderen spätrömischen Gräberfeldern Pannoniens bekannt: Keszthely-Fenékpuszta Grab 1901/24 (MÜLleR 2010, 205); Esztergom-Bánomi-dülő (KELEMEN 2008, 98-99). Márta Kelemen erklärte dieses Phänomen damit, dass die Personen Linkshänder waren; KelEMEN 2008, 99.

${ }^{207}$ Im Gräberfeld vor der südlichen Festungsmauer von Keszthely gibt es je ein Beispiel dafür, dass eine Fibel in die rechte (Grab 1901/110) bzw. linke Hand (Grab 2000/94A) der Verstorbenen gelegt wurde; MüLLER 2010, 205.

${ }^{208}$ Margit Nagy hält die Personen, die mit einer Zwiebelknopffibel und einem militärischen Gürtel bestattet worden sind, für Soldaten; NAGY 2005, 466. László Barkóczi identifiziert Personen mit Gürtelbeschlag als Offiziere, die Kombination von Schnallen und Riemenzungen als einfache Militärtracht und Zwiebelknopffibeln an sich als Bestandteil der zivilen Beamtentracht; BARKócZI 1994, 90. Marcus Zagermann ordnet die Gürtelbeschläge neben der Militärtracht auch der Kleidung der Zivilbediensteten zu; ZAGERMANN 2014, 349.

${ }^{209}$ Siehe Anm. 201.

Acta Archaeologica Academiae Scientiarum Hungaricae 70, 2019 
Gratian (Grab 81) vor. ${ }^{210}$ Marcus Pröttel setzt die Gruppe D innerhalb des Typs Pröttel 3/4 relativchronologisch später an. ${ }^{211}$ In unserem Fall kommen solche Fibeln mit einer in den Jahren 351-354 geprägten Münze von Constantius II. (Grab 39) bzw. in Grab 60 mit einer Münze von Valens vor.

\section{Ringfibeln}

In Somogyszil fanden sich Ringfibeln in insgesamt sieben Gräbern (Abb. 6; Tabelle 6). ${ }^{212}$ Bis auf die zum Typ Merczi 3 gehörende Fibel mit Ansatz ${ }^{213}$ (= Sellye Typ IV) ${ }^{214}$ aus Grab 46 sind alle Exemplare trotz der unterschiedlichen Größe, Gestaltung und Material zu ein und demselben Typ Merczi 1 zu rechnen. ${ }^{215}$ Die Fundlage der Somogysziler Stücke spricht für eine Interpretation als Gewandnadel und nicht als Ringschnalle. ${ }^{216}$ Sie dienten zum Zusammenhalten des typischen Kleidungsstückes, des Mantels, in der Regel im Schulter-, Hals- oder Oberkörperbereich. In Somogyszil wurden die Ringfibeln hauptsächlich in den Männerbestattungen der Altersgruppe maturus und in einem Fall adultus gefunden, wenngleich wohl auch von Kindern und Frauen getragen wurden. ${ }^{217}$ An der Fibel aus Grab 120 war ein durch das Eisenoxid erhaltenes, grobfaseriges Textilfragment zu beobachten. Die pannonischen Vertreter des Typs mit Ansatz wie aus Grab 46 sind in ihrer Ausführung trotz der Größenunterschiede ziemlich einheitlich. ${ }^{218}$ Die Mehrheit der von Ibolya Sellye kartierten Exemplare (insgesamt 8 Stücke) stammt aus Savaria. Ein Stück ist aus Brigetio und ein weiteres Exemplar aus dem südpannonischen Raum im Gräberfeld von Ságvár ${ }^{219}$ bekannt. ${ }^{220}$ In den Donauprovinzen treten sie frühestens in der zweiten Hälfte des 3. Jahrhunderts auf. Die meisten Stücke Pannoniens sind mit konstantinischen Münzen datiert. ${ }^{221}$ In Somogyszil kamen Ringfibeln in vier Gräbern mit Münzen ans Tageslicht, die eine Datierung bis zum zweiten Drittel des 4. Jahrhunderts bekräftigen.

Tabelle 6.

Verteilung der Ringfibeln nach Geschlecht, Altersgruppe, der Lage im Grab, Material und ihre Datierungsanhaltspunkte

\begin{tabular}{|c|c|c|c|c|c|c|}
\hline $\begin{array}{l}\text { Grab- } \\
\text { nummer }\end{array}$ & Geschlecht & Altersgruppe & \multicolumn{2}{|c|}{ Lage im Grab } & Material & Abschlussmünze \\
\hline 134 & Kind & infans II & \multirow{3}{*}{ rechts } & Schlüsselbein & \multirow{4}{*}{ Eisen } & $355-361$ \\
\hline 27 & \multirow{3}{*}{ männlich } & adultus & & Schulter & & - \\
\hline 117 & & \multirow{3}{*}{ maturus } & & Oberarm & & konstantinisch \\
\hline 7 & & & links & C 1 & & $351-361$ \\
\hline 46 & männlich? & & rechts & & \multirow{3}{*}{ Bronze } & - \\
\hline 34 & \multirow{2}{*}{ weiblich } & infans II & \multicolumn{2}{|c|}{ Brustbein } & & $355-361$ \\
\hline 120 & & adultus-maturus & $?$ & & & - \\
\hline
\end{tabular}

${ }^{210}$ Nach der jüngsten Zusammenfassung von Martina Paul kann man anhand der Münzen auch im zweiten Drittel des 4. Jahrhunderts mit der beinahe gleichen Häufigkeit dieser Fibeln rechnen wie in der Periode von 350-380 n. Chr.; Paul 2013, Abb. 12, 85; siehe dazu MercZi 2012, 503, 508; MerCZi 2016, 466.

${ }^{211}$ PRÖTTEL 1988, 364, Abb. 11.

${ }^{212}$ Die Ringfibeln haben sich im 3. und 4. Jahrhundert im römischen Territorium verbreitet, aber sie kommen auch im Barbaricum vor; KeLLER 1971, 55-56; MerCZI 2000, 260-264. Zum Katalog der Fundorte siehe Merczi 2000, 266-272.

${ }^{213}$ MerCZI 2000, 262-264, Abb. 2.

${ }^{214}$ Sellye 1990, 69-71, Taf. 3. 14-19, Karte 3.
${ }^{215}$ MerCZi 2000, 260-262, Abb. 1.

${ }^{216}$ Mit einer Funktion als Ringschnalle ist in manchen Fällen auch zu rechnen; siehe dazu SCHNURBEIN 1995, 148; GUI 2015, 175.

${ }^{217}$ In Pannonien sind Ringfibeln in Männergräbern in Überzahl, aus einer Frauenbestattung ist ein Exemplar aus Tordas (Grab 1) bekannt; BÁNKI 1968, 233, Abb. 12. 2.

${ }^{218}$ SELLYe 1990, 69.

${ }^{219}$ Burger 1966, Grab 280. Im Inventarbuch des Ungarischen Nationalmuseums wurden die Beigaben der Gräber 280 und 284 verwechselt; siehe dazu SELlYe 1990, Anm. 123.

${ }^{220}$ SELLYE 1990, 69-71.

${ }^{221}$ MerCZI 2000, 261, mit weiterer Literatur. 


\section{Scheibenfibeln}

Die Frauengräber mit Fibeln ${ }^{222}$ sind gegenüber den sarmatischen und den Gräbern aus dem 5. Jahrhundert in den spätrömischen Gräberfeldern Pannoniens wesentlich unterrepräsentiert. In Somogyszil ist die Brosche aus dem reich ausgestatteten, Ost-West orientierten Grab 52 ein Unikat, die in der ursprünglichen Traglage, auf dem Brustbein des Skeletts einer erwachsenen Frau (adultus) vorgefunden wurde. Die aus dünnem Bronzeblech gepresste, am Rand mit punziertem Perlenrahmen geschmückte Scheibe wurde in der Mitte mit einem Medusenhaupt verziert. Auf der Rückseite ist ein Nadelhalter angesetzt. Die Fundumstände lassen darauf schließen, dass sie zum Befestigen eines Frauenmantels auf der Brust dienen könnte. ${ }^{223}$ Weitere Exemplare von solchen dünnen Platten mit Medusenhaupt und Perlenrahmen sind in Pannonien aus Pécs bekannt geworden. In einem spätrömischen Grab (Grab R/212) von Pécs kamen insgesamt 4 Stücke zum Vorschein, die mit Propellerbeschlägen und mit einer Delphinschnalle zum Gürtel der männlichen Verstorbenen gehörten. ${ }^{224}$ Diese vier Beschläge stimmen mit dem behandelten Stück in Größe und Verzierung völlig überein. Das Ost-West orientierte Grab in Pécs wurde mit den Prägungen der konstantinischen Dynastie, ${ }^{225}$ das Grab in Somogyszil mit den valentinianischen Münzen t.p.q. datiert.

\section{Bügelknopffibeln}

Bügelknopffibeln ${ }^{226}$ finden sich in Somogyszil in zwei Männergräbern (Grab 122 und 140) jeweils in unterschiedlichen Typen vor (Abb. 6). ${ }^{227}$ Das Exemplar aus Grab 122 vertritt den Typ mit offenem Nadelhalter und das andere aus Grab 140 die Variante mit kastenförmig geschlossenem Nadelhalter.

Das Stück aus Grab 122 aus Bronze mit oberer Sehne besitzt eine kurze Spirale, ${ }^{228}$ einen langen, massiven Halbkreisbügel mit einem halbkugelförmigen Knopf und einen spitz zulaufenden Fuß mit leicht verkürztem offenem Nadelhalter, der in einem kleinen Fußknopf endet. ${ }^{229}$ Die Verbreitung des Typs deckt ein breites Territorium vom Elbgelände über Polen, die mährischen Gebiete, Rumänien bis hin zum Küstengebiet des Schwarzen Meeres ab. Innerhalb des Reichsgebiets kommen sie nur vereinzelt, in Rätien, Norditalien und Pannonien ${ }^{230}$ vor. $^{231}$

Die Fibeln vom Typ Leutkirch (Grab 140) ${ }^{232}$ treten außer dem Elbgelände im Böhmisch-Mährischen Becken mit einem weiteren Häufungsgebiet im Provinzinneren in direkter Kontaktzone des alamannischen Gebietes und des germanischen Limes auf. ${ }^{233}$

${ }^{222}$ Grab 34, 52, 120.

${ }^{223}$ Von der Frau wurde ein Schleier getragen, der unter dem Kinn mit Nadeln festgehalten wurde.

${ }^{224}$ FÜleP 1977, 40, Pl. 30. 6, Pl. 32. 3. Ein ähnlicher Gürtel ist von Intercisa bekannt, der anstatt der kreisförmigen mit eckigen Beschlägen ohne Medusenhaupt verziert ist; SALAMON-BARKÓCZI 1975, 80 (Grab 72), Taf. 25. 8-14.

${ }^{225}$ FÜLEP 1977, 40.

${ }^{226}$ HORVÁth et al. 2018, 49-50.

${ }^{227}$ Sie vertreten ein ,rechtsrheinisches Pendant zu den Zwiebelknopffibeln“, die „,durch ähnliche Fibeln ersetzt, nicht aber kopiert wurden“; ZAGERMANN 2014, 347-348. Auf germanischem Territorium machen die Zwiebelknopffibeln $45 \%$ der Bügelknopffibeln aus und haben einen Bezug zu Soldaten, die als Söldner im römischen Heer gedient haben. Horst Wolfgang Böhme zählte die Fibeln von Somogyszil zu den Funden, die auf Anwerbung von Alamannen ins spätrömische Heer schließen lassen; BÖHME 1986, Anm. 41; BöHME 2012, 315-317.

${ }^{228}$ Bei den spätrömischen Fibeln innerhalb des Imperiums war vielmehr die Scharnierkonstruktion in Mode. Mechtild Schulze-Dörrlamm hält bereits die kurze Spiralarmkonstruktion des sog. germanischen Typs in erster Linie für verschiedene völkerwanderungszeitliche Varianten typisch, führt jedoch ihre Anfänge bis in die zweite Hälfte des 4. Jahrhunderts zurück; SCHULZE-DöRRLAMM 1986, 674.
${ }^{229}$ Beim behandelten Stück ist der Bügel länger als der Fuß, was Mechtild Schulze-Dörrlamm bei den Armbrust- und Bügelknopffibeln des 3. und 4. Jahrhunderts in der Germania libera registriert hat. Alle auf römischem Reichsgebiet hergestellten Serien des späten 5. und frühen 6. Jahrhunderts sind mit einem kurzen Bügel und langem Fuß zu charakterisieren; SCHUlze-DöRrLAMMM 1986, $669-670$

${ }^{230}$ Vindobona (FrIESINGER 1984, 132, Abb. 15. 3), Carnuntum (Groller 1908, Abb. 538), Keszthely (Cs. Sós 1961, 250, Taf. 55. 8, sekundär) und Siscia (KoščEvić 1980, Taf. 30. 265, 267, 269).

${ }^{231}$ Die Fundorte wurden von Mechtild Schulze-Dörrlamm kartiert (Schulze-DörRlamm 1986, Abb. 112, Fundliste 25).

${ }^{232}$ Die Fibeln mit doppelkonischem Bügelknopf (Serie IV, Variante 3) wurden erst von MEYER 1960 kartiert und von КосH 1974 verfeinert. Eine bedeutendere Sammelarbeit verbindet sich mit dem Namen von SchUlze-DörRlamm 1986, Abb. 113. Mit Fibeln des Typs Leutkirch befassten sich KELLER 1971, 56; HOEPER 2003, 45, Abb. 14; BEMmanN 2008, 29-31. Die letzte Sammlung erfolgte durch Eduard Droberjar (Droberjar 2015, Abb. 9), der die Karte von SteuerHOEPER 2008 ergänzte.

${ }^{233}$ Am Fundort von Leutkirch kam ein frühalamannischer Grabfund zutage, bei dem ein alamannischer Kämpfer außer der Fibel mit einer Riemenzunge mit Pferdekopfprotome und drei Pfeilspitzen bestattet wurde; SCHACH-DöRGES 1997, Abb. 79; vgl. KONRAD 1997, 178. 
Bügelknopffibeln sind vornehmlich aus den Männergräbern bekannt. ${ }^{234}$ In Grab 122 lag ein Kind ${ }^{235}$ und in Grab 140, das sich inmitten einer separaten nördlichen Grabgruppe befindet, ein Mann im adultus-Alter. Im Kindergrab befand sich die Fibel mit dem Fuß nach oben an der rechten Schulter des Verstorbenen. In Grab 140 gehörte die Fibel der Tracht eines gegürtelten Mannes an.

Das Grab 122 von Somogyszil kann anhand der zwischen 335 und 337 geprägten Münzen von Constantin I. und Constantius Gallus t.p.q. datiert werden. ${ }^{236}$ Das zweite Stück wurde ebenfalls mit Prägungen der konstantinischen Dynastie ins Grab gelegt (Constantius II). ${ }^{237}$ Anhand der Münzdatierungen lassen sich unsere Exemplare auf die vorvalentinianische Periode setzen.

\section{Stützarmfibel}

In Grab 44 kam eine Stützarmfibel ${ }^{238}$ mit Achsenträger zum Vorschein (Abb. 6). ${ }^{239}$ Anhand der anthropologischen Revision ruhte in Grab 44 eine Frau im maturus-Alter. ${ }^{240}$ Die Fibel lag in üblicher Tragweise auf der rechten Schulter, mit Fuß nach oben gerichtet. Auf germanischem Gebiet handelt es sich um einen von beiden Geschlechtern getragenen Fibeltyp. ${ }^{241}$ Die Frauengräber mit Stützarmfibeln von filigraner Ausführung melden sich vornehmlich östlich der Weser. ${ }^{242}$ Ähnliche Stücke sind vereinzelt im Provinzbereich in der Schweiz (Brugg) und in Italien registriert (Aquileia). ${ }^{243}$ Die Anfertigungs-, Benutzungs- und Bestattungszeit der Stücke wird zumeist gegen Ende des 4. bzw. Anfang des 5. Jahrhunderts (um 400) angesetzt. ${ }^{244}$ Die Fibel von Somogyszil war mit 11 Münzen der konstantinischen Dynastie vergesellschaftet.

\section{Fibeln mit umgeschlagenem Fuß (Almgren VI)}

Aus dem Ost-West ausgerichteten Grab $75 b^{245}$ stammen zwei zweigliedrige Bronzeblechfibeln ${ }^{246}$ mit umgeschlagenem Fuß (Almgren 168) (Abb. 6). ${ }^{247}$ Das Grab 75b gehörte zu einer separaten Grabgruppe am südlichen Rand der Nordfläche und ist durch eine Münze von Valentinian I. t.p.q. datiert. Die Fibeln lagen in Kniehöhe einer Frau im maturus-Alter. Ihre Grablage setzt eine Interpretation als persönliche Beigabe für die Tote voraus. ${ }^{248} \mathrm{An}$ hand der Parallelen könnten diese Fibeln aller Wahrscheinlichkeit nach an den beiden Schultern getragen worden

${ }^{234}$ SCHUlZE-DÖRRLAMm 1986, 686-689. Die Autorin wies darauf hin, dass sie auch aus zahlreichen Frauengräbern bekannt sind, und zwar hauptsächlich aus dem 5.-6. Jahrhundert (Grablage: unter dem Kinn, auf beiden Schultern, in der Mitte des Brustkorbes oder im Becken). beobachtet.

${ }^{235}$ Bei den Füßen der Verstorbenen wurden Brandspuren

${ }^{236}$ Jörg Kleemann verbindet sie mit der zweiten Hälfte des 4. Jahrhunderts und setzt ihre Verbergungszeit im letzten Drittel oder gegen Ende des Jahrhunderts an. Für dieses Exemplar gibt er eine der römischen Provinzen als Herstellungsort der ,mit den Barbaren verdächtigen“ Fibel aus Grab 122 an; KLEEMANN 2015, 510; vgl. SALAMON-BARKÓCZI 1982, 162.

${ }^{237}$ Das Exemplar sei nach Jörg Kleemann kein lokales Produkt. Er datiert es erst nach 380 und setzt die Zeit der Bestattung gegen Ende des 4. bzw. Anfang des 5. Jahrhunderts (um 400) an; KLEEMAnN 2015, 510.

${ }^{238}$ BöHME 1974, 51, mit weiterer Literatur.

${ }^{239} \mathrm{Ihr}$ Bügel ist von breitem, trapezförmigem Querschnitt und hat einen Rechteckfuß. Der Bügel besitzt eine durch niellierte Kerben verzierte Mittelkehle (L: 4,7 cm); HoRvÁTH et al. 2018, 50-51.

${ }^{240}$ ÉVINGER-BERNERT 2019.

${ }^{241}$ Die im letzten Jahrzehnt in Westfalen gefundenen Exemplare zeichnen eine direkte Verbindung zwischen dem Kernge- biet im Elbe-Weser-Dreieck und den provinzialrömischen Gebieten in Nordgallien und Belgica nach; siehe dazu BöHME 1974, 52, Karte 10; BrIESKe 2001, 47; BRIESKE 2010, 104, Abb. 4.

${ }^{242}$ Böhme 1974, 52; Böhme 1999; Steuer-Bierbrauer 2008.

${ }^{243}$ BRIESKe 2001, 45; BRIESKe 2010, Abb. 4, Nr. 39-40.

${ }^{244}$ BÖHME 1974, 52; KLEEMANn 2015, 510.

${ }^{245}$ In Grab 75 lagen zwei Personen. Der Leichnam des früher beerdigten Mannes im maturus-Alter wurde bei den Füßen des Frauenskeletts übereinandergeworfen; BURGER 1979, 41. Zum Fibelpaar siehe HoRvÁtH et al. 2018, 51-52.

${ }^{246}$ Der flach gewölbte und bandförmige Bügel wurde zurückgewickelt. In die auf diese Weise entstandene Hülse wurde ein Bronzedraht gelegt, auf den die Spiralkonstruktion mit je zwei Windungen (!) mit unterer Sehne aufgewickelt wurde. Der Nadelhalter zeigt einen trapezförmigen Querschnitt. Das drahtförmige Ende wurde dreifach um das Bügelende gewickelt. Durch die einen Winkel darstellende Gestaltung von Fuß und Bügel passt das Exemplar aus Somogyszil in die Spätgruppe der Fibeln mit umgeschlagenem Fuß; siehe dazu Merczi 2012, 497-498; Merczi 2016, 451-453.

${ }^{247}$ Burger 1979, Taf. 27. 2-3; MerCZi 2016, 454.

${ }^{248}$ Dafür spricht, dass eine von den beiden Fibeln beschädigt ist (teilweise erhaltener Spiralarm); BuRgER 1979, Taf. 27. 2. Siehe dazu KLEEMANN 2015, 510. 
sein. ${ }^{249}$ Die Anfertigungszeit des Fibelpaares ist frühestens Ende des 4. Jahrhunderts. Die Benutzungs- oder Tragezeit sowie die Bestattung sind zu Beginn des 5. Jahrhunderts anzusetzen. ${ }^{250}$

Eine direkte Analogie des Fibelpaares aus Somogyszil ist aus dem Material des Legionslagers Lauriacum bekannt. ${ }^{251}$ Die Stücke aus Somogyszil und Lauriacum sind der Form und der Verzierung nach identisch und stehen einander auch in der Größe nahe. ${ }^{252}$ Ein wohlerhaltenes Exemplar des zweigliedrigen, spiralarmigen Typs kam in Grab 261 des Gräberfeldes von Budaörs zum Vorschein. ${ }^{253}$ Weitere pannonische Exemplare sind aus den Fundorten Baláca, ${ }^{254}$ Savaria, ${ }^{255}$ Siscia, ${ }^{256}$ Budaörs-Vicus ${ }^{257}$ und Halbturn ${ }^{258}$ bekannt. Weitere Fundstücke im provinzialrömischen Gebiet sind außer Pannonien aus Moesien ${ }^{259}$ Dazien $^{260}$ und Noricum ${ }^{261}$ bekannt. In Dazien waren fast allein die zweigliedrigen Varianten verbreitet. ${ }^{262}$ Bei den Sarmaten der Ungarischen Tiefebene können die ein- und zweigliedrigen Typen beinahe in gleicher Zahl nachgefolgt werden. ${ }^{263}$ Man rechnet mit diesen Fibeln ab der zweiten Hälfte des 3. Jahrhunderts und sie blieben im gesamten 4. Jahrhundert im Gebrauch. ${ }^{264}$ Die Variante von Somogyszil vertritt allerdings eine jüngere Phase.

\section{Schnallen und Riemenzungen}

Im Gräberfeld kamen Schnallen aus Bronze (16 Stück aus 15 Gräbern) bzw. aus Eisen (14 Stück aus 14 Gräbern) in gleicher Menge vor (Tabelle 7). Die Gürtelschnallen von Somogyszil weisen, bis auf ein einziges Exemplar (Grab 29/2), eine dreigliedrige Konstruktion auf. Sie sind der Form C, Typ a, b und c von Sommer oder Cavadas Typ A zuzuordnen. ${ }^{265}$

Anhand der Formmerkmale des Schnallenbügels stellen unter den Schnallen die Varianten mit sattelförmigem bis ovalem Bügel die größte Gruppe dar (insgesamt 15 Stück, davon 7 aus Bronze und 8 aus Eisen). Die Anzahl der Varianten mit D-förmigem Bügel beträgt 8 (5 aus Bronze, 3 aus Eisen) und die der rechteckigen Varianten aus Eisen beträgt $3{ }^{266}$ Den massiven, D-förmigen Schnallenbügel mit sich verdickenden Schenkeln vertritt ein Exemplar (Kindergrab 42, zwischen 6-7 Jahren). ${ }^{267}$ Bügel mit ähnlicher Formgebung sind im pannonischen Material aus dem 5. Jahrhundert und sogar aus dem 6. Jahrhundert belegt. ${ }^{268}$

Beinahe bei der Hälfte der Bronzeschnallen könnte ein Dorn mit stilisiertem Tierkopfende beobachtet werden (Grab 33, 39, 54, 72, 114/1, 114/2, 142a und 144). ${ }^{269}$ Es kommt mit Ausnahme der trapezförmigen und rechteckigen Schnallen bei jedem Typ vor.

${ }^{249}$ Das paarweise Tragen von Fibeln wird als eine nicht römische Sitte betrachtet. Diese Sitte war bei den Germanen und Sarmaten ebenfalls verbreitet. Zu den Germanen siehe PIRLING 1993, 111 (Tutulusfibeln); zu den Sarmaten der Ungarischen Tiefebene siehe KULCSÁR 1998, 53.

${ }^{250}$ Die Datierung der Fibeln korreliert annähernd mit der Entstehung der auf beiden Schultern mit Fibeln (paarweise) getragenen Peplos-Tracht.

${ }^{251}$ Es wurde in einem 1906 freigelegten Gebäude gefunden. Genauere Fundumstände und die chronologische Lage sind nicht bekannt JoBST 1975, 79-80, Taf. 26; 198, Taf. 60. Im Legionslager Lauriacum kam auch ein weiteres Exemplar der zweigliedrigen Fibeln mit umgeschlagenem Fuß zutage (Kat.-Nr. 197). Dieses Exemplar stammt aus einer Kaserne und wurde nach Werner Jobst von einem Legionär getragen.

${ }^{252}$ Die Fibel aus Somogyszil ist $6,1 \mathrm{~cm}$, die aus Lauriacum $6,5 \mathrm{~cm}$ lang. Am breiten Bügel des zweigliedrigen Exemplars mit zwei Spiralen aus Noricum befindet sich - wie bei unserem Stück - eine aus punzierten Dreiecken bestehende Musterreihe; JoBsT 1975, 77 80, Taf. 26; 198, Taf. 60 .

${ }^{253}$ MercZi 2016, 454, Abb. 9. 32; OtTOMÁNyi 2016, 77, Abb. 37. 261/1. Dieses Exemplar weicht jedoch insofern davon ab, dass die Hülse, die die Achse der Spiralfeder hält, durch Rückverbiegung des Bügels gestaltet wurde.

${ }^{254}$ Kovrig 1937, 22, 68, Taf. 12. 127; PATEK 1942, 65, Taf.

26. 13 .

${ }^{255}$ Kovrig 1937, 22, 68, Taf. 12. 128
${ }^{256}$ PATEK 1942, 64, Taf. 26. 4.

${ }^{257}$ MerCZI 2012, 497-498, Typ 15.

${ }^{258}$ Doneus 2014, 119 (Grab 8), Taf. 560. 2

${ }^{259}$ BoJović 1983, 71-74, 143, Kat. 319, Taf. 33; GENČEvA

2004, 111, 168, Taf. 16. 10-12.

${ }^{260}$ CoCIș 2004, 146-147.

${ }^{261}$ JoBst 1975, 77-80, Taf. 26. 198, Taf. 60.

${ }^{262}$ Cociş 2004, 146-147. Sorin Cociş geht davon aus, dass sie sich in Dazien herausentwickelt haben und von dort sowohl in provinzialrömische als auch in barbarische Gebiete gelangt sind.

${ }^{263}$ VADAY 1989, 86-90.

${ }^{264}$ GENČEVA 2004, 111. Die Gräber in Budaörs (OTTOMÁNYI 2016, 77) und Halbturn (VoNDROCEV-WINTER 2014, 246, Kat.-Nr. 24) sind früh anzusetzen. In Halbturn wird das Grabensemble durch eine zwischen 313-315 geprägte Münze von Licinius t.p.q. datiert.

${ }^{265}$ SOMMER 1984, 21-23; CAVADA 1999, 97-98.

${ }^{266}$ Im Gräberfeldmaterial von Budaörs kommen ähnliche Typen (D-förmig, viereckig) aus Eisen vor; RUPNIK 2016, 569, Abb. 15. 10-11, Abb. 15. 14-15.

${ }^{267}$ Ein ähnliches Exemplar ist in Intercisa bekannt; VÁGÓBóNA 1976, 80, Taf. 19 (Grab 1116).

${ }^{268}$ IVANIŠEVIĆ-KAZANSKI-MASTYKOVA 2006, 21-22, fig. 11. 5-28, fig. 40. 2-15.

${ }^{269}$ Diese Art von Verzierung wurde mit Sicherheit bei mehreren Eisenschnallen verwendet, sie ist jedoch infolge der Korrosion nicht mehr sichtbar. 
Tabelle 7

Verteilung der Schnallen nach den Typen von SOMMER 1984

Sorte 1 = ringförmig geschlossener Bügel; Sorte 3 = „mit festem Beschlag“; Form A= „,mit taschenförmigem Beschlag“; Form C= „mit rechteckigem Beschlag"; Typ $a=$,mit deutlich D-förmigem Bügel“; Typ $b=$,mit sattelförmigem bis ovalem Bügel“; Typ $c=$,mit rechteckigem Bügel“" (Grabnummern mit Kursive bei SOMMER 1984 angegeben; die Nummern entsprechen den Nummern an den Tafeln von BURGER 1979)

\begin{tabular}{|l|l|l|l|}
\hline Schnallen & Typen & Bronzeschnalle (Grabnummer) & Eisenschnalle (Grabnummer) \\
\hline Bügel und Beschlag & Sorte 1, Form A, Typ a & 14 & \\
\hline nur Beschlag & Sorte 1 (?), Form A & $53,81 / 2,84 / 4$ & \\
\hline \multirow{5}{*}{ Bügel und Beschlag } & Sorte 1, Form A, Typ a & 107 & \\
\cline { 2 - 4 } & Sorte 1, Form C, Typ a & $142 a$ & \\
\cline { 2 - 4 } & Sorte 1, Form C, Typ b* & $54,72,79,114 / 4,144 / 4$ & $29 / 1$ \\
\hline & Sorte 1, Form C, Typ c** & & $19,39,140$ \\
\hline \multirow{5}{*}{ nur Bügel } & Sorte 1, Form ?, Typ a & $42,114 / 2$ & $3,15,33 / 2,67,84 / 3,86,94,107$ \\
\hline & Sorte 1, Form ?, Typ b & $33 / 8,113$ & $81 / 3,144 / 5$ \\
\hline & Sorte 1?, Form ?, Typ c & & $29 / 2$ \\
\hline \multirow{2}{*}{ Bügel und Beschlag } & Sorte 3, Typ e & & \\
\hline
\end{tabular}

* Die Verbreitungsschwerpunkte der Schnallen mit sattelförmigem Bügel sind in Belgica II, in Rätien und in der südlichen Hälfte Pannoniens zu registrieren (SOMMER 1984, 23).

** Die von Markus Sommer gesammelten Exemplare stammen - mit einer Ausnahme - aus Pannonien (SommER 1984, Liste V).

Die Riemenplatte ist lediglich bei neun Bronzeschnallen erhalten. Bei einer davon wurde sie aus Eisen angefertigt oder ersetzt (Grab 29/1). Innerhalb des dreigliedrigen Typs mit geschlossenem Schnallenbügel machen Exemplare mit rechteckigem Beschlag die Mehrheit aus. Die Anzahl der Stücke mit taschenförmigem Beschlag ist gering. Sie bestehen größtenteils aus einer Platte und haben eine zurückgerollte Hülse (Grab 29, 54, 72, 79, 81, 114, 144). Ein Stück besteht aus zwei Platten (Grab 14) und eine ist mit dem Bügel mitgegossen (Grab 29/2). Es sind nur drei Exemplare verziert (Grab 72: die Randkante gekerbt, an der Basis des Dorns zwei strahlenförmig eingekratzte Linien; Grab 107: Kreisaugen; Grab 144: Rillen und Profilierung).

Die Gürtelschnalle, die zwischen den Schenkelbeinen des Mannes (maturus) in Grab 29 (Grab 29/2) zum Vorschein kam, gehört zu den Varianten, bei denen der Bügel und der Schnallenkörper mitgegossen sind. Zur Anbringung des Dorns wurde der Schnallenkörper durchlocht. Sie kann nach der Sommerschen Typologie der Variante Sorte 3, Typ e zugeordnet werden, der nach Formkriterien den Schnallen der Sorte 1, Form B nach Sommer entspricht, strukturell weicht aber davon ab. ${ }^{270}$ Diese gegossene Bronzeschnalle mit festem, dreieckigem Beschlag stellt ein Vorbild des Typs D6 nach Schulze-Dörrlamm dar. ${ }^{271}$ Nach der Kartierung von Horst Wolfgang Böhme zeigt sich der spätrömische Schnallentyp auf provinzialem Gebiet - abgesehen von einigen Vertretern in Gallien und Hispanien ${ }^{272}$ - vor allem in Britannia, Belgica und Germania. Ein weiteres Häufungsgebiet ist dem rheinischen und dem Donau-Limes folgend in der Provinz Valeria festzustellen. ${ }^{273}$ Die Datierung des Typs umfasst das gesamte 4. Jahrhundert. Anhand einiger germanischer, rätischer und pannonischer Fundstellen ist ab der ersten Hälfte des 4. Jahrhunderts mit ihrer Verbreitung zu rechnen. ${ }^{274}$ Weitere pannonische Exemplare sind aus den Fundorten Carnuntum, ${ }^{275}$ Mosonszentmiklós-Jánosházapuszta (Grab 23), ${ }^{276}$ Gorsium, ${ }^{277}$ Szentlászló-Szentegyedpuszta ${ }^{278}$ und Kisasszonyfa ${ }^{279}$ bekannt. $^{280}$

${ }^{270} \mathrm{Im}$ Grab wurde auf dem linken Schambein auch ein Exemplar mit viereckigem Bügel aus Bronze und eiserner Riemenplatte gefunden; BURGER 1979, Taf. 5. 29/1.

${ }^{271}$ Die Exemplare dieses Typs wurden von Horst Wolfgang Böhme und Roksanda M. Swoboda systematisch gesammelt; BöHME 1986, 485-487, Abb. 14; Swoboda 1986, 91-100.

${ }^{272}$ Markus Sommer berichtet auch von einem Exemplar aus Marokko; Sommer 1984, Anm. 187.

${ }^{273}$ BÖHME 1986, 485-487, Abb. 14.

${ }^{274}$ Clarke 1979, 272; Böhme 1986, 486-487, Anm. 35; KONRAD 1997, 50, mit weiterer Literatur. In unserem Fall ohne Münzdatierung.

Acta Archaeologica Academiae Scientiarum Hungaricae 70, 2019
${ }^{275}$ WERNER 1962, 86, Abb. 15. 1.

${ }^{276}$ BÖHME 1986, 486-487, Anm. 35, mit weiteren Fundorten.

${ }^{277}$ FITZ 1978, Taf. 8. 114.

${ }^{278}$ Dombay 1957, Taf. 37. 10.

${ }^{279}$ Dombay 1957, Taf. 40. 2.

${ }^{280}$ Das Hauptverbreitungsgebiet der dreigliedrigen Varianten, die formal mit den mitgegossenen Schnallen identisch sind, liegt ebenfalls in den Donauprovinzen. In Gallien und Germanien kommen sie seltener vor, aber sie sind im Küstengebiet des Schwarzen Meeres auch anzutreffen; SOMMER 1984, 21, Anm. 29-30. Pannonische Exemplare sind in Intercisa, Ságvár, Somodorpuszta und Pécs bekannt; SOMMER 1984, Liste II. 
Von zwei Frauengräbern (Grab 67 und 94, ${ }^{281}$ maturus) abgesehen ${ }^{282}$ kamen die Schnallen in Männer- und Kindergräbern vor. Im Frauengrab 67 lag sie in Traglage am Becken. Manche Gräber enthielten allerdings mehrere Schnallen (Grab 29, 33, 84, 114 und 144).

Im Gräberfeld von Somogyszil kamen keine Gürtelbeschläge zum Vorschein, ${ }^{283}$ Riemenzungen liegen dagegen aus vier Gräbern vor. Auf dem linken Unterschenkel einer jugendlichen Person (infans II) in Grab 54 lag eine herzförmige Riemenzunge, die zu einer Gürtelschnalle mit B-förmigem Schnallenbügel und eckiger Riemenplatte gehörte. Das Fundensemble lässt erkennen, dass der Gürtel neben dem linken Bein der Bestatteten gelegt worden war. In der Mitte des Beckens des in Grab 84 liegenden adulten Mannes befand sich eine Gürtelschnalle mit ovaler Riemenplatte, zu der eine mit Voluten gestaltete bronzene Riemenzunge in Form eines umgekehrten Dreiecks gehörte (Form C, Typ b nach Sommer). Die Bronzeschnalle lag etwa in der Höhe des linken Knöchels das heißt, hier hatte man den Gürtel des Mannes wie bei Grab 54 neben den linken Unterschenkel gelegt. ${ }^{284}$ Neben dem in Grab 79 bestatteten Mann der Altersgruppe maturus wurde eine mit Voluten gestaltete bronzene Riemenzunge mit abgerundetem Ende (Form C, Typ b nach Sommer) gefunden, die zu einer mit B-förmigem Schnallenbügel und viereckiger Riemenplatte ausgestatteten Gürtelschnalle gehörte. Der Gürtel war auch in diesem Fall neben dem rechten Unterschenkel in das Grab gelegt worden. ${ }^{285}$ Neben dem rechten Oberschenkel des jungen Mannes (iuvenis) in Grab 81 lag eine amphoraförmige Riemenzunge aus Bronze (Form B, Typ b, Var. 1-2 nach Sommer), die zu einer Gürtelschnalle mit taschenförmigem Beschlag gehörte. ${ }^{286}$ Bei der Riemenbefestigung hatte sich zwischen den beiden Platten ein Rest vom Gürtel konserviert. Die Lage der Schnalle und der Riemenzunge weist in diesem Fall auf die Trageposition hin.

Zwiebelknopffibeln und Schnallen wurden insgesamt in neun Gräbern gefunden (Grab 14, 15, 19, 39, 79, 81, 84, 112, 114). In vier davon kamen sogar je zwei Schnallen zum Vorschein (Grab 14, 8, 84 und 114) (Tabelle 8). Ein Ensemble von Schnalle und Riemenzunge ist in drei Fällen mit einer Fibel ergänzt, und zwar ausschließlich mit Zwiebelknopffibeln vom Typ Keller-Pröttel 3/4B (Grab 79, 81 und 84).

Tabelle 8

Verteilung von Schnallen und Riemenzungen in Vergesellschaftung mit Zwiebelknopffibeln

\begin{tabular}{|c|c|c|c|c|}
\hline Grabnummer & $\begin{array}{l}\text { Bronzeschnalle } \\
\text { (Bügel/Beschlag) }\end{array}$ & Bronzene Riemenzunge & Eisenschnalle & Typ der Fibel \\
\hline 112 & Beschlag nicht bestimmbar & & & Typ Keller-Pröttel 3/4B \\
\hline \multirow[t]{2}{*}{14} & Ringschnalle & & & \\
\hline & D-förmiger Bügel mit taschenförmigem Beschlag & & & \\
\hline \multirow[t]{2}{*}{114} & D-förmiger Bügel & & & \\
\hline & \multirow[t]{2}{*}{ sattelförmiger Bügel mit rechteckigem Beschlag } & & & \\
\hline 79 & & \multirow[t]{3}{*}{ amphoraförmig } & & \\
\hline 81 & \multirow[t]{2}{*}{ taschenförmiger Beschlag } & & rechteckiger Bügel & \\
\hline 84 & & & ringförmiger Bügel & \\
\hline 15 & & & ovalförmiger Bügel & \\
\hline 19 & & & D-förmiger Bügel & \\
\hline 39 & & & & Typ Keller-Pröttel 3/4D \\
\hline
\end{tabular}

${ }^{281}$ Anhand der Angaben der veröffentlichten Publikation von Alice Sz. Burger handelt es sich um eine Frau. Bei der Revision wurde die Person dagegen als Mann identifiziert. Das Geschlecht lässt sich anhand des archäologischen Materials nicht eindeutig bestimmen

${ }^{282}$ Schnallen kamen im Gräberfeldmaterial von Budaörs ausschließlich als Zubehör der Männertracht vor; SEY 2016, 529.

${ }^{283}$ Vgl. MÜLLER 2010, 205.
${ }^{284}$ Die andere, im Grab gefundene runde Eisenschnalle lag bei der rechten Hand und in ihrer Nähe wurden Reste eines Lederbeutels entdeckt, in dem die 15 Münzen des Grabfundes gelegen haben dürften; BURGER 1979, 44-45.

${ }^{285}$ Siehe dazu KonRAD 1997, 44

${ }^{286}$ Der hier behandelte Riemenzungentyp erschien in Pannonien in verschiedenen Formvarianten - von der klassischen Amphora bis hin zur Blattform. Zu den Fundorten siehe KelEMEN 2008, 104-105.

Acta Archaeologica Academiae Scientiarum Hungaricae 70, 2019 


\section{Schmuckgegenstände}

\section{Stirnbänder}

Am Schädel des in Grab 96 bestatteten Mädchens (6-7 Jahre?) wurden kleine, eckige, vergoldete Plattenornamente aus Bronze gefunden, die ursprünglich mit Glaseinlage verziert waren und aller Wahrscheinlichkeit nach auf einer Unterlage aus organischem Stoff befestigt worden waren. Das Tragen von Stirnbändern wurde anhand von Beispielen aus Kaiseraugst mit jungen ledigen Mädchen verbindet, was durch pannonische Bestattungen unterstützt wird. ${ }^{287}$ Einschlägige Belege aus Pannonien sind in größerer Zahl vorhanden (Aquincum, ${ }^{288}$ Intercisa, ${ }^{289}$ SzentlászlóSzentegyedpuszta, ${ }^{290}$ Bátaszék [4 Gräber], ${ }^{291}$ Ságvár, ${ }^{292}$ Tokod ${ }^{293}$ Csákvár ${ }^{294}$ und Solva $\left.{ }^{295}\right) .{ }^{296}$ Das Tragen von Stirnbändern war für das ganze 4. Jahrhundert und für das frühe 5. Jahrhundert typisch. ${ }^{297}$ Aus dem Grab von Somogyszil kamen keine Münzen vor.

\section{Haar- und/oder Schleiernadeln}

Nadeln aus Bein, Bronze, Silber oder Eisen sind in Pannonien in mehreren Exemplaren belegt. Die Stücke aus Gold sind aber sehr selten. ${ }^{298}$

In Somogyszil kamen in fünf Gräbern aus Silber oder Bronze gefertigte Nadeln oder Nadelpaare zum Vorschein (infans: Grab 34; adultus: Grab 38, 52 und 75b; adultus/maturus: Grab 100). Aus Grab 52 ist der silberne Typ mit kugelförmigem Kopf belegt, der unmittelbar über der mit Medusenhaupt verzierten Scheibe, bei dem Halswirbel lag. Die Fundlage lässt wohl darauf schließen, dass diese Nadel zur Befestigung des Schleiers unter dem Kinn gedient haben muss. In Grab 75 b fand man rechts und links vom Schädel je ein bronzenes Nadelpaar mit doppelkonischem Kopf, mit dem vermutlich ebenfalls ein Schleier befestigt worden war. In Grab 100 kam auf der rechten Seite des Schädels eine Bronzenadel ohne Kopf zum Vorschein und in Grab 38 lag auf der linken Seite des Schädels eine Nadel mit doppelkonischem Kopf - diese dürften ebenfalls Schleier- oder Haarnadeln gewesen sein. ${ }^{299}$ In Grab 34 (infans II) lag unter dem Schädel, etwa in Scheitelhöhe ein Nadelpaar aus Bronze mit kuboktaederförmigem Kopf, wobei die Lage des Fundes auf eine Verwendung als Haarknotennadel hinweist.

Die Gräber 34, 38 und 52 liegen einander nahe. Alle drei waren reich mit Schmuckgegenständen und Beigaben ausgestattet $(A b b .8)$. Alle Gräber hatten Münzbeigaben: Die Nadeln mit kuboktaederförmigem bzw. kegel- und kugelförmigem Kopf in den Gräbern 34 bzw. 38 sowie die unverzierte Bronzenadel in Grab 100 werden durch Münzen der konstantinischen Dynastie, die Nadeln mit kugelförmigem bzw. bikonischem Kopf in den Gräbern 52 bzw. 75b durch Münzen der valentinianischen Dynastie datiert.

\section{Ohrringe}

Die pannonischen Ohrringe des 4. Jahrhunderts lassen sich in technologischer Hinsicht grundsätzlich in zwei Gruppen teilen: Ohrringe mit geschlossenem bzw. offenem Ende. Im Gräberfeld von Somogyszil kamen Ohr-

${ }^{287}$ MARTIN 1991, 28.

${ }^{288}$ MADARASSY 1999, 62-63.

${ }^{289}$ VÁGÓ-BónA 1976, Taf. 20. 1134/1, Taf. 41. 1.

${ }^{290}$ DOMBAY 1957, Taf. 29. 1a-b.

${ }^{291}$ PÉTERfi 1993, 49, 60, 71, 74 (Grab 13, 70, 119 und 138).

${ }^{292}$ Burger 1966, fig. 97. 54/7-8; SCHMidT 2000, 391, Taf.

2. 95/3; mit weiteren Beispielen aus den Gräbern 201, 286, 300 und 316.

${ }^{293}$ LÁNYI 1981, 179 (Grab 77).

${ }^{294}$ NÁDORFI 1996, 96.

${ }^{295}$ KeLEMEN 2008, 116.

${ }^{296}$ KELEMEN 2008, 116-117, mit weiterer Literatur.

${ }^{297}$ Das Exemplar aus Grab 138 von Bátaszék wird durch die Münzen an den Anfang des 4. Jahrhunderts datiert; PÉTERFI 1993, 84, 104. Márta Kelemen setzt das Grab von Solva am Ende des 4.
Jahrhunderts bzw. bedingt am Anfang des 5. Jahrhunderts; KeLEMEN 2008, 116.

${ }^{298}$ Sie sind meist unverziert oder haben einen kugelförmigen Kopf; seltener sind sie mit Edelsteinen oder einer Büste verziert. Der größte Teil hat einen Zwiebelknopf oder einen Kopf in Form eines Kuboktaeders. Letztere haben sich hauptsächlich in der zweiten Hälfte des 4. Jahrhunderts verbreitet; LÁNYI 1972, Abb. 66; BARTus 2007, 152. Zur Verbreitung von Haarnadeln unterschiedlichen Typs in Pannonien siehe zuletzt KeLEMEN 2008, 113-116.

${ }^{299}$ Die Beispiele aus Esztergom zeigen ebenfalls, dass die Stücke in unversehrten Gräbern rechts oder links neben dem Schädel, gegebenenfalls in Schulterhöhe lagen. Woraus die Autorin die Schlussfolgerung zieht, dass es sich um Haarnadeln handeln könnte; KELEMEN 2008, 113. 

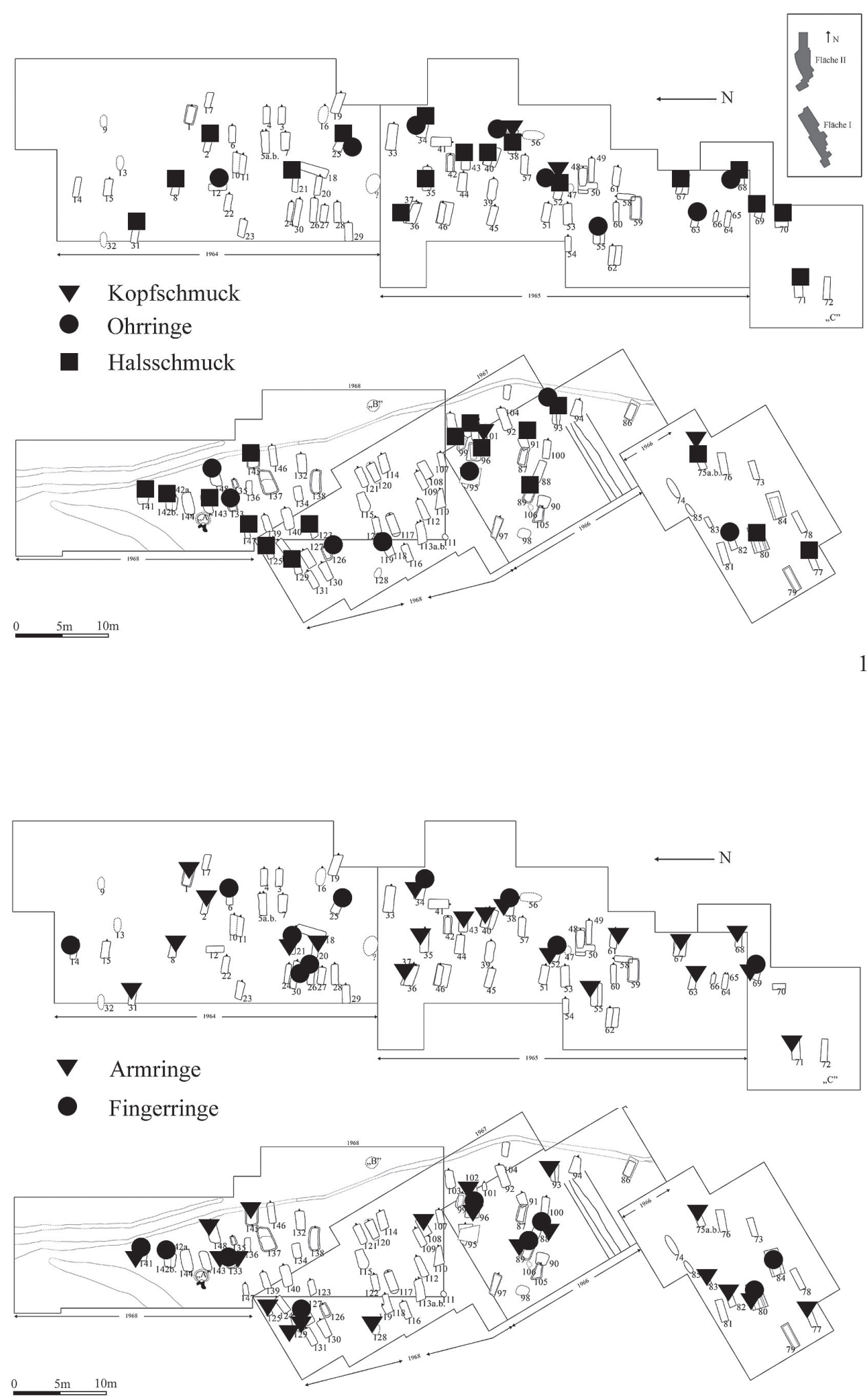

Abb. 8. 1: Verteilung der Gräber mit Kopfschmuck, Ohrringen und Halsschmuck; 2: Verteilung der Gräber mit Arm- und Fingerringen 
ringe insgesamt aus 20 Gräbern zum Vorschein, die fast ausschließlich zur Variante mit Anhängern und mit HakenÖsenverschluss gehören (Tabelle 9). Allgemein verbreitet ist die aus Bronzedraht gefertigte Variante mit Anhänger aus einem Bronzeprisma von viereckigem oder rundem Querschnitt, deren Ende mit einer kleinen Perle abgeschlossen wurde (Typ Lányi 4) ${ }^{300}$ Exemplare dieses Typs aus Bronze kamen in 7 Gräbern zum Vorschein, eines aus Silber ist in einem Grab belegt. Einfache Silberdrahtohrringe mit Perlenanhängern sind aus Grab 12 und 52 bekannt. Silberne Drahtohrringe mit gewundenen Enden (2 Stück) treten allein im Frauengrab 62 (adultus-Alter) auf. Sie befanden sich mit zwei Glasperlen zusammen wohl in einem Beutel in der rechten Hand.

Tabelle 9

Verteilung der Ohrringe nach den Typen und Altersgruppen sowie ihre Münzdatierung

\begin{tabular}{|c|c|c|c|c|c|c|}
\hline Grabnummer & Material & Typ & Anhänger & Abschlussperle & Abschlussmüinze & Altersgruppe \\
\hline 62 & \multirow[t]{5}{*}{ Silber } & mit gewundenen Enden & - & - & - & \multirow[t]{4}{*}{ adultus } \\
\hline 12 & & & \multirow[t]{3}{*}{-} & \multirow[t]{2}{*}{ grüne Glasperle } & - & \\
\hline 52 & & & & & \multirow[t]{2}{*}{ Valens } & \\
\hline 141 & & & & - & & \\
\hline 69 & & \multirow[t]{14}{*}{ Typ Lányi 4} & \multirow[t]{2}{*}{ kegelförmig } & Perle & Iulian & \multirow[t]{2}{*}{ infans II } \\
\hline 34 & \multirow[t]{15}{*}{ Bronze } & & & weiße Glasperle & Const. Gallus & \\
\hline 38 & & & \multirow[t]{3}{*}{ walzenförmig } & \multirow[t]{7}{*}{ grüne Glasperle } & Constantin II. & \multirow[t]{9}{*}{ adultus } \\
\hline $82 / 1$ & & & & & Gratian & \\
\hline $82 / 2$ & & & & & & \\
\hline 55 & & & gerippelt, kegelförmig & & - & \\
\hline 68 & & & gekerbt, kegelförmig & & Valentinian I. & \\
\hline 133 & & & $\begin{array}{l}\text { kegelförmig, aus Draht } \\
\text { gewunden }\end{array}$ & & - & \\
\hline 145 & & & kegelförmig & & & \\
\hline $5 \mathrm{a}$ & & & \multirow[t]{2}{*}{-} & \multirow[t]{3}{*}{-} & Constans & \\
\hline 93 & & & & & Vespasian I. & \\
\hline 63 & & & gerippelt, kegelförmig & & \multirow[t]{2}{*}{ Valentinian I. } & infans II \\
\hline 126 & & & tordiert & grüne Glasperle & & infans I \\
\hline 25 & & & - & - & Constans & \multirow[t]{3}{*}{ iuvenis } \\
\hline 118 & & Typ Lányi 13 & Draht & weiße Glasperle & - & \\
\hline 148 & & Typ Lányi 16 & lyraförmig (herzförmig) & - & - & \\
\hline 40 & \multicolumn{4}{|c|}{ unbekannt } & Constantius II. & adultus \\
\hline
\end{tabular}

Rechts neben dem Schädel der in Grab 148 bestatteten Frau kam ein an einen Ring aufgehängter, lyra- oder herzförmiger Anhänger mit einer kleinen grünen walzenförmigen Perle (ohne Gegenstück) zum Vorschein ${ }^{301}$ dessen nächstes Pendant aus einem Absatzgrab (Grab 15) ${ }^{302}$ und aus einem Erdgrab (Grab 116) ${ }^{303}$ vom Gräberfeld Budapest-Gazdagrét stammt (Typ Lányi 16). ${ }^{304}$

In 11 Gräbern wurden Ohrringe durch Münzen datiert: In 6 Fällen waren es Münzen der konstantinischen, in weiteren 4 Fällen Münzen der valentinianischen Dynastie. Bei den einzelnen Varianten ist kein zeitlicher Schwerpunkt auszumachen. Die Vertreter des Typs Lányi 4 kommen mit Prägungen beider Dynastien vor. Die Mehrheit der Ohrringe kam als Bestandteil der Frauen-Accessoires im adultus-Alter (13 Fälle) zum Vorschein. In 6 weiteren Gräbern gehörten sie zu Toten der Altersgruppen infans I und II bzw. iuvenis. Ohrringe in West-Ost und Süd-Nord orientierten Gräbern wurden nur je einmal registriert (Grab 145 und 12). Alle übrigen Gräber waren Ost-West ausgerichtet. Die Mehrheit der Verstorbenen mit Ohrringen wurde in einfachem Erdgrab bestattet. Darüber hinaus

${ }^{300}$ LÁNYI 1972, 88, Abb. 65. 4.

${ }^{301}$ Dieser Anhängertyp tritt nicht nur an Ohrringen, sondern auch an Halsketten auf. Ein Exemplar dafür ist aus Viminacium bekannt. Sie sind ab dem 3. Jahrhundert bis in die spätrömische Periode datiert; RAIČKOVIĆ-Milovanović 2010, 97, Fig. 44.

\footnotetext{
${ }^{302}$ Grabgruppe I, die Paula Zsidi in die zweite Hälfte bzw. das Ende des zweiten Drittels des 4. Jahrhunderts datiert; ZsIDI 1987 , 47, 69, Abb. 5. 15/1-2.

${ }^{303}$ Grabgruppe II, die von der Autorin vom Ende des 4. Jahrhunderts bis auf das gesamte 5. Jahrhundert gesetzt wird; ZsIDI 1987, 66-67, 69, Abb. 15. 116/1.

${ }^{304}$ LÁNYI 1972, Abb. 65. 16.
} 
kamen Ohrringe in je zwei Ziegelgräbern (Grab 126, 145) und Absatzgräbern (Grab 133, 148; Ziegelgrab mit Absatzwänden) zum Vorschein, beziehungsweise Grab 55 und 62 war je ein Nischengrab.

\section{Hals- und/oder Kleidungsschmuck $k^{305}$}

In Somogyszil enthielten 34 von den 57 Frauengräbern Perlenfunde, die mehr als die Hälfte der Frauenbestattungen ausmachen. Hinzu kommen noch zwei weitere Kindergräber (Grab 34 und 69) (Tabelle 10). ${ }^{306}$ Die in Grab 38 bestattete Frau trug sogar zwei Ketten um den Hals: eine Perlenkette und eine bronzene Halskette mit aus drei Bronzedrähten gewundenen Gliedern. Der Frau im iuvenis-Alter in Grab 75b hatte man in drei, dem Kind in Grab 102 sogar in sechs Reihen Perlenketten um den Hals gelegt. ${ }^{307}$

Tabelle 10

Verteilung der Haupttypen von Perlen nach Material, Form und Stückzahl

\begin{tabular}{|l|l|l|l|}
\hline Perlenmaterial & Perlenformen & Stückzahl der Perlen & Grabnummer \\
\hline Korallen & prismatisch, walzenförmig & 36 & 38 \\
\cline { 3 - 4 } & & $8-10$ & $25,34,52$ \\
\cline { 2 - 4 } & & $1-2$ & $2,21,40,75 \mathrm{~b}, 93,96$ \\
\hline Silberblech & $?$ & $? *$ & 93 \\
\hline Bronzeblech & amphoraförmig & $3,2,18,13$ & $25,34,38,52$ \\
\cline { 2 - 4 } & walzenförmig & 2,35 & 2,52 \\
\cline { 2 - 4 } & gerippelt & 2 & 2 \\
\hline Bernstein und Chalzedon & kuboktaedrisch & je 1 & 70 \\
\hline Bernstein & prismatisch & 1 & 102 \\
\hline Muschel, echte Perle? & oval- und scheibenförmig & $1-1$ & 77,99 \\
\hline Glas & kuboktaedrisch & 90 & $75 \mathrm{~b}$ \\
\cline { 2 - 4 } & & 30 & 2 \\
\cline { 2 - 4 } & & $8-9$ & 38 \\
\cline { 2 - 4 } & & 4 & 141,145 \\
\hline & & $1-2$ & $25,34,89,91$ \\
\hline
\end{tabular}

* Es sind 11 Silberplättchen publiziert (BURGER 1979, Taf. 17. 93/6).

In unserem Material kommen vor allem dunkelblaue und grüne scheiben- und linsenförmige sowie prismatische und oktaedrische Glas- oder Glaspastenperlen vor. ${ }^{308}$ Außerdem sind kugelige und amphoraförmige Perlen bzw. Reibenperlen aus goldflimmerfarbenem Glas in 17 Gräbern zu registrieren, deren zeitlicher Schwerpunkt auf die Regierungsjahre der kontstantinischen Dynastie fällt. ${ }^{309}$ Dunkelgrüne tropfenförmige Glasperlen ${ }^{310}$ oder große Opalperlen mit Glasfadenauflage gelten als ausdrücklich seltene Typen. Im Grab 62 fand man in der rechten Hand der weiblichen Bestatteten zwei solche Glasperlen vor: eine größere, schwarze Perle mit hellblauer Glasfladenauflage sowie eine kleinere, schwarze, kugelige Perle mit weißer Glasfladenauflage. Form- und fertigungstechnische Analogien dieser Perlen kommen in zahlreichen pannonischen Gräberfeldern des 4. und 5. Jahrhunderts vor. ${ }^{311}$

\footnotetext{
${ }^{305}$ Die zumeist am Halswirbel vorkommenden Perlen können in erster Linie als Halsketten, seltener als Verzierungen am Gewandsaum interpretiert werden.

${ }^{306}$ In Solva rechnet Márta Kelemen mit um $50 \%$; KeLEMEN 2008, 124.

${ }^{307},[\ldots]$ in den oberen 5 Reihen [befanden sich] die kleineren, in der unteren, sechsten Reihe die größeren Perlen“; BURGER 1979, 14

${ }^{308}$ Burger 1979, 14.

${ }^{309}$ Grab 34, 35, 37, 38, 40, 52, 69, 80, 89, 91, 93, 96, 99, $102,125,127,141$.

${ }^{310}$ Grab 80, 89, 96, 125.

${ }^{311}$ Zum Beispiel aus Bogád, Ságvár, Csákvár und Sármellék - meistens opalische Perlen mit weißen, blauen oder
}

roten wellenartigen Glasfadenauflagen auf schwarzem Grund. In Grab 14 von Bogád kamen solche Perlen mit anderen Glas- und Pasteperlen um den Hals vor (Burger 1963, 119, Abb. 15, Abb. 26). Im Ziegelgrab 24 von Csákvár kamen ebenfalls mit drei Glasperlen und einer polyedrischen Karneolperle vor (SALAMONBARKóczi 1971, 41, 43, Abb. 7). Weitere Beispiele sind in Ságvár-Tömlőchegy (Grab 247, 314 und 317; BURGER 1966, 124, 132, fig. 113. 247/1, fig. 120. 314/3d, 317) und in SármellékÉgenföld (MüLLER 1998, 260-261) bekannt. Im Material des 5. und 6. Jahrhunderts findet man sie in fast ähnlicher Form, aber oft in anderen Größen und Farben (rot mit gelben Wellenlinien): z. B. Unterhaching Grab 8 und 9 (WAMSER 2010, Abb. 19a, Abb. 26) und Walheim (QUAST 1997, 176, Abb. 181). 
In den münzdatierten Gräbern treten sie mit den Prägungen der konstantinischen Dynastie auf. Kuboktaederförmige, dunkelblaue, durchscheinende Glasperlen sind aus neun Gräbern bekannt. ${ }^{312}$ Diese Perlentypen kommen in Gräbern sowohl mit verhältnismäßig reicheren als auch mit ärmlicheren Beigaben vor. Die in Grab 70 gefundenen oktaederförmigen Perlen (2 Stücke) weichen nicht nur in ihrer Form (ein Viereck mit geschrägten Ecken), sondern auch in ihrem Material ab: Eine wurde aus Bernstein, ${ }^{313}$ die andere aus Chalzedon angefertigt. ${ }^{314}$

In zehn Frauen- bzw. Kindergräbern wurden Korallenperlen in Kurzwalzen-, Walzen- oder Prismaform entdeckt. ${ }^{315}$ Im Frauengrab 38 kamen sie in bedeutender Anzahl (36 Stücke) vor. In drei weiteren Gräbern wurden ebenfalls mehrere Exemplare (Grab 25, 34 und 52: 8-10 Stücke) und in fünf weiteren Gräbern lediglich ein bis zwei Stücke registriert (Grab 21, 40, 75b, 93 und 96). Die Korallen kamen beinahe immer in den reichsten Bestattungen mit anderen Perlen als Halskettenschmuck vor. ${ }^{316}$ Ein einziges Stück aus Koralle in Walzenform in Grab 93 lag nicht im Halsbereich, sondern in einem Perlenensemble aus 66 Perlen (amorphe Silberblechperlen, grüne Glasperlen in unterschiedlicher Form) um den rechten Fußknöchel der weiblichen Verstorbenen. In diesem Grab wurden eine Perlenkette um den Hals der Toten und weitere Perlen zwischen den Füßen gefunden, ${ }^{317}$ die bereits Alice Sz. Burger als Schmuckelemente eines Langgürtels des Frauenkleides betrachtete. ${ }^{318}$ Das Tragen des mit Perlen geschmückten Langgürtels war für die sarmatische Frauentracht seit dem Ende des 2. Jahrhunderts typisch. ${ }^{319}$ Korallen mit Karneolperlen waren im Bereich der Černjachov-Sintana de Mureș-Kultur und im sarmatischen Barbaricum vielmehr verbreitet als sonst in den Provinzen. ${ }^{320}$ In Rätien und in der Rheingegend waren sie nicht besonders häufig und hatten sich westlich von Pannonien kaum verbreitet. ${ }^{321}$

Goldblechperlen können in den spätrömischen Gräberfeldern Pannoniens mehrmals nachgewiesen werden. ${ }^{322}$ In Somogyszil sind sie aber nicht belegt. In unserem Fall treten außer den Silberblechperlen aus Grab 93 zumeist Bronzeblechperlen auf (Grab 2, 25, 34, 38 und 52). ${ }^{323}$ Als Unikat ist eine winzige Perlmutterperle (eventuell echte Perle) mit unregelmäßiger Kugelform zu betrachten, die mit verschiedenen anderen Glasperlen in Frauengrab 77 im adultus-Alter gefunden wurde.

In Grab 129 mit konstantinischen Prägungen kam teils auf der Stirn und teils auf dem Brustkorb des Skeletts eine Halskette mit 9 aus Bronzedraht gewundenen Gliedern zum Vorschein. Auf einem Glied wurden sogar Textilüberreste beobachtet.

Im Gräberfeld von Somogyszil treten die Haken-Ösenverschlüsse aus Bronzedraht in einfacher, schmaler Form ohne Verzierungen ${ }^{324}$ bei den Halsketten relativ häufig vor (17 \% der Frauen- und Kindergräber). Spiralförmig gewundene Verschlüsse sind viermal belegt (Grab 38, 69, 91 und 127). ${ }^{325}$

${ }^{312}$ Die Länge liegt zwischen 0,3 und $0,8 \mathrm{~cm}$, der Durchmesser zwischen 0,3 und $0,7 \mathrm{~cm}$. Die Anzahl der Perlen beträgt durchschnittlich 14-15; ihre Verteilung zeigt bei den einzelnen Perlenketten ein ungleichmäßiges Bild zwischen 1 und 90. Alle sind aus dunkelblauem Glas gefertigt, durchscheinend und haben eine regelmäßige Form. In allen Fällen waren sie mit anderen Perlentypen aufgeschnürt - selbst bei Grab 75b, das eine große Anzahl von Kuboktaederperlen enthielt.

${ }^{313}$ Michaela Konrad hält die Bernsteinperle vorwiegend für die germanische Frauentracht typisch; KonRAD 1997, 78. Zu den kulturellen Hintergründen siehe weiterhin HoRvÁtH et al. 2018, 53.

${ }^{314}$ Das Grab ist Nord-Süd ausgerichtet. Die Frau im adultus-Alter hatte außer der Halskette keine weiteren Grabbeigaben. In Somogyszil kamen keine weiteren Chalzedonperlen zum Vorschein.

${ }^{315} \mathrm{Grab} 2,21,25,34,38,40,52,75 \mathrm{~b}, 93$ und 96. Die Größe variiert auf einer breiten Skala; die Länge liegt zwischen 0,2 und 1,6 cm, der Durchmesser zwischen 0,2 und 0,4 cm. Siehe dazu LÁNYI 1972, 182 (Typen: Abb. 63. 8 und 12).

${ }^{316}$ In Pannonien sind sie in den folgenden Gräberfeldern belegt: Intercisa (Grab 1308; VÁGÓ-BóNA 1976), Majs (Grab 19, 34; Burger 1972), Ságvár (Grab 24, 131, 275, 283, 284; BuRger 1966; SCHMidt 2000, 392), Somodorpuszta (Grab 35; Burger 1974), Keszthely-Fenékpuszta (Grab 1966/81, 2000/131; MÜLLER 2010); Keszthely-Dobogó (Grab 49, 64, 73, 74, 89 und 102; SÁGI 1981, 108), Solva (Grab 47, 57, 282; KELEMEN 2008, 125).
${ }^{317}$ Auch im Gräberfeld von Solva kommen zwei Perlenketten vor: eine um den Hals und eine bei den Füßen (Grab 264, 282); KELEMEN 2008, 124.

${ }^{318}$ Burger 1979, 14.

${ }^{319}$ HendZSEl et al. 2008, 33-35, fig. 3. 3-4; IsTVÁNOVITSKulCSÁr 2018, 289-292, Abb. 250-251, 255.

${ }^{320}$ KELLER 1979, 47-48, Anm. 245, mit weiterer Literatur; MARTIN 1991, 32.

${ }^{321}$ MARTIN 1991, 32-33.

${ }^{322}$ Z. B. Ságvár-Tömlőchegy: Burger 1966, fig. 103. 145/7a, fig. 108. 188/1; Budaörs: OtTOMÁNYi 2016, 542, Abb. 13. 1; Esztergom-Bánomi-dülő: KELEMEN 2008, 124-125 (insgesamt 13 Gräber); München-Harlaching: WAMSER 2010, 115, Abb. 3.

${ }^{323}$ Die Länge variiert zwischen 0,6 und $1 \mathrm{~cm}$, der Durchmesser zwischen 0,3 und $0,5 \mathrm{~cm}$.

${ }^{324}$ KeLEMEN 2008, 128-129, Anm. 518, mit weiterer Literatur. Eine Gravierung lässt sich lediglich am Exemplar aus Grab 77 beobachten; BURGER 1979, Taf. 15. 77/1.

${ }^{325}$ Für Letztere gibt es Analogien in Intercisa, Ságvár, Keszthely-Dobogó, Solva (castellum) und Zengővárkony. Der Haken aus zwei Bronzeplatten ist im Gräberfeld von Somogyszil nicht belegt; vgl. KELEMEN 2008, 128-129. 


\section{Armringe}

In Somogyszil kamen aus 44 Gräbern insgesamt 84 Armringe aus Bronze, etwa 34 aus Bein, ${ }^{326} 5$ aus Eisen $^{327}$ und 3 aus Gagat oder Lignit zum Vorschein, die oft miteinander kombiniert getragen wurden (Tabelle 11). ${ }^{328}$ Es macht fast die Hälfte der Frauen- und Mädchengräber aus (8 Gräber größtenteils im Alter infans II).

Tabelle 11

Verteilung der Bronzearmringe nach Material, Technik, Gesamtzahl, Typen, Form und Tragweise

\begin{tabular}{|c|c|c|c|c|c|c|c|}
\hline 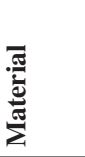 & 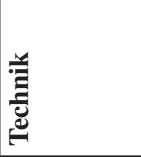 & 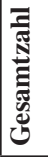 & ह & 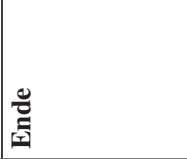 & 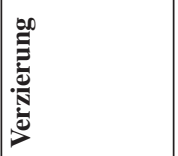 & 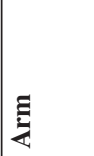 & 富 \\
\hline \multirow[t]{25}{*}{ Bronze } & \multirow{11}{*}{$\begin{array}{l}\text { massiv } \\
\text { (Draht, } \\
\text { gegossen) }\end{array}$} & 17 & \multirow[t]{9}{*}{ offen } & \multirow[t]{3}{*}{$\begin{array}{l}\text { stilisierter } \\
\text { Schlangenkopf }\end{array}$} & & linker & $\begin{array}{l}20,25,34,37,38,52,77,80,82,83,96, \\
143,145\end{array}$ \\
\hline & & 21 & & & & rechter & $\begin{array}{l}2,21,34,43,55,63,67,68,69,80,82 \\
83,96,108,129,137,141,145,148\end{array}$ \\
\hline & & 4 & & & & $?$ & 35 \\
\hline & & 1 & & \multirow[t]{3}{*}{ verjüngt } & \multirow{2}{*}{$\begin{array}{l}\text { kanneliert/ } \\
\text { Pseudoperlen }\end{array}$} & $?$ & 1 \\
\hline & & 1 & & & & linker & $34,75 b$ \\
\hline & & 1 & & & unverziert & linker & 38 \\
\hline & & 1 & & $\begin{array}{l}\text { aufeinander } \\
\text { verdrehte Enden }\end{array}$ & & rechter & 99 \\
\hline & & 1 & & \multirow[t]{2}{*}{ keulenförmig } & \multirow[t]{2}{*}{ unverziert } & linker & 52 \\
\hline & & 1 & & & & $?$ & 128 \\
\hline & & \multirow[t]{2}{*}{2} & \multirow[t]{2}{*}{ geschlossen } & & $\begin{array}{l}\text { kanneliert/ } \\
\text { Pseudoperlen }\end{array}$ & linker & 129 \\
\hline & & & & $\begin{array}{l}\text { in Knoten } \\
\text { verschlungen }\end{array}$ & & rechter & 133 \\
\hline & \multirow[t]{5}{*}{$\begin{array}{l}\text { Band aus } \\
\text { Blech }\end{array}$} & 1 & \multirow[t]{4}{*}{ offen } & $\begin{array}{l}\text { verjüngt, } \\
\text { abgerundet }\end{array}$ & $\begin{array}{l}\text { Punktkreise, } \\
\text { Fischgräten }\end{array}$ & rechter & $71 *$ \\
\hline & & 2 & & \multirow{2}{*}{$\begin{array}{l}\text { Haken- } \\
\text { Ösenverschluss }\end{array}$} & \multirow{2}{*}{$\begin{array}{l}\text { Fischgräten, } \\
\text { Knoten }\end{array}$} & rechter & 102,127 \\
\hline & & 2 & & & & linker & 96,127 \\
\hline & & 1 & & $?$ & $\begin{array}{l}\text { Rippe + Punkt- } \\
\text { kreise }\end{array}$ & rechter & 52 \\
\hline & & 1 & geschlossen & & Punktkreise & linker & 37 \\
\hline & \multirow{7}{*}{$\begin{array}{l}\text { Hohlarm- } \\
\text { ringe }\end{array}$} & 2 & \multirow[t]{2}{*}{ geschlossen } & \multirow{2}{*}{$\begin{array}{l}\text { mit } \\
\text { kolbenförmigem } \\
\text { Schlussglied } \\
\end{array}$} & & rechter & 38 \\
\hline & & 2 & & & & $?$ & 40 \\
\hline & & 1 & \multirow[t]{2}{*}{ offen } & \multirow{2}{*}{$\begin{array}{l}\text { mit Kerbungen } \\
\text { an den Enden }\end{array}$} & & rechter & 80 \\
\hline & & 1 & & & & linker & 80 \\
\hline & & 3 & \multirow[t]{3}{*}{$?$} & & \multirow[t]{2}{*}{ unverziert } & rechter & 52, 88 (Fußringe), 89 \\
\hline & & 3 & & & & $?$ & $1,40,115$ \\
\hline & & 1 & & & $\begin{array}{l}\text { Diagonale mit } \\
\text { Punktkreisen }\end{array}$ & rechter & 125 \\
\hline & \multirow[t]{2}{*}{$\begin{array}{l}\text { aus Drähten } \\
\text { gewunden }\end{array}$} & 7 & Haken-Ösenverschluss & $\begin{array}{l}\text { kolbenförmiges } \\
\text { Schlussglied }\end{array}$ & & & $1,77,93,141$ \\
\hline & & 5 & Haken-Ösenverschluss & - & & & $8,25,77,96,125$ \\
\hline
\end{tabular}

* In Budaörs ist es mit Punktkreisverzierung bekannt (Grab 233, 386; SEY 2016, 535), dessen Parallelen aus mehreren Provinzen stammen (SwIFT 2000, 136, fig. 181).

${ }^{326}$ Wegen dem fragmentarischen Erhaltungszustand der Funde kann keine genaue Anzahl angegeben werden.
${ }^{327}$ Dem Tragen von Eisenarmringen schreibt man ein Unheil abwehrende Funktion zu, da sie nicht aus Gräbern mit ärmlichen Beigaben stammen; siehe OtтомÁNYi 2010, 206.

${ }^{328}$ Siehe dazu LÁNYi 1972, 84-86.

Acta Archaeologica Academiae Scientiarum Hungaricae 70, 2019 
Unter den Bronzearmringen erscheinen neben massiven Draht- und gegossenen Exemplaren auch Bandund Hohlarmringe aus Blech. Diese sind mehrheitlich offen, mit aufeinander (Grab 99) oder nebeneinander gewundenen Enden angefertigt. Besondere Aufmerksamkeit verdienen die beiden hohlen Fußringe aus Bronzeblech in Grab 88, die sich jeweils an den Füßen der Frau im adultus-Alter befanden. Das Grab wird durch eine Münze der konstantinischen Dynastie datiert. ${ }^{329}$ Als nahe Analogie zum Fußring ist das Exemplar in Grab 10 aus Páty zu erwähnen. ${ }^{330}$ Die Knöchelringe sind weder im provinzialrömischen noch im barbarischen Territorium besonders geläufig. ${ }^{331}$ Die geschlossenen Varianten vertreten ein gegossener, mit Kanneluren gegliederter Armring aus Grab 129, ein Drahtarmring aus Grab 133 und ein geschlossenes Blechband aus Grab 37 sowie Hohlarmringe mit kolbenförmigem Schlussglied aus Grab 38 bzw. 40. Dem Exemplar aus Grab 129 ähnliche Armringe mit Pseudoperlen sind aus Grab 34 und 75b in offener Variante bekannt.

Unter den massiven offenen Armringen ${ }^{332}$ gab es sowohl an beiden Enden flach gehämmerte Exemplare als auch welche mit sich keulenförmig verdickenden bzw. sich verjüngenden Enden. Die massiveren Bronzearmringe mit kreisaugenverzierten und teils stilisierten Tierkopfenden wurden in der Fachliteratur am meisten beachtet. ${ }^{333}$ Dieser Typ, der im mittleren und letzten Drittel des 4. Jahrhunderts sowie am Anfang des 5. Jahrhunderts anzusetzen ist, gilt als häufiger Fund pannonischer Gräberfelder. ${ }^{334}$

Die breiten Blechbandarmringe sind mit 7 Exemplaren teilweise in offener Ausführung, mit oval abgerundeten Enden ${ }^{335}$ bzw. mit Haken-Ösenverschluss vertreten. ${ }^{336}$ Im pannonischen Gebiet tritt bei diesem Typ das Fischgrätenmuster als typische Verzierung auf. ${ }^{337}$

Die so genannten Hohlarmringe weisen in zwei Fällen Verzierungen auf: In Grab 80 an den Enden mit Kerbungen (stilisierter Schlangenkopf?) und in Grab 125 mit diagonalem Muster an den Treffpunkten mit Kreisaugenverzierungen. Die Hohlarmringe sind zumeist fragmentarisch. Bei zwei Exemplaren aus Grab 38 ist das kolbenförmige Schlussglied noch erhalten. Die Exemplare aus Grab 80 vertreten die offene Variante. ${ }^{338}$

Einen weiteren Typ stellen die aus Draht gewundenen Exemplare dar, ${ }^{339}$ und zwar in zwei Varianten: Haken-Ösenverschluss mit kolbenförmigen Gliedern, die bei anderen fehlen. ${ }^{340}$ Es handelt sich meistens um Stücke aus zwei (Grab 8, 25, 77, 93, 96), in einem Grab aus drei (Grab 93) bzw. in einem weiteren Grab aus vier Drähten (Grab 141), die miteinander verdreht wurden. Als einzigartig gilt das Exemplar aus Grab 77, bei dem der Draht zunächst gedreht und anschließend mit den Enden nebeneinander gedreht wurde.

Die geschlossenen Armringe vertreten die Stücke aus Eisen und Gagat (Schwarzglas?). Eisenarmringe kommen im Gräberfeld von Somogyszil in erster Linie am linken Arm vor (Grab 63, 68, 96, 102, 148). ${ }^{341}$ Gagat- $/$ Lignitarmringe befanden sich in zwei Fällen am rechten (Grab 31, 99) und in einem Grab am linken Arm (Grab 96). ${ }^{342}$

${ }^{329}$ BURGER 1979, Abb. 59.

${ }^{330}$ Otтома́nYi 2012, 5, Abb. 9. 8. In diesem Fall handelt es sich um einen Blechbandarmring mit Kreisaugendekor; siehe dazu LÁNYI 1972, Abb. 59. 23.

${ }^{331}$ HoRVÁth et al. 2018, 54.

${ }^{332}$ Es ist ein häufiger Typ in Gräberfeldern, der in die zweite Hälfte oder ans Ende des 4. Jahrhunderts oder sogar ins frühe 5. Jahrhundert datiert werden kann: Budapest-Bécsi út, BudapestEmese u., Keszthely-Fenékpuszta, Keszthely-Dobogó, Zengővárkony, Bátaszék, Tótvázsony, Pilismarót, Ságvár, Intercisa, Győr, Győrszentiván, Szentendre, Budapest-Gazdagrét, Solva (castellum); KELEMEN 2008, 130-131.

${ }^{333}$ Kelemen 2008, 134; Sey 2016, 533-535.

${ }^{334}$ Nach den Ansichten von Erwin Keller kann der Typ auf germanischen Ursprung zurückgeführt werden; KELLER 1971, 94107. Michaela Konrad betrachtet diese als überregional verbreitete Typen in den Alpen- und Donauprovinzen sowie in Italien; KONRAD 1997, 175. Anhand der jüngsten Forschungsergebnisse können Armringe dieser Art sogar in Südbritannien nachgewiesen werden; SwIFT 2000, 153, Type 93, fig. 222.

${ }^{335}$ Zur Verbreitung und Verzierung in Pannonien siehe KELEMEN 2008, 133.

${ }^{336} \mathrm{Zu}$ den pannonischen Fundorten siehe KELEMEN 2008, 132-133, mit weiterer Literatur; SEY 2016, 535.
2016, 535. ${ }^{338}$ Siehe Beispiele in Budaörs (Grab 347, 401, 443); SEY 131-132; SwIFT 2000, 127, fig. 153; sowie SEY 2016, 535-536. Siehe noch HoRvÁth et al. 2018, 54.

${ }^{339}$ Sie waren vom Ende des 3. Jahrhunderts bis ins mittlere Drittel des 4. Jahrhunderts am linken Rheinufer und in den Donauprovinzen typisch; KELLER 1971, 98. In Pannonien kommen sie im zweiten Drittel des Jahrhunderts, in der Zeit Valentinians und sogar zu Beginn des 5. Jahrhunderts beinahe in allen Gräberfeldern vor, so z. B. Keszthely-Fenékpuszta, Szomor-Somodorpuszta, Intercisa, Mucsfa, Pécs, Meződ, Dombóvár, Győr, Szentendre, Keszthely-Dobogó, Budapest-Gazdagrét, Bátaszék, Aquincum-Bécsi út, Solva (Bánom); KELEMEN 2008, 135.

${ }^{340} \mathrm{Vgl}$. SEY 2016, 533.

${ }^{341}$ In Grab 99 wurde er am rechten Arm getragen; BURGER 1979, 49, Abb. 68 .

${ }^{342}$ Gagat- bzw. Glasarmringe sind im pannonischen Material relativ selten. Im Gräberfeld von Esztergom (Grab 309) kommen sie in offener und geschlossener Variante vor. Zur Verbreitung siehe KELEMEN 2008, 136-137. Aus dem Material von Budaörs ist eine aus gerillten Perlen bestehende Variante bekannt, die von der Autorin in die zweite Hälfte des 3. Jahrhunderts bzw. um die Wende des 3./4. Jahrhunderts datiert wird; OTTOMÁNYI 2016, 206. Die Gagatarmringe 
Knochenarmringe kamen in 13 Gräbern in unverzierter Ausführung (Grab 21, 25, 34, 40, 43, 52, 67, 69, 75b, 80, 89, 102 und 133), in 8 Gräbern in verzierter Ausführung (Grab 21, 25, 52, 61, 63, 89, 143 und 145) zum Vorschein (Tabelle 12). ${ }^{343}$

Auf die Zusammenhänge zwischen dem Material und der Tragweise von Armringen hat Vera Lányi bereits hingewiesen. ${ }^{344}$ Am rechten Arm trug man in der Regel 1, eventuell 2 (Grab 21, 34, 38, 40, 52, 69, 96, 102) und ausnahmsweise 3 (Grab 99) Armringe. Die Zahl der am linken Arm getragenen Armringe war in der Regel damit identisch oder überstieg sogar die Zahl der am rechten Arm getragenen. Eine Ausnahme stellt Grab 102 mit einem Bronze- und einem Knochenarmring am rechten Arm und einem Eisenarmring am linken Arm dar. In Somogyszil wurden die meistens einzeln oder paarweise getragenen Bronzearmringe in erster Linie am rechten Arm beobachtet. ${ }^{345}$ Die jeweils zu zweit, zu viert oder zu sechst getragenen Knochenarmringe sowie die Eisen- ${ }^{346}$ und Gagatarmringe - jeweils nur ein Stück ${ }^{347}$ - wurden am linken Arm registriert. Eisenarmringe sind hauptsächlich in Mädchengräbern (infans II), ${ }^{348}$ in zwei weiteren Fällen in Frauengräbern vorhanden. ${ }^{349}$

Die Tragweise der einzelnen Typen von Bronzearmringen kann nicht als spezifisch betrachtet werden. Wenn die verstorbene Person drei oder weniger Armringe besaß, wurden die massiven Bronzedrahtarmringe fast ausschließlich an den rechten Arm aufgesetzt. Massivere Armringe aus widerstandsfähigerem Material wurden in der Regel am rechten und die verletzungsanfälligen Varianten am linken Arm getragen. ${ }^{350}$ Dementsprechend wurden die Knochenarmringe ${ }^{351}$ unabhängig vom Alter des Besitzers - hauptsächlich adultus - meistens am linken Arm getragen. ${ }^{352}$ Knochenarmringe am rechten Arm kamen nur in drei Fällen vor (Grab 61, 75b und 102 mit einem Blechbandarmring aus Bronze). ${ }^{353}$

Die Gagatarmringe sind in zwei Gräbern durch Münzen der konstantinischen Dynastie datiert (Grab 31, 99). ${ }^{354}$ Dieser Periode sind auch die Stücke von Pécs, ${ }^{355}$ Bátaszék $^{356}$ und Keszthely-Dobogó ${ }^{357}$ zuzuordnen, während das Esztergomer Exemplar anhand der gestempelten Ziegel später, in den Regierungsjahren von Valentinian, anzusetzen ist. ${ }^{358}$ Armringe aus Eisen sind ab Anfang des 4. Jahrhunderts belegt. ${ }^{359}$ In Somogyszil traten sie in einem Fall mit Münzen von Constantin I. und Constantius Gallus (Grab 99), in zwei Fällen mit Münzen der valentinianischen Periode auf (Grab 63, 68). Die diversen Typen von Bronze- und Knochenarmringen treten zusammen mit Münzen beider Dynastien auf. Ein chronologischer Schwerpunkt lässt sich nicht feststellen. Es handelt sich um Varianten, die vom zweiten Drittel des 4. Jahrhunderts bis in den Anfang des 5. Jahrhunderts allgemein verbreitet waren.

aus Gräbern 96 und 99 von Somogyszil sind mit schrägen Kanneluren verziert. Gagat- oder Lignitarmringe verbindet Michaela Konrad mit den gallisch-germanischen Provinzen; KONRAD 1997, 175.

${ }^{343}$ Als Verzierungen kommen entweder Kerbungen (Grab $25,89)$ oder Kreisaugenverzierungen in Reihen oder in verschiedenen Mustern geordnet vor (Grab 21, 52, 61, 63, 143, 145).

${ }^{344}$ In Zengővárkony kommen Schlangenkopfarmringe sowohl einzeln als auch paarweise an beiden Armen, Bronzeblechund Knochenarmringe dagegen vor allem am rechten Arm vor. Für Keszthely-Dobogó sind zumeist am linken Arm getragene Knochenarmringe und ,sonstige“ Armringe typisch. Falls am linken Arm verschiedene Armringe getragen wurden, kamen auch am rechten Arm verschiedene Varianten vor; siehe dazu LÁNYI 1972, 84-86, 103, 106, Abb. 22.

${ }^{345}$ In den meisten Gräbern kam lediglich je ein Bronzearmring vor (21 Gräber). Zwei Armringe (in diesem Fall erscheint in der Regel je ein Armring an beiden Armen) oder drei Armringe wurden in 6 Fällen gefunden. Die Anzahl der in einem Grab beigegebenen Bronzearmringe beträgt maximal 4 bzw. 5 (Grab 34, 38, 52, 69, 77, 80 und 96).

${ }^{346}$ Bei den Sarmaten hat sich eine ähnliche Tragweise verbreitet.

${ }^{347}$ Im Material von Budaörs befanden sich in Grab 238 zwei Exemplare aus Eisen am linken Arm; OтTOMÁNYi 2016, 206.

${ }^{348}$ Grab 63, 96, 102 bzw. Grab 99 (infans I).
${ }^{349}$ Im Gräberfeldmaterial von Esztergom-Bánomi-dülő ist der Eisenarmring auch als Zubehör eines verstorbenen Mannes belegt; KeLEMEN 2008, 138.

${ }^{350}$ KeLemen 2008, 138.

${ }^{351}$ Das Tragen von Knochenarmringen war sowohl in der Rheingegend als auch in den Donauprovinzen ausdrücklich typisch. Erwin Keller geht davon aus, dass das Tragen von Knochenarmringen mit den Germanen bzw. der germanischen Mode in Verbindung gebracht werden kann; KeLLER 1971, 107. Siehe dazu KeLEMEN 2008, 137.

${ }^{352}$ In diesen Fällen ist von einer Präferenz der rechten Hand auszugehen. In der Regel kommen am linken Arm jeweils drei (mindestens ein, höchstens fünf) Exemplare der Knochenarmringe, häufig von Eisenarmringen begleitet, vor.

${ }^{353}$ Diese Beispiele lassen eventuell darauf schließen, dass die Person ein Linkshänder war.

${ }^{354}$ Das früheste Exemplar in Pannonien ist aus einem Grab von Intercisa bekannt (Maximian II.); VÁGÓ-BÓNA 1976, Taf. 24. 1239/8.

${ }^{355}$ FÜLEP 1977, Pl. 15. 2

356 PÉTERFI 1993, Taf. 1. 3/2, Taf. 14. 101/7.

${ }^{357}$ SÁGI 1981, Abb. 36. 89/6a, Abb. 56. 110/6f

${ }^{358}$ KELEMEN 2008, 136.

${ }^{359}$ Die Münzbeigaben der verschiedenen Gräberfelder zeigen ein dem Material von Somogyszil entsprechendes Bild; vgl. Intercisa: VÁGÓ-BóNA 1976, Taf. 24. 1239/7; Bátaszék: PÉTERFI 1993, Taf. 19. 138

Acta Archaeologica Academiae Scientiarum Hungaricae 70, 2019 
Tabelle 12

Verteilung der Knochenarmringe nach Altersgruppe und Tragweise

\begin{tabular}{|c|c|c|c|c|c|}
\hline Grabnummer & Altersgruppe & Stückzahl & \multicolumn{3}{|l|}{ Tragweise } \\
\hline $75 b$ & maturus & 2 & beide Arme & & \\
\hline 40 & adultus & 9 & & \multirow[t]{15}{*}{ linker Arm } & \\
\hline 69 & infans II & 5 & & & \\
\hline 21 & adultus & 4 & & & \\
\hline 25 & iuvenis & \multirow[t]{2}{*}{3} & & & \\
\hline 52 & adultus & & & & \\
\hline 89 & adultus & 2 & & & \\
\hline 34 & \multirow[t]{2}{*}{ infans II } & \multirow[t]{11}{*}{1} & & & \\
\hline 63 & & & & & \\
\hline 67 & \multirow{6}{*}{ adultus } & & & & \\
\hline 68 & & & & & \\
\hline 80 & & & & & \\
\hline 133 & & & & & \\
\hline 143 & & & & & \\
\hline 145 & & & & & \\
\hline 43 & maturus & & & & \\
\hline 102 & infans II & & & & rechter Arm \\
\hline 61 & adultus & & & & \\
\hline
\end{tabular}

\section{Ringe}

Außer drei silbernen und sechs Eisenringen wurden in Somogyszil Ringe aus Bronzeblech oder Bronzedraht gefunden (27 Stück) (Tabelle 13). Sie sind teilweise unverzierte Bandringe, aber den größeren Teil machen Ringe mit runder bzw. ovaler und seltener mit eckiger Ringplatte aus. ${ }^{360}$ Unter den offenen Draht- und Bandringen sind neben den unverzierten Varianten auch mit verschiedenen Kerbungen verzierte Exemplare vorhanden. Die Varianten mit stilisierten Schlangenkopfenden sind bei mehreren Exemplaren meist durch valentinianische Münzen datiert (Grab 25, 71, 79, 80 und 141).

Die meisten Ringe kommen in den Frauen- und Kindergräbern vor (Grab 34 und 52), die auch mit sonstigen Schmuckgegenständen reich ausgestattet sind. In Grab 34 (infans II) kamen fünf Ringe an der linken und einer an der rechten Hand, in Grab 52 (adultus) drei Ringe auf dem Becken des Skeletts zum Vorschein (Tabelle 14). ${ }^{361}$ Bei zwei Frauen (adultus), was Armringe und Fingerringe betrifft, dominieren der linke Arm und die linke Hand (Grab 80 und 89). Außerdem steckte der Ring in mehreren weiteren Fällen an einem Finger der linken Hand. ${ }^{362}$ In Gräbern, zu denen genauere Grabungsbeobachtungen vorliegen, sind Ringe am Mittelfinger der linken bzw. am Mittel- und Ringfinger der rechten Hand belegt. Das häufige Tragen von Armringen am linken Unterarm schloss das Tragen von Fingerringen an der rechten Hand nicht aus (Grab 69, 88). Ringe wurden in lediglich 3 Männergräbern gefunden: in Grab 14 ein Eisenring mit Ringplatte und in den Gräbern 79 und 84 je ein Fingerring aus Bronze in einfacherer Ausführung an der linken Hand.

\section{Sonstige Kleinfunde}

In einigen wenigen Frauengräbern kamen auch kleine Kästchen zum Vorschein (Grab 35, 38, 52). ${ }^{363}$ Eines dieser Gräber, Grab 52, wurde anhand einer Valens-Münze t.p.q. belegt. Aus den anderen beiden Gräbern wurden

${ }^{360}$ Die Ringplatten wurden meist mit gravierten Mustern verziert; die Stücke mit Gemma bzw. die mit Glaseinlage sind lediglich viermal belegt (Silber: Grab 52, 69; Bronze: Grab 30, 38).

${ }^{361}$ Diese dürften zusammen mit den Münzen in einem Geldbeutel hingelegt worden sein.
${ }^{362}$ Das Tragen des Fingerrings an der linken Hand war vor allem westlich von Rätien verbreitet; KONRAD 1997, 175.

${ }^{363}$ Die Kästchen verfügten über keinen Inhalt. Die in den einzelnen Gräbern gefundenen Schmuckgegenstände wurden funktionsgemäß getragen; BURGER 1979, 13. 
Tabelle 13

Verteilung der Ringe nach Material, Typen, Münzspektrum und Geschlecht

\begin{tabular}{|c|c|c|c|c|}
\hline Material & Grabnummer & Typ & Münzspektrum & Geschlecht \\
\hline \multirow[t]{3}{*}{ Silber } & 69 & geschlossen, Draht, mit runder Ringplatte, mit opaler Glaseinlage & \multirow[t]{2}{*}{ konstantinisch } & Kind \\
\hline & 100 & geschlossen, mit ovaler Ringplatte & & \multirow[t]{2}{*}{ weiblich } \\
\hline & 52 & geschlossen, mit runder Ringplatte, Einlage fehlt & valentinianisch & \\
\hline \multirow[t]{6}{*}{ Eisen } & 14 & \multirow[t]{3}{*}{ geschlossen, mit runder Ringplatte } & konstantinisch & männlich \\
\hline & 21 & & \multirow[t]{2}{*}{-} & \multirow[t]{2}{*}{ weiblich } \\
\hline & 89 & & & \\
\hline & 88 & geschlossen (?), aus zwei Drähten, mit runder Ringplatte & konstantinisch & männlich? \\
\hline & 141 & \multirow[t]{2}{*}{ Band } & valentinianisch & weiblich \\
\hline & $142 b$ & & - & Kind \\
\hline \multirow[t]{27}{*}{ Bronze } & \multirow[t]{2}{*}{25} & geschlossen, mit eckiger Ringplatte & \multirow{11}{*}{ konstantinisch } & \multirow{5}{*}{ weiblich } \\
\hline & & unverzierte Reifen & & \\
\hline & \multirow[t]{2}{*}{30} & geschlossen, mit runder Ringplatte (mit Einlage) & & \\
\hline & & geschlossen, Blech, die Mitte mit breiter Fingerplatte & & \\
\hline & 38 & $\begin{array}{l}\text { geschlossen, runde Ringplatte mit Blattmuster umrahmt, Gemma } \\
\text { fehlt }\end{array}$ & & \\
\hline & \multirow[t]{6}{*}{34} & geschlossen, Ringplatte mit Kreisaugen verziert & & \multirow[t]{6}{*}{ Kind } \\
\hline & & geschlossen, mit runder Ringplatte & & \\
\hline & & offen, Blech, verziert & & \\
\hline & & offen, Blech, glatt & & \\
\hline & & offen (?), Band & & \\
\hline & & ?, mit gekerbten Rändern & & \\
\hline & 52 & geschlossen, Reif mit Kanneluren, mit gravierter Ringplatte & \multirow[t]{2}{*}{ valentinianisch } & \multirow[t]{2}{*}{ weiblich } \\
\hline & 52 & \multirow[t]{3}{*}{ geschlossen, mit gravierter Ringplatte } & & \\
\hline & 69 & & \multirow[t]{3}{*}{ konstantinisch } & Kind \\
\hline & \multirow[t]{2}{*}{80} & & & \multirow[t]{5}{*}{ weiblich } \\
\hline & & offen, mit Schlangenkopfenden & & \\
\hline & 89 & geschlossen, mit runder, gravierter Ringplatte & \multirow[t]{3}{*}{-} & \\
\hline & 127 & \multirow[t]{2}{*}{ geschlossen, Draht mit runder gravierter Ringplatte } & & \\
\hline & 133 & & & \\
\hline & 79 & \multirow[t]{2}{*}{ offen, Draht mit Schlangenkopfenden } & 4. Jahrhundert & männlich \\
\hline & 71 & & \multirow[t]{2}{*}{ valentinianisch } & \multirow[t]{2}{*}{ weiblich } \\
\hline & 141 & offen, Blech mit Schlangenkopfenden & & \\
\hline & 6 & offen, mit Kerbungen & konstantinisch & \multirow[t]{2}{*}{ Kind } \\
\hline & 96 & offen, Band, mit Kerbungen verziert & - & \\
\hline & 84 & ?, Draht, unverziert & \multirow[t]{3}{*}{ valentinianisch } & männlich \\
\hline & 68 & Draht (verloren) & & weiblich \\
\hline & 26 & offen, mit Schlangenkopfenden & & \\
\hline
\end{tabular}

Münzen der konstantinischen Dynastie zutage gefördert. In unseren Fällen kamen sie in der Oberschenkel- und Beckengegend ans Tageslicht. ${ }^{364}$ Aus Grab 35 stehen uns unverzierte eiserne Platten, Haken und Schlüssel zur Verfügung. In Grab 38 befanden sich Schloss und Schlüssel, in Grab 52 allein ein Eisenschlüssel.

Das Gräberfeldmaterial von Somogyszil bekräftigt die Annahme, dass die Pinzetten kein geschlechtsspezifisches Charakteristikum tragen. Ein Vertreter aus Bronze gehört zum Inventar des Frauengrabes 95 und eine eiserne Variante ist aus dem Männergrab 124 bekannt geworden.

${ }^{364}$ Die meisten pannonischen Beispiele weisen auf eine

Position in der Fußgegend hin; MülLER 2010, 227. 
Tabelle 14

Verteilung der Ringe nach Altersgruppe und Tragweise

\begin{tabular}{|c|c|c|c|c|}
\hline Grabnummer & Altersgruppe & Linke Hand (Stückzahl) & Rechte Hand (Stückzahl) & Ohne Angabe (Stückzahl) \\
\hline $142 \mathrm{~b}$ & infans I & 1 & & \\
\hline 34 & \multirow[t]{4}{*}{ infans II } & 5 & 1 & \\
\hline 69 & & 1 (mittlerer Finger) & 2 & \\
\hline 6 & & & 1 & \\
\hline 96 & & & & 1 \\
\hline 30 & \multirow[t]{3}{*}{ iuvenis } & 2 & & \\
\hline 26 & & 1 & & \\
\hline 25 & & & & 2 \\
\hline 52 & \multirow[t]{12}{*}{ adultus } & & & 3 wohl in einem Beutel \\
\hline 80 & & 2 & & \\
\hline 141 & & & & \\
\hline 89 & & 1 (mittlerer Finger) & 1 (Ringfinger) & \\
\hline 127 & & & & \\
\hline 21 & & & 1 (mittlerer Finger) & \\
\hline 133 & & & 1 (Ringfinger) & \\
\hline 38 & & 1 & & \\
\hline 84 & & & & \\
\hline 88 & & & 1 & \\
\hline 14 & & & & 1 \\
\hline 68 & & & & \\
\hline 100 & adultus-maturus & & & \\
\hline 71 & \multirow[t]{2}{*}{ maturus } & 1 (mittlerer Finger) & & \\
\hline 79 & & 1 & & \\
\hline
\end{tabular}

Die einfachen Tiegellampen mit sackförmigem Behälter und vertikal gelochtem Griffzapfen (Typ Loeschke XIIIb) aus Grab 102 (2 Stück, handgearbeitet) und 143 sind aus grobem Ton gefertigt. ${ }^{365}$ In den spätrömischen Grabinventaren Pannoniens trifft man selten Tonlampen. ${ }^{366}$ Im Mädchengrab 102 lag sie zwischen den Füßen, im Frauengrab 143 zwischen den Knien.

\section{SPEZIFIKA DER MÄNNER- UND FRAUENGRÄBER VON SOMOGYSZIL}

Die statusanzeigenden Elemente der männlichen Tracht bildeten in der Regel das an der rechten - seltener an der linken - Schulter mit einer Fibel befestigte, mantelartige Kleidungsstück und der Gürtel mit Zubehör, die in 11 Gräbern von Somogyszil gemeinsam registriert werden konnten (Tabelle 17 im Anhang). Diese Bestatteten gehörten verschiedenen Altersgruppen an, vom iuvenis- (Grab 81, 112) über adultus- (Grab 15, 84, 140) und maturus(Grab 14, 33, 39, 79, 114) bis zum senilis-Alter (Grab 19). Unter den männlichen Gräbern mit Fibel und Gürtel wurde eine Beigabe von Fingerringen dreimal beobachtet. Im Grab 79 und 84 handelt es sich um Bronzeringe, die an der linken Hand getragen wurden. Der Verstorbene aus Grab 14 trug einen Fingerring aus Eisen (ohne weitere Angaben). In anderen Männergräbern tauchen keine Fingerringe auf. Allein vier Männer haben Gürtel mit Riemenzungen, aber ohne Gürtelbeschläge getragen - diese letztere Fundgruppe ist in Somogyszil nicht belegt (Grab 54, 79, 81, 84). In Grab 54 beruhte ein Kind im infans II-Alter; der Gürtel mit Schnalle und Riemenzunge wurde auf der linken Seite der Beine platziert. In der Mehrheit der Fälle wies die Lage der Gürtelbestandteile im Grab - unabhängig vom Alter der Bestatteten - auf einen parallel oder quer über dem Leib gelegten Gürtel hin. Zwei Schnallen kamen in vier

${ }^{365}$ Die Tiegellampen waren wohl im gesamten Imperium verbreitet und es handelt sich um einen langlebigen Typ. Siehe dazu: http://www.getty.edu/publications/ancientlamps/catalogue/461 (28. 11. 2018). Die chronologischen Rahmen unserer Exemplare liegen weit über den Datierungsvorschlägen.
${ }^{366}$ Die pannonischen Beispiele sind von Márta Kelemen zusammengestellt; KELEMEN 2008, 148, Anm. 718, mit betreffender Literatur. 
Gräbern vor (Grab 14, 33, 81, 114). Etwa in gleicher Anzahl treten Gräber auf, in denen entweder Gürtelteile oder eine Fibel vorhanden waren. Bei den Bestatteten handelte es sich sowohl um Kinder als auch um Erwachsene.

Die in den Männergräbern gefundenen Gewandnadeln sind größtenteils durch die Zwiebelknopffibeln, zum geringeren Teil durch Bügelknopf- oder Ringfibeln repräsentiert. Einzelne Männergräber mit Zwiebelknopffibeln sind meistens von ,ärmlicheren“ Männer- und Frauengräbern umgeben. Anhand dieser Situation ist davon auszugehen, dass im Gräberfeld vor allem mit Männern der Militär- oder Beamtenkreise sowie deren Familienangehörigen (Frauen und Kinder mit Schmuck) zu rechnen ist.

Vier Gräber, je von zwei erwachsenen Frauen im adultus-Alter (Grab 38 und 52) mit valentinianischen Prägungen bzw. von zwei Mädchen im infans II-Alter (Grab 34 mit konstantinischen Münzen und 96), gehören zu den mit Tracht und Schmuck am reichsten ausgestatteten Frauen- und Mädchengräbern (Tabelle 18 im Anhang). Diese Verstorbenen wurden mit Kopf-, Ohr-, Hals-, Arm- und Handschmuck bestattet. Auffallend sind die hohe Anzahl von Armringen und die mittelhohe Anzahl von Fingerringen. In Grab 52 befanden sich sieben Arm- und drei Handschmuckstücke. In Grab 96 gab es sieben Armringe und einen Handschmuck. In Grab 34 wurden fünf Armringe und sechs Fingerringe gefunden und ebenfalls fünf Armringe sowie ein Fingerring kamen in Grab 38 zum Vorschein. Von sechs Fingerringen wurden fünf an der linken Hand getragen. In Grab 52 wurden sie wohl in einem Beutel ins Grab gelegt. In Grab 96 des Kindes im infans II-Alter gab es neben dem Kopf- und Halsschmuck sieben Armringe und einen Handschmuck.

Der Schleier (Mantel?) der Frau in Grab 52 (adultus) und des Mädchens in Grab 34 (infans II) wurde jeweils mit einer Fibel (Scheiben- und Ringfibel) unter dem Kinn angesteckt. In beiden Gräbern sind auch Haarnadeln belegt. Ebenfalls als reich zu bezeichnen sind die Gräber von drei Frauen im adultus-Alter (Grab 68, 141 und 145), eines Kindes (infans II, Grab 69) sowie einer jungen Frau (iuvenis, Grab 25) ${ }^{367}$ Etwas ärmlicher sind die mit einer Kombination von Ohr-, Arm- und Handschmuck bzw. Ohr-, Hals- und Armschmuck oder Hals-, Arm- und Handschmuck bestatteten Toten. Als noch bescheidener gilt der Schmuckbestand bei den Frauen, denen nur Hals- und Armschmuck beigesetzt wurde. Hier handelt es sich um die Schmuckstücke von zwei Verstorbenen im infans II(Grab 102 und 125), von fünf Frauen im adultus- (Grab 31, 37, 77, 129 und 143), von einer Frau im maturus- (Grab 43), von vier Frauen im senilis-Alter (Grab 2, 8, 35) sowie um die Bestattung einer jungen Frau im iuvenis-Alter (Grab 148) mit Ohr- und Armschmuck. Schließlich wurden mehrere Frauen im adultus-Alter (Grab1, 20, 61, 108, $115,128,137)$ lediglich mit Armringen geschmückt. Zwei Fingerringe befanden sich an der linken Hand einer Frau im iuvenis-Alter (Grab 30) und ein einziger Ring einer jungen Frau ebenfalls im iuvenis-Alter in Grab 26.

Im Gräberfeld von Somogyszil gilt die Fibeltracht der Frauen in Grab 44 mit Stützarmfibel bzw. in Grab $75 \mathrm{~b}$ mit paarweise getragenen Fibeln mit umgeschlagenem Fuß als Einzelfall, die die Kontakte des Provinzgebietes mit den Barbarenstämmen von Germanen und Sarmaten anzeigen. ${ }^{368}$ Von den Geschlechtern und dem Alter unabhängige Trachtbestandteile waren die Ringfibeln. Schnallen sind in Form eines fragmentarischen Schnallenbügels unter den Frauengräbern nur einmal belegt (Grab 67). Das Gräberfeldmaterial spiegelt das für pannonische Provinzen charakteristische Keramik- und Glasgefäßspektrum des 4. Jahrhunderts wider.

Das unter der konstantinischen Dynastie eröffnete Gräberfeld konnte als Bestattungsort einer kleinen ländlichen Gemeinschaft dienen. Unter der Bevölkerung rechnet man anhand der Fibeln und Gürtelgarnituren mit mehreren Personen aus dem Militär- oder Beamtenkreis und deren Familienmitgliedern. Die meisten Bestattungen fanden in der Mitte und zweiten Hälfte des 4. Jahrhunderts statt. Die Belegung des Gräberfeldes ist bis zu den ersten Jahrzehnten des 5. Jahrhunderts zu vermuten.

Als typisch westgermanische Funde aus dem Gräberfeld sind Bügelknopffibeln, Stützarmfibel zu nennen. Die Beziehungen mit den Sarmaten sind anhand der Tragweise der mit Perlen geschmückten Kleider und Fibeln mit umgeschlagenem Fuß wahrnehmbar. Feuerzeuge mit Messern und eisernen Ahlen in und an einer am Gürtel befestigten Tasche sowie Spinnwirtel, Bernstein- und Korallenperlen sind solche Phänomene in den Gräbern, die grundsätzlich an Fundorten zu registrieren sind, wo man mit barbarischer Präsenz rechnet. Der barbarisch geprägte Fundstoff setzt sich bereits im ersten Drittel, in der Mitte des 4. Jahrhunderts ein. In dieser Phase können die Verbindungen einerseits mit den germanischen Territorien durch das Militär und andererseits mit den provinzialrömischen Territorien in südlicher Richtung betont werden. Die spätsarmatischen Einflüsse lassen sich in unserem Fall

${ }^{367}$ Die reiche Ausstattung von Frauengräbern mit Schmuck

${ }^{368}$ HoRvÁTH et al. 2018, 50-52. hält Michaela Konrad für ein Spezifikum der donauländischen Provinzen; KONRAD 1997, 176. 
mit der späteren Phase des Gräberfeldes verbinden. Die Gräber mit fremden Charakterzügen in Somogyszil setzen sich nicht durch eine von den gleichzeitigen Bestattungen mit provinzialrömischen Geprägen separierte Lage ab. In den Gräbern mit fremdem Fundstoff zeigt sich eine Angleichung an römische Tracht- und Beigabensitten und es ist zu vermuten, dass die Bevölkerung von barbarischer Abstammung im behandelten Zeitraum dem provinzialrömischen Gemeinwesen mehr oder weniger angepasst war.

ANHANG

Tabelle 15

Ausstattung der Frauengräber mit Gefäßbeigaben

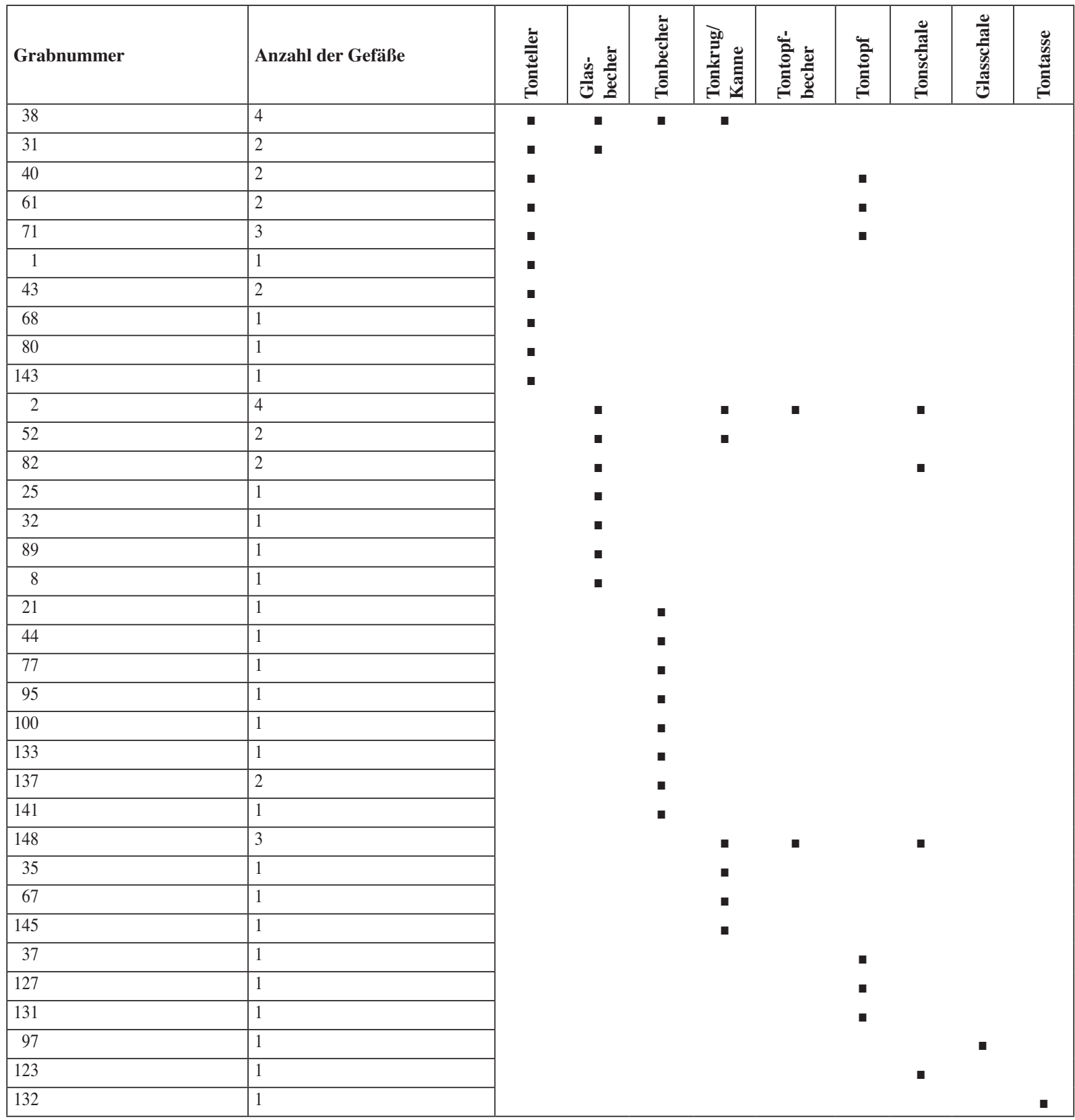


Tabelle 16

Ausstattung der Männergräber mit Gefäßbeigaben

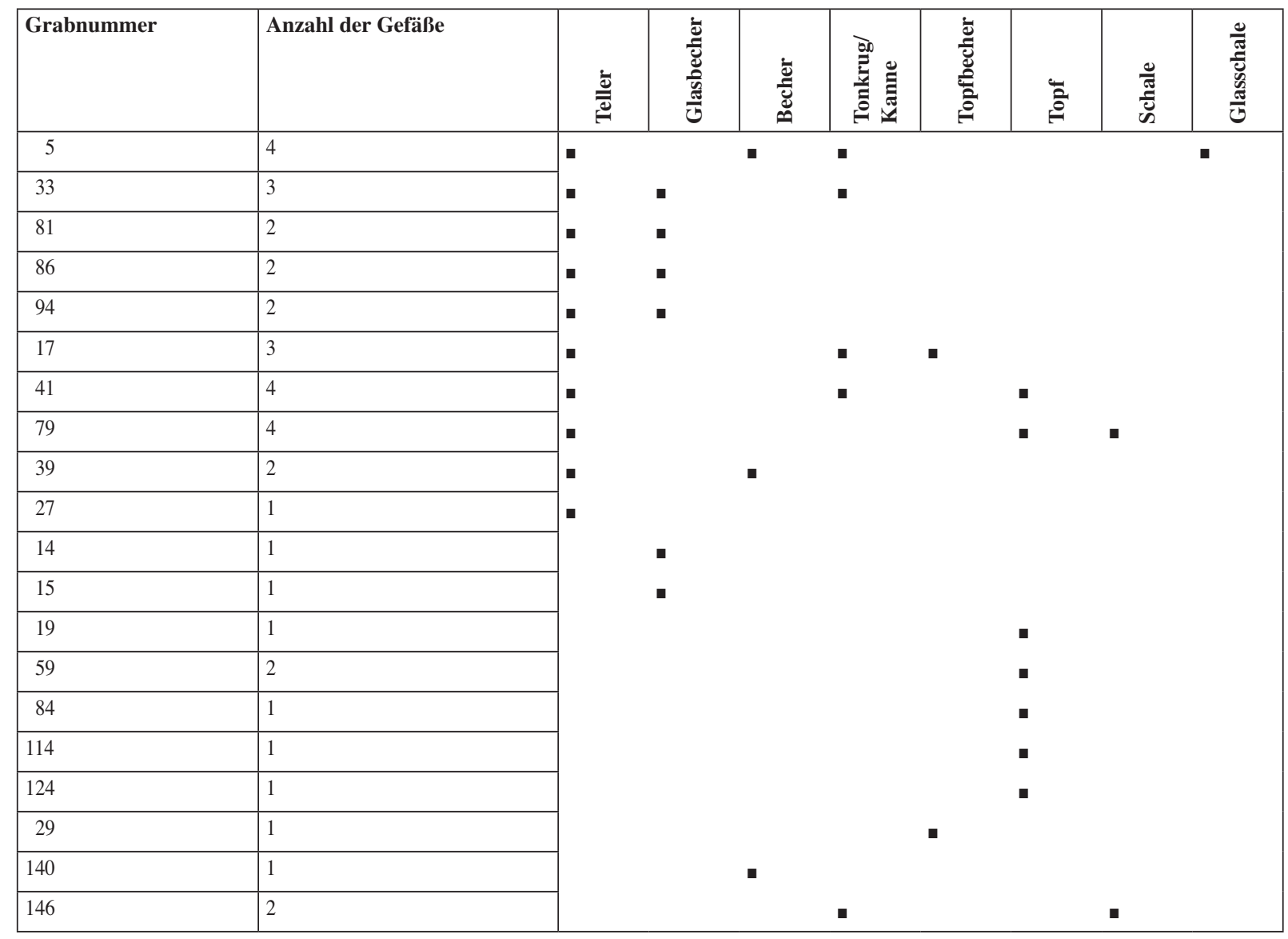


Tabelle 17

Kombination der männlichen Trachtzubehöre mit der Altersgruppe

\begin{tabular}{|c|c|c|c|c|c|c|}
\hline Grabnummer & Altersgruppe & \multicolumn{5}{|c|}{ Kombination der männlichen Trachtzubehöre } \\
\hline 81 & iuvenis & \multirow[t]{3}{*}{ Fibel Schnalle Riemenzunge } & & & & \\
\hline 84 & adultus & & & & & \\
\hline 79 & maturus & & & & & \\
\hline 112 & iuvenis & & Fibel Schnalle & & & \\
\hline 15 & \multirow[t]{2}{*}{ adultus } & & & & & \\
\hline 140 & & & & & & \\
\hline 14 & adultus/maturus & & & & & \\
\hline 33 & \multirow[t]{3}{*}{ maturus } & & & & & \\
\hline 39 & & & & & & \\
\hline 114 & & & & & & \\
\hline 19 & senilis & & & & & \\
\hline 54 & infans II & & & Schnalle Riemenzunge & & \\
\hline 65 & infans I? & & & & Fibel & \\
\hline 122 & infans I & & & & & \\
\hline 134 & infans II & & & & & \\
\hline $5 \mathrm{a}$ & \multirow[t]{3}{*}{ adultus } & & & & & \\
\hline 27 & & & & & & \\
\hline 130 & & & & & & \\
\hline 41 & \multirow[t]{5}{*}{ maturus } & & & & & \\
\hline 46 & & & & & & \\
\hline 48 & & & & & & \\
\hline 60 & & & & & & \\
\hline 117 & & & & & & \\
\hline 98 & Erwachsener & & & & & \\
\hline 42 & \multirow[t]{4}{*}{ infans II } & & & & & Schnalle \\
\hline 110 & & & & & & \\
\hline $142 \mathrm{a}$ & & & & & & \\
\hline 107 & & & & & & \\
\hline 86 & iuvenis & & & & & \\
\hline 94 & \multirow[t]{3}{*}{ adultus } & & & & & \\
\hline $113 a$ & & & & & & \\
\hline 53 & & & & & & \\
\hline 3 & \multirow[t]{5}{*}{ maturus } & & & & & \\
\hline 7 & & & & & & \\
\hline 29 & & & & & & \\
\hline 72 & & & & & & \\
\hline 144 & & & & & & \\
\hline
\end{tabular}


Tabelle 18.

Kombination der weiblichen Kleidungszubehöre und Schmuck mit der Altersgruppe

( $i I=$ infans $I, i I I=$ infans $I I$, iuv = iuvenis, ad=adultus, mat= maturus, sen= senilis, Kopf $=$ Stirnband, Ohr=Ohrringe,

Hals $=$ Hals- und/oder Kleidungsschmuck, Arm=Armringe, Hand=Ringe)

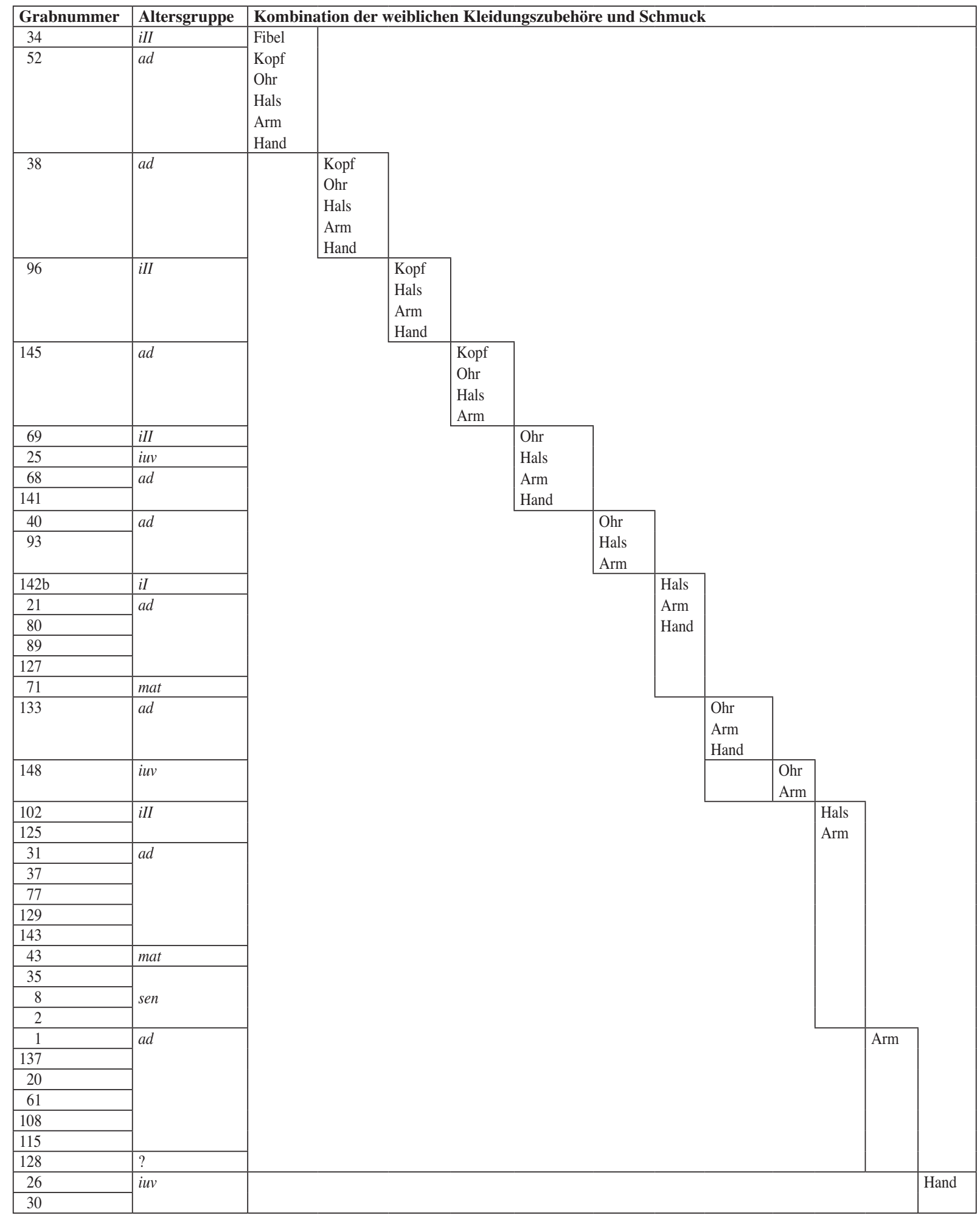


BÁNKI 1968

BARKÓCZI 1988

BARKÓCZI 1994

BARKÓCZI-BÓNIS 1954

BARTUS 2007

BEMMANN 2008

BíRÓ 2011

BORUZS 2016

BORUZS-SZABÓ 2018

BÖHME 1974

BÖHME 1986

BÖHME 1999

BÖHME 2012

BRIESKE 2001

BRIESKE 2010

BURGER 1963

BuRger 1966

BURGER 1972

BURGER 1979

Capelle 1996

Cavada 1999

Clarke 1979

Coale-Demeny 1966

CocIŞ 2004

DÉVAI 2012

\section{LITERATUR}

= Zs. BÁNKI: Későrómai sírok Tordason (Das spätrömische Gräberfeld von Tordas). Alba Regia 8-9 (1967-1968) [1968] 233-240.

= L. BARKóCZI: Pannonische Glasfunde in Ungarn. StudArch 9. Budapest 1988.

= L. BARKÓCZI: Beiträge zur Geschichte der Provinz Valeria im IV.-VI. Jh. SpecN 20 (1994) 57-136.

= L. BARKóCZI-É. BóNIS: Das frührömische Lager und die Wohnsiedlung von Adony (Vetus Salina), ActaArchHung 4 (1954) 129-199.

= D. BARTUS: A csontból és egyéb nyersanyagokból készült római kori figurális díszitésű hajtűk és késnyelek kapcsolatrendszerének összehasonlító elemzése. A római kori csontfaragás és a kismüvészetek összefüggései [Vergleichende Analyse der Beziehungen zwischen den Haarnadeln mit figürlichen Darstellungen aus Knochen und sonstigen Materialien und den Messergriffen. Römische Knochenschnitzerei und die kleinen Künste]. Manuskript, PhD-Dissertation an der Eötvös Loránd Universität, Fakultät für Geisteswissenschaften. Budapest 2007.

$=$ J. BEMMANN: Anmerkungen zu einigen Kleinfunden der jüngeren römischen Kaiserzeit und Völkerwanderungszeit aus Mitteldeutschland. In: The Turbulent Epoch. II.: New materials from the Late Roman Period and the Migration Period. Eds: B. Niezabitowska-Wiśniewska, M. Juściński, P. Łuczkiewicz, S. Sadowski. Monumenta Studia Gothica 5. Lublin 2008, 21-38.

$=$ M. T. Bíró: A guzsaly és orsó szerepe a római temetkezési kultuszban [Die Rolle der Spinnrocken und Spinnwindel im römischen Bestattungskult]. Orpheus Noster 3/1. 63-74.

= K. Boruzs: A budaörsi temető üveg és üvegpaszta mellékletei [Beigaben aus Glas und Glaspaste im Gräberfeld von Budaörs]. In: A budaörsi római vicus temetője. Régészeti tanulmányok. Hrsg.: K. Ottományi. Budapest 2016, 373-395.

= K. Boruzs-G. Szabó: Late Roman Graves in Dombóvár. In: Fiatal Római Koros Kutatók 4. Konferenciakötete - Proceedings of the Conference for Young Researchers of Roman Age. Eds: D. Bartus, K. Boruzs. DissArch Supplementum 1. Budapest-Visegrád 2018, 197-242.

$=$ H. W. BöHME: Germanische Grabfunde des 4. bis 5. Jahrhunderts zwischen unterer Elbe und Loire. Studien zur Chronologie und Bevölkerungsgeschichte. München 1974.

= H. W. BöHME: Das Ende der Römerherrschaft in Britannien und die angelsächsische Besiedlung Englands im 5. Jahrhundert. JRGZM 33 (1986) 469-575.

= H. W. BöHME: Sächsische Söldner im römischen Heer. Das Land zwischen Ems und Niederelbe während des 4. und 5. Jahrhunderts. In: Über allen Fronten. Nordwestdeutschland zwischen Augustus und Karl dem Großen. Sonderausstellung, Staatliches Museum für Naturkunde und Vorgeschichte Oldenburg, vom 3. Oktober bis 21. November 1999. Hrsg.: F. Both, H. Aouni. Oldenburg 1999, 49-73.

= H. W. BöHME: Spätrömische Zwiebelknopffibeln in der Germania magna zwischen Rhein und Oder. In: Hunde - Menschen - Artefakte: Gedenkschrift für Gretel Gallay. Hrsg.: B. Ramminger, H. Lasch. IntArch Studia honoraria 32. Rahden 2012, 307-323.

= V. BRIESKE: Eine spätrömische Stützarmfibel aus Werther-Isingdorf, Kreis Gütersloh. AiO 6 (2001) 44-47.

= V. BRIESKE: Neue Sondenfunde spätkaiserzeitlicher Stützarmfibeln aus Westfalen. AiWL (2010) 103-106.

= A. Sz. Burger: A bogádi későrómai temető (Das spätrömische Gräberfeld von Bogád). JPMÉ (1962) [1963] 111-136.

= A. Sz. BuRgER: The late Roman cemetery at Ságvár. ActaArchHung 18 (1966) 99-234.

= A. Sz. Burger: Rómaikori temető Majson (Ein römerzeitliches Gräberfeld in Majs). ArchÉrt 99 (1972) 64-100.

= A. Sz. Burger: Das spätrömische Gräberfeld von Somogyszil. FontArchHung. Budapest 1979.

= T. CAPELlE: Fußring. RGA 10. Berlin 1996, 272-273.

= E. CAVADA: Complementi dell'abbigliamento maschile e militaria tardoantichi (fine IV-V secolo d. C.) nelle valli alpine centrorientali (bacini del Sarca e dell'Adige). In: Le fortificazioni del Garda e i sistemi di difesa dell'Italia settentrionale tra tardo anticho e alto Medioevo: 2o Convegno Archeologico del Garda, Gardone Riviera (Brescia), 7-9 ottobre 1998. Ed.: G. P. Brogiolo. Documenti di archeologia 20. Mantova 1999, 93-108.

= G. ClaRKE: Pre-Roman and Roman Winchester. 2.: The Roman Cemetery at Lankhills. Winchester studies 3. Oxford 1979.

= A. J. Conle-P. G. Demeny: Regional Model Life Tables and Stable Populations. Princeton 1966.

= S. Cocış: Fibulele din Dacia Romană - The Brooches from Roman Dacia. BiblEphNapoc 3. ClujNapoca 2004.

= K. DÉvaI: Késő római temetkezések üvegmellékletei Pannoniában. Üvegedények a mai Magyarország területéről I [Glasgefäßbeigaben in den spätrömischen Gräberfeldern Pannoniens. Glasge- 
DomBAY 1957

Doneus 2014

DROBERJAR 2015

EKE-HoRVÁTH 2010

ÉVINGER-BERNERT 2019

FASOLD 1992

FITZ 1978

FRIESINGER 1984

FÜLEP 1977

GENČEVA 2004

GROLLER 1908

GSCHWANTLER-WINTER 1989-1990

GuI 2015

HARTYÁNI-NOVÁKI 1975

HENDZSEL et al. 2008

HOEPER 2003

HORVÁTH 2016

HoRvÁTH et al. 2018

ISTVÁNOVITS-KULCSÁR 2018

IVANIŠEVIĆ-KAZANSKI-MASTYKOVA 2006 = V. IVANIŠEVIĆ-M. KAZANSKI-A. MASTYKOVA: Les nécropoles de Viminacium à l'époque des Grandes Migrations. Collége de France CNRS Centre de Recherche d'Histoire et Civilisation de Byzance, Monographies 22. Paris 2006.

JoBST 1975

KALTOFEN 1984

KELEMEN 2008

KELLER 1971

KELLER 1979

KLEEMANN 2015

fäße aus dem Gebiet Ugarns I]. Manuskript. PhD-Dissertation an der Eötvös Loránd Universität, Fakultät für Geisteswissenschaften. Budapest 2007.

= J. DoMBAY: Késő római temetők Baranyában (Spätrömische Friedhöfe im Komitat Baranya). JPMÉ 2 (1957) 181-330.

= N. DoNEus: Halbturn I - Ein römerzeitliches Gräberfeld aus dem Burgenland. Struktur und Grabrituale eines ländlichen Gräberfeldes im Hinterland von Carnuntum zwischen dem 2. und 5. Jahrhundert. In: Das kaiserzeitliche Gräberfeld von Halbturn, Burgenland 1-4. Hrsg.: N. Doneus. Monographien des RGZM 122/1. Mainz 2014, 1-230.

= E. DROBERJAR: Cizorodý nálezový soubor z konce doby ř́mske až počátku doby stěhování národů z Pšovlk, Okr. Rakovník (Ein fremdartiger Fundkomplex vom Ende der römischen Kaiserzeit bis Anfang der Völkerwanderungszeit aus Pšovlky, Bez. Rakovník). ArchSC 19 (2015) 707-729.

= I. EKE-L. HoRvÁTH: Késő római temetők Nagykanizsán (Anyagközlés) [Spätrömische Gräberfelder in Nagykanizsa (Materialveröffentlichung)]. ZalaiMúz 19 (2010) 155-227.

$=\mathrm{S}$. ÉVINGER-Zs. BERNERT: Anthropological assessment of the late Roman cemetery at SomogyszilDögkuti dülő. ActaArchHung 70 (2019) 137-166.

= P. FASOLD: Römischer Grabbrauch in Süddeutschland. Schriften des Limesmuseums Aalen 46. Stuttgart 1992.

= J. FitZ: Forschungen in Gorsium im Jahre 1976. Alba Regia 17 (1976) [1978] 191-243.

$=\mathrm{H}$. FrIESINGER: Bemerkungen zu den frühgeschichtlichen Grab- und Siedlungsfunden von WienLeopoldau. ArchA 68 (1984) 127-154.

= F. FüLEP: Roman Cemeteries on the Territory of Pécs (Sopianae). FontArchHung. Budapest 1977.

= E. GENČEVA: Rimskite fibuli ot Bălgaria: ot kraja na I. v. v. pr. n. e. do kraja na VI. v. n. e. - Les fibules romaines de Bulgarie de la fin du $\mathrm{I}^{\mathrm{er}}$ s. av. J.-C. à la fin du VI ${ }^{\mathrm{e}}$ s. ap. J.-C. Veliko Tarnovo 2004.

$=$ M. V. GROLLER: Die Grabungen in Carnuntum. RLÖ 9 (1908) 1-80.

= K. GsChWANTLER-H. WinteR: Bronzewerkstätten in der Austria Romana. Ein Forschungsprojekt. RÖ 17-18 (1989-1990) 107-142.

= M. GuI: How to wear the Ringschnallencingulum in Dacia. In: Ad Finem Imperii Romani. Studies in Honour of Coriolan H. Opreanu. Eds: S. Cociş, V.-A. Lăzărescu, M. Gui, D.-A. Deac. BiblEphNapoc 8. Cluj-Napoca 2015, 175-181.

= B. P. HARTYÁNI-Gy. NovÁKI: Samen- und Fruchtfunde in Ungarn von der Neusteinzeit bis zum 18. Jahrhundert. AgrSz 17 (1975) Suppl., 1-65.

= I. Hendzsel-E. Istvánovits-V. KulcsáR-D. Ligeti-A. ÓváRI-J. PÁsZtóKAi-SzeÖKe: "On the borders of East and West": A reconstruction of Roman provincial and barbarian dress in the Hungarian National Museum. In: Dressing the Past. Eds: M. Gleba, Ch. Munkholt, M.-L. Nosch. Ancient textiles series 3. Oxford 2008, 29-42.

= M. HoEPER: Völkerwanderungszeitliche Höhenstationen am Oberrhein. Geißkopf bei Berghaupten und Kügeleskopf bei Ortenberg. Archäologie und Geschichte. Freiburger Forschungen zum ersten Jahrtausend in Südwestdeutschland 12. Ostfildern 2003.

$=$ F. HORVÁtH: Eine besondere Gruppe der spätrömischen Keramik mit polierter Oberfläche. Beiträge zu den römisch-barbarischen Beziehungen. Antaeus 34 (2016) 41-106.

= F. Horváth-A. MihÁCZI-PÁLFI-S. Évinger-Zs. Bernert: Barbarisierte Römer - Romanisierte Barbaren? Interpretationsmöglichkeiten der fremden Komponente am Beispiel des Gräberfeldes von Somogyszil. Antaeus 35-36 (2017-2018) [2018] 39-65.

= E. ISTVÁNOVITS-V. KULCSÁR: „,... Aligha állhat nekik bármely csatarend ellent.” Egy elfelejtett nép, E. ISTVÁNOVITS-V. KULCSÁR:, „... Aligha állhat nekik barmely

= W. JOBST: Die römischen Fibeln aus Lauriacum. FiL 10. Linz 1975.

= A. KALTOFEN: Studien zur Chronologie der Völkerwanderungszeit im südöstlichen Mitteleuropa. BAR IntSer 191. Oxford 1984.

= M. H. KeLEMEN: Solva. Esztergom későrómai temetői (Die spätrömischen Gräberfelder von Esztergom). Libelli archaeologici 3. Budapest 2008.

= E. KelLER: Die spätrömischen Grabfunde in Südbayern. MBV 14. München 1971.

= E. KELLER: Das spätrömische Gräberfeld von Neuburg an der Donau. MhBV A/40. Kallmünz/Opf. 1979.

= J. KLEEMANN: Hospes: Archäologische Aspekte zur Integration von Barbaren in das römische Imperium. Eine vergleichende Betrachtung zur Beigabensitte in gallischen und pannonischen Provinzen. In: Romania Gothica. 2.: The Frontier World. Romans, Barbarians and Military Culture. Proceedings of the International Conference at the Eötvös Loránd University, Budapest, 1-2 October 2010. Ed.: T. Vida. Budapest 2015, 499-515. 
134

Косн 1974

KONRAD 1997

KoŠČEVIĆ 1980

KOVRIG 1937

KULCSÁR 1998

LAKATOS 1956

LÁNYI 1972

LÁNYI 1980

LÁNYI 1981

LÁNYI 1990

LÁSZLÓ 2011

MADARASSY 1999

MADARASSY 2000

MARTIN 1991

MERCZI 2000

MERCZI 2010

MERCZI 2012

MERCZI 2016

MEYER 1960

MÜLlER 1998

MüLleR 2009

MÜLleR 2010

MÜLLER 2011

MÜLLER 2017

NÁDORFI 1996

NAGY 2005

NAGY 2014

\section{FRIDERIKA HORVÁTH - ANETT MIHÁCZI-PÁLFI}

$=$ R. KосH: Spätkaiserzeitliche Fibeln aus Süddeutschland. In: Studien zur vor- und frühgeschichtlichen Archäologie 1. Festschrift für Joachim Werner zum 65. Geburtstag. Hrsg.: G. Kossack, G. Ulbert. MBV Ergänzungsband 1/I-II. München 1974, 227-246.

= M. KONRAD: Das römische Gräberfeld von Bregenz-Brigantium I: Die Körpergräber des 3. bis 5. Jahrhunderts. MBV 51. München 1997.

= R. KoščEvić: Antičke fibule s područja Siska - Roman Fibulae from Siscia. Zagreb 1980.

= I. Kovrig: Die Haupttypen der kaiserzeitlichen Fibeln in Pannonien. DissPann II/4. Budapest 1937.

= V. KulCSÁR: A Kárpát-medencei szarmaták temetkezési szokásai (The Burial Rite of the Sarmatians of the Carpathian Basin). Múzeumi füzetek 49. Aszód 1998.

= P. LAKATOS: Római sírlelet Márok község határában [Römischer Grabfund im Gebiet der Gemeinde Márok]. JPMÉ 1 (1956) 167-170.

= V. LÁNYI: Die spätantiken Gräberfelder von Pannonien. ActaArchHung 24 (1972) 53-213.

= V. LÁNYI: A. Sz. Burger, Das spätrömische Gräberfeld von Somogyszil. Besprechungen. AR 18 (1977-1978) [1980] 344-345.

= V. LÁNYI: Das spätrömische Gräberfeld. In: Die spätrömische Festung und das Gräberfeld von Tokod. Hrsg.: A. Mócsy. Budapest 1981, 169-221.

= V. LÁNYi: Temetkezés és halottkultusz [Bestattung und Totenkult]. In: Pannonia régészeti kézikönyve. Hrsg.: A. Mócsy, J. Fitz. Budapest 1990, 243-253.

= J. LÁsZLÓ: Római kori villagazdaság vaseszközei Tatabánya-Felső-Rét-földről [Eisengeräte einer römischen Villenwirtschaft von Tatabánya-Felső-Rét-föld]. KMMK17 (2011) 151-170.

= O. MADARASSY: Újabb eredmények a katonaváros nyugati szélének kutatásában (Recent results of research along the western edge of the Military Town). AqFüz 5 (1999) 57-64.

$=$ O. MADARASSY: Kutatások az aquincumi katonaváros déli részén (Research in the southern part of the Aquincum Military Town). AqFüz 7 (2000) 38-43.

= M. MARTin: Das spätrömisch-frühmittelalterliche Gräberfeld von Kaiseraugst, Kr. Aargau. Basler Beiträge zur Ur- und Frühgeschichte 5. Derendingen-Solothurn 1991.

= M. MERCZI: Római kori gyürüfibulák Komárom-Esztergom megyéből (Römerzeitliche Ringfibeln aus dem Komitat Komárom-Esztergom). KMMK 7 (2000) 253-287.

= M. MERCzI: Valeria tartomány északi felének embertani képe a késő római korban (Tác-Margittelep és az északi határvidék összevetése) (The late Roman population of the Nothern part of Valeria). Alba Regia 39 (2010) 69-86.

= M. Merczi: A Budaörs-Kamaraerdei dülöben feltárt római vicus fibulái (Die Fibeln des römischen Vicus in Budaörs-Kamaraerdei dülő). In: Római vicus Budaörsön. Régészeti tanulmányok. Hrsg.: K. Ottományi. Budapest 2012, 473-528.

= M. MerCZI: A Budaörs-Kamaraerdei dülőben feltárt római temető fibulái (Fibeln des römischen Gräberfeldes von Budaörs-Kamaraerdei Flur. Bewertung des Fundmaterials der Siedlung und des Gräberfeldes). In: A budaörsi római vicus temetője. Régészeti tanulmányok. Hrsg.: K. Ottományi. Budapest 2016, 432-489.

= E. MEYER: Die Bügelknopffibeln. AFD 8 (1960) 216-349.

= R. MÜLLER: Ein frühvölkerwanderungszeitliches Grab aus Sármellék-Égenföld. SpecN 12 (1998) 259-263.

= R. MÜLLER: Guzsalyok és orsógombok Pannóniában [Spinnrocken und Spinnwirtel in Pannonien]. ZalaiMúz 18 (2009) 39-54

= R. MüLLER: Die Gräberfelder vor der Südmauer der Befestigung von Keszthely-Fenékpuszta. CPP 1. Budapest-Leipzig-Keszthely-Rahden/Westf. 2010.

$=$ R. MÜLLER: Spinnrocken aus Metall und Spinnwirtel im spätkaiserzeitlichen Pannonien. ActaArchHung 62 (2011) 175-198.

$=\mathrm{R}$. MüLLER: Cece vagy guzsaly, radius vagy colus? Textilgyártás és a Balaton vízállása a 4. században (Pin-beater or distaff, radius or colus? Textile production and the water level of Lake Balaton in the 4th century). ZalaiMúz 23 (2017) 145-162.

= G. NÁDORFI: Das hunnenzeitliche Gräberfeld von Csákvár. In: Hunnen + Awaren. Reitervölker aus dem Osten: Burgenländische Landesausstellung 1996, Schloss Halbturn, 26. April-31. Oktober 1996. Begleitbuch und Katalog. Hrsg.: F. Daim. Eisenstadt 1996, 96-99.

= M. NAGY: Zwei spätrömerzeitliche Waffengräber am Westrand der Canabae von Aquincum. ActaArchHung 56 (2005) 403-486.

= M. NagY: Megjegyzések a Budapest, XVII. Rákoscsaba-Péceli út mellett és a Madaras-Halmokon (Bács-Kiskun m.) feltárt császárkori temetők temetkezési szokásaihoz (Remarks on burial custom noted in the Roman Period cemeteries uncovered at Budapest, District XVII, Rákocsaba-Péceli út and Madaras-Halmok [County Bács-Kiskun]). In: Avarok pusztái. Régészeti tanulmányok Lőrinczy Gábor 60. születésnapjára. Hrsg.: A. Anders, Cs. Balogh, A. Türk. Budapest 2014, 115-160. 
OTTOMÁNYI 2012

OTTOMÁNYI 2016

PÁSZTÓKAI-SZEŐKE 2012a

PÁSZTÓKAI-SZEŐKE 2012b

PÁSZTÓKAI-SZEŐKE 2013

PATEK 1942

PATEK 1950

Paul 2013

PÉTERFI 1993

PIRLING 1993

PRÖTtel 1988

Puschnigg 1996

QuAst 1997

RAIČKOVIĆ-MILOVANOVIĆ 2010

REDŐ 1999

RUPNIK 2012

RUPNIK 2016

RUPRECHTSBERGER 1987

SÁGI 1954

SÁGI 1973

SÁGI 1981

SALAMON-BARKÓCZI 1971

SALAMON-BARKÓCZI 1975

SALAMON-BARKÓCZI 1982
= K. OTTOMÁNYI: Késő római sírcsoportok a pátyi temetőben [Spätrömische Grabgruppen im Gräberfeld von Páty]. Archaeologia - Altum Castrum Online. Visegrád 2012, 2-16.

$=\mathrm{K}$. ОттомÁNYI: A budaörsi római vicus temetője (The cemetery of the Roman vicus at Budaörs). In: A budaörsi római vicus temetője. Régészeti tanulmányok. Hrsg.: K. Ottományi. Budapest 2016, 9-372.

= J. PÁSZTÓKAI-SzEŐKE: „Míg az anya fogy, a gyermek hízik. Mi az?” Gondolatok ókori nőkkel kapcsolatos társadalmi elvárásokról a scarbantiai borostyán guzsalyok kapcsán [„,Während die Mutter abnimmt, nimmt das Kind zu. Was ist das?" Überlegungen zu den gesellschaftlichen Anforderungen für Frauen anhand der Spinnrocken aus Bernstein von Scarbantia]. SSz 66/1 (2012) 5-19.

= J. PÁszTÓKAI-SzEŐKE: Vasból készült szövőeszközök és textilművesség a 4. századi Dunántúlon (Iron weaving tools and textile production in Transdanubia during the fourth century AD). In: Hadak útján XX. Népvándorláskor fiatal kutatói XX. összejövetelének konferenciakötete. BudapestSzigethalom, 28th-30th October 2010. Hrsg.: Zs. Petkes. Budapest 2012, 15-26.

= J. PÁszTóKAI-SzEỏKe: Following a Clew: From Tools to Textile Production in Roman Pannonia. In: NESA XI. The North European Symposium for Archaeological Textiles XI. 10-13 May 2011 in Esslingen am Neckar. Eds: J. Bank-Burgess, C. Nübold. Rahden/Westf. 2013, 257-262.

= E. PATEK: A pannoniai fibulatípusok elterjedése és eredete - Verbreitung und Herkunft der römischen Fibeltypen in Pannonien. DissPann II/19. Budapest 1942.

= E. PATEK: Biztosítószerkezettel készített fibulák Pannoniából (Fibules pannoniennes muni d'un appareil de sureté). BudRég 15 (1950) 501-512.

= M. PAUL: Fibeln und Gürtelzubehör der späten römischen Kaiserzeit aus Augusta Vindelicum/Augsburg. Münchner Beiträge zur Provinzialrömischen Archäologie 3. Wiesbaden 2013.

= Zs. V. PÉTERFI: A Bátaszék-Kövesd pusztai későrómai temető (Der spätrömische Friedhof von Bátaszék-Kövesd puszta). WMMÉ 13 (1993) 47-168.

= R. PIRLING: Römische Gräber mit barbarischem Einschlag auf den Gräberfeldern von KrefeldGellep. In: L'armée romaine et les barbares du III $^{\mathrm{e}}$ au VII ${ }^{\mathrm{e}}$ siècle. Actes du colloque international, Saint-Germain-en-Laye 24-28 février 1990. Éd.: F. Vallet, M. Kazanski. Memoires de l'Association française d'archéologie mérovingienne 5. Saint-Germain-en-Laye 1993.

= PH. M. PrötTEL: Zur Chronologie der Zwiebelknopffibel. JRGZM 35 (1988) 347-372.

= G. PusCHNIGG: Ein spätantikes Gräberfeld: Oggau. Wissenschaftliche Arbeiten aus dem Burgenland 96 (1996) 59-129.

= D. QUAST: Vom Einzelgrab zum Friedhof: Beginn der Reihengräbersitte im 5. Jahrhundert. In: Die Alamannen. Ausstellungskatalog Stuttgart, 14. Juni bis 14. September 1997. Hrsg.: K. Fuchs, M. Kempa, R. Redies. Stuttgart 1997, 171-190.

= A. RaIČKović-B. Milovanović: Development and changes in Roman fashion schowcase Viminacium. Arheologija i Prirodne Nauke (Archaeology and Sciences) 6 (2010) 77-107.

= F. REDÖ: Problems of dating with coins and the late Roman cemetery at Hegyeshalom - Az éremmel való keltezés problémái és a hegyeshalmi késő római temető. In: Festschrift für Katalin Bíró-Sey und István Gedai zum 65. Geburtstag. Hrsg.: K. Bertók, M. Torbágyi. Budapest 1999, 165-190.

= L. RUPNIK: Római vastárgyak Budaörs 2. lelőhelyről (Römerzeitliches Fundmaterial aus Eisen von Fundstelle 2 aus Budaörs). In: Római vicus Budaörsön. Régészeti tanulmányok. Hrsg.: K. Ottományi. Budapest 2012, 553-583.

= L. RUPNIK: A budaörsi temető sírjaiból elökerült vastárgyak elemzése (The analysis of the iron objects came to light during the excavation of the roman cemetery in Budaörs). In: A budaörsi római vicus temetője. Régészeti tanulmányok. Hrsg.: K. Ottományi. Budapest 2016, 546-555.

= E. M. RuprechtSBERGER: SG Linz (Steinbogen über dem „Tiefen Graben“). FÖ 26 (1987) 275-276.

= K. SÁGI: Die Ausgrabungen im römischen Gräberfeld von Intercisa im Jahre 1949. In: L. BarkócziG. Erdélyi-E. Ferenczy-F. Fülep-J. Nemeskéri-M. R. Alföldi-K. Sági: Intercisa I (DunapenteleSztálinváros). Geschichte der Stadt in der Römerzeit. ArchHung 33. Budapest 1954, 61-123.

= K. SÁGI: Római téglasír Balatonberényben és ókeresztény kapcsolatai (Ein Ziegelgrab in Balatonberény und seine altchristlichen Zusammenhänge). SMMK 1 (1973) 289-297.

= K. SÁGI: Das römische Gräberfeld von Keszthely-Dobogó. FontArchHung. Budapest 1981.

= Á. SAlAmon-L. BARKóczi: Bestattungen von Csákvár aus dem Ende des 4. und dem Anfang des 5. Jahrhunderts. Alba Regia 11 (1970) [1971] 35-80.

= Á. SALAMON-L. BARKÓCZI: Archäologische Angaben zur spätrömischen Geschichte des pannonischen Limes - Gräberfelder von Intercisa I. MittArchInst 4 (1973) [1975] 73-95.

= Á. SALAMON-L. BARKÓCZI: Pannonien in nachvalentinischer Zeit (376-476). Ein Versuch zur Periodisation. In: Severin. Zwischen Römerzeit und Völkerwanderung. Ausstellung des Landes Oberösterreich, 24. April-26. Oktober 1982 im Stadtmuseum Enns. Hrsg. : D. Straub. Linz 1982, 147-178. 
SCHACH-DÖRGES 1997

SCHMIDT 2000

SCHNURBEIN 1995

SCHULZE-DÖRRLAMM 1986

SELLYE 1990

SEY 2016

SOMMER 1984

Cs. Sós 1961

STEUER-BIERBRAUER 2008

Steuer-Hoeper 2008

SWIFT 2000

SwOBODA 1986

TóTH 2015

VADAY 1989

VÁGÓ-BÓNA 1976

VONDROCEV-WINTER 2014

WAMSER 2010

WERNER 1962

ZAGERMANN 2014

ZSIDI 1987

ZSIDI 1997
FRIDERIKA HORVÁTH - ANETT MIHÁCZI-PÁLFI

$=$ H. SCHACH-DÖRGES: „Zusammengespülte und vermengte Menschen“: Suebische Kriegerbünde werden sesshaft. In: Die Alamannen. Ausstellungskatalog Stuttgart, 14. Juni bis 14. September 1997. Hrsg.: K. Fuchs, M. Kempa, R. Redies. Stuttgart 1997, 79-102.

= W. SchмiDT: Spätantike Gräberfelder in den Nordprovinzen des Römischen Reiches und das Aufkommen christlichen Bestattungsbrauchtums. Tricciana (Ságvár) in der Provinz Valeria. SJ 50 (2000) 213-441.

$=$ S. von SchnURBeIn: Merkur als Soldat? Zur Gürtelmode des 3. Jahrhunderts n. Chr. In: Provinzialrömische Forschungen. Festschrift für Günter Ulbert zum 65. Geburtstag. Hrsg.: W. Czysz, C. M. Hüssen, H. P. Kuhnen, C. S. Sommer, G. Weber. Espelkamp 1995, 139-148.

$=$ M. SCHUlzE-DÖRRLAMM: Romanisch oder Germanisch? Untersuchungen zu den Armbrust- und Bügelknopffibeln des 5. und 6. Jahrhunderts n. Chr. aus den Gebieten westlich des Rheins und südlich der Donau. JRGZM 33 (1986) 593-720.

= I. SELLYE: Ringfibeln mit Ansatz aus Pannonien. Savaria 19/1 (1990) 17-102.

$=$ N. SEY: A budaörsi temetö bronzmellékletei (Bronze grave goods from the cemetery of Budaörs). In: A budaörsi római vicus temetője. Régészeti tanulmányok. Hrsg.: K. Ottományi. Budapest 2016 , 529-545.

= M. SOMmER: Die Gürtel und Gürtelbeschläge des 4. und 5. Jahrhunderts im römischen Reich. Bonner Hefte zur Vorgeschichte 22. Bonn 1984.

= Á. Cs. Sós: Das frühmittelalterliche Gräberfeld von Keszthely-Fenékpuszta. ActaArchHung 11 (1961) 247-305.

= H. Steuer-V. Bierbrauer (Hrsg.): Höhensiedlungen zwischen Antike und Mittelalter von den Ardennen bis zur Adria. Ergänzungsbände zum RGA 58. Berlin-New York 2008.

$=$ H. Steuer-M. Hoeper: Völkerwanderungszeitliche Höhenstationen am Schwarzwaldrand. Eine Zusammenfassung der Gemeinsamkeiten und Unterschiede. In: STEUER-BIERBRAUER 2008, 213 260 .

= E. SWIFT: Regionality in Dress Accessories in the Late Roman West. Monographies instrumentum 11. Montagnac 2000.

= R. M. Swoboda: Zu spätantiken Bronzeschnallen mit festem, dreieckigem Beschlag. Germania 64 (1986) 92-103.

= E. TóTH: Typologie der nicht gegossenen Zwiebelknopffibeln. In: Romania Gothica. 2.: The Frontier World. Romans, Barbarians and Military Culture. Proceedings of the International Conference at the Eötvös Loránd University, Budapest, 1-2 October 2010. Ed.: T. Vida. Budapest 2015, 329-361.

= A. H. VADAY: Die sarmatischen Denkmäler des Komitats Szolnok. Ein Beitrag zur Archäologie und Geschichte des sarmatischen Barbaricums. Antaeus 17-18. Budapest 1989.

= E. B. VÁGÓ-I. BÓNA: Die Gräberfelder von Intercisa. I.: Der spätrömische Südostfriedhof. Budapest 1976.

= K. VONDROCEV-H. WINTER: Die Münzen aus den Brand- und Körpergräbern sowie den Grabgärtchen und Flurgräbern von Halbturn. In: Das kaiserzeitliche Gräberfeld von Halbturn, Burgenland 1-4. Hrsg.: N. Doneus. Monographien des RGZM 122/1. Mainz 2014, 237-254.

= L. WAMSER: Karfunkelstein und Seide. Neue Schätze aus Bayerns Frühzeit. Katalog zur Sonderausstellung der Archäologischen Staatssammlung München, 29. Januar 2010-04. Juli 2010. München 2010

= J. WERnER: Die Langobarden in Pannonien. Beiträge zur Kenntnis der langobardischen Bodenfunde vor 568. Abhandlungen der Bayerischen Akademie der Wissenschaften, Philosophisch-Historische Klasse, Neue Folge 55A. München 1962.

= M. ZaGERmAnN: Spätrömische Kleidungs- und Ausrüstungsbestandteile entlang der via Claudia Augusta in Nordtirol, Südtirol und im Trentino. Militarisierung der Alpen in der Spätantike? BRGK 95 (2014) 337-441.

= P. ZsIDI: A Budapest XI. kerületi Gazdagréten feltárt 4-5. századi temető (Das auf dem Gazdagrét [Budapest XI. Bez.] freigelegte Gräberfeld aus dem 4.-5. Jahrhundert). ComArchHung (1987) 45-71.

= P. ZsIDI: Temetőelemzési módszerek az aquincumi katonaváros északi temetőjében [Methoden der Gräberfeldanalyse im nördlichen Friedhof der Canabae von Aquincum]. ArchÉrt 123-124 (19961997) [1997] 17-48. 